Florida International University FIU Digital Commons

$10-26-2011$

\title{
Groundwater-Surface Water Interactions on Tree Islands in the Everglades, South Florida
}

Pamela L. Sullivan

psull001@fiu.edu

DOI: $10.25148 /$ etd.FI11120203

Follow this and additional works at: https://digitalcommons.fiu.edu/etd

\section{Recommended Citation}

Sullivan, Pamela L., "Groundwater-Surface Water Interactions on Tree Islands in the Everglades, South Florida" (2011). FIU Electronic Theses and Dissertations. 474.

https://digitalcommons.fiu.edu/etd/474

This work is brought to you for free and open access by the University Graduate School at FIU Digital Commons. It has been accepted for inclusion in FIU Electronic Theses and Dissertations by an authorized administrator of FIU Digital Commons. For more information, please contact dcc@fiu.edu. 


\section{FLORIDA INTERNATIONAL UNIVERSITY \\ Miami, Florida}

\section{GROUNDWATER-SURFACE WATER INTERACTIONS ON TREE ISLANDS IN}

THE EVERGLADES, SOUTH FLORIDA

A dissertation submitted in partial fulfillment

of the requirements for the degree of

DOCTOR OF PHILOSOPHY

in

GEOSCIENCES

by

Pamela Lee Sullivan

2011 


\section{To: Dean Kenneth Furton}

College of Arts and Sciences

This dissertation, written by Pamela Lee Sullivan, and entitled Groundwater-Surface Water Interactions on Tree Islands in the Everglades, South Florida, having been approved in respect to style and intellectual content, is referred to you for judgment.

We have read this dissertation and recommend that it be approved.

William T. Anderson

Maureen A. Donnelly

Thomas W. Dreschel

Michael S. Ross

Leonard J. Scinto

René M. Price, Major Professor

Date of Defense: October 26, 2011

The dissertation of Pamela Lee Sullivan is approved.

Dean Kenneth Furton College of Arts and Sciences

Dean Lakshmi N. Reddi

University Graduate School

Florida International University, 2011 
(C) Copyright 2011 by Pamela Lee Sullivan All rights reserved. 


\section{DEDICATION}

I dedicate this dissertation to my family as they have always encouraged me to follow my dreams. I am excited to share what comes next with them. 


\section{ACKNOWLEDGMENTS}

I would like to thank my major advisor, Dr. René Price, and committee members, Dr. William Anderson, Dr. Thomas Dreschel, Dr. Maureen Donnelly, Dr. Michael Ross and Dr. Leonard Scinto, for their support and guidance over the last five years. Dr. Price is owed special recognition, as she was a true mentor, who motivated me and pushed me to actualize my academic dream of obtaining a doctoral degree. In addition to my committee members, the direction and content of my dissertation in many ways can be attributed to the scientific aptitude and constructive comments of Dr. Vic Engel, Dr. Fernando Miralles-Wilhelm, Dr. Leonel Sternberg, Dr. Jay Sah, Susana Stoffella, Eric Cline and Dr. Fred Sklar.

The vast amount of data collected in my dissertation was made possible thanks to the amazing physical efforts of Danielle Ogurcak, David Lagomasino, Dr. Jeremy Stalker, Xavier Zapata, Pablo Ruiz, Carrie Rebenack, Estefania Sandoval, Ryan Desliu, Rafael Travieso, Nate Colbert, Mike Kline, Lawrence Lopez, Amartya and Sonali Saha, Franco Tobias, Julie Johnson, Adrian Potra, Diana Rodriguez, Allison Lambert, Danielle Crosotomo, and Katie Bardsley. I would also like to acknowledge Nicole Neira, Diana Johnson, Tatiana Marquez, Mark Kershaw, and Patricia and Patricia Ellsworth for their help in analyzing samples and keeping the lab and equipment in great working condition

- I know that is not an easy feat. In addition to all those who helped in the field and lab, the support from Diane Pirie, Rafael Gonzalez Collazo and Sergio Giglio made much of the work possible, so thank you.

Completing my dissertation, in a large way, can be credited to the wonderful support of my family and friends. I could not have made it over many of the hurdles of this doctoral 
degree without the encouragement and love of my boyfriend, Ben Pollara. Lastly, I would like to thank my sister, Tara Sullivan, who is always cheering for me and ready to lend support however she can.

My dissertation research was made possible thanks to funding from the South Florida Water Management District (SFWMD), the Everglades Foundation, the Southeast Environmental Research Center (SERC), the National Science Foundation (NSF) Florida Coastal Everglades Long Term Ecological Research Program (FCE-LTER), the National Aeronautics and Space Administration's (NASA) Water Science of Coupled Aquatic Processes in Ecosystems from Space (WaterSCAPES) Program, the Department of Earth and Environment at Florida International University (FIU) and the College of Arts and Science at FIU. 


\section{ABSTRACT OF THE DISSERTAION \\ GROUNDWATER-SURFACE WATER INTERACTIONS ON TREE ISLANDS IN \\ THE EVERGLADES, SOUTH FLORIDA \\ by}

Pamela Lee Sullivan

Florida International University, 2011

Miami, Florida

\section{Professor René M. Price, Major Professor}

The marked decline in tree island cover across the Everglades over the last century, has been attributed to landscape-scale hydrologic degradation. To preserve and restore Everglades tree islands, a clear understanding of tree island groundwater-surface water interactions is needed, as these interactions strongly influence the chemistry of shallow groundwater and the location and patterns of vegetation in many wetlands. The goal of this work was to define the relationship between groundwater-surface water interactions, plant-water uptake, and the groundwater geochemical condition of tree islands. Groundwater and surface water levels, temperature, and chemistry were monitored on eight constructed and one natural tree island in the Everglades from 2007-2010. Sap flow, diurnal water table fluctuations and stable oxygen isotopes of stem, ground and soil water were used to determine the effect of plant-water uptake on groundwater-surface water interactions. Hydrologic and geochemical modeling was used to further explore the effect of plant-groundwater-surface water interactions on ion concentrations and potential mineral formation. 
A comparison of groundwater and surface water levels, along with calculated groundwater evapotranspiration rates, revealed that the presence of a water table depression under the islands was concurrent with elevated groundwater uptake by the overlying trees. Groundwater chemistry indicated that the water table depression resulted in the advective movement of regional groundwater into the islands. A chloride budget and oxygen isotopes indicated that the elevated ionic strength of tree island groundwater was a result of transpiration. Geochemical modeling indicated that the elevated ionic strength of the groundwater created conditions conducive to the precipitation of aragonite and calcite, and suggests that trees may alter underlying geologic and hydrologic properties. The interaction of tree island and regional groundwater was mediated by the underlying soil type and aboveground biomass, with greater inputs of regional groundwater found on islands underlain by limestone with high amounts of aboveground biomass. Variations in climate, geologic material and aboveground biomass created complex groundwater-surface water interactions that affected the hydrogeochemical condition of tree islands. 


\section{TABLE OF CONTENTS}

CHAPTER

PAGE

CHAPTER 1. INTRODUCTION

1.1 Objectives 3

1.2 Dissertation Organization 3

1.3 References $\quad 8$

CHAPTER 2. HYDROLOGIC PROCESSES ON TREE ISLANDS IN THE

EVERGLADES (FLORIDA, USA): TRACKING THE EFFECTS OF TREE ESTABLISHMENT AND GROWTH 10

2.1 Abstract $\quad 10$

2.2 Introduction 11

2.3 Study Site 14

2.4 Materials and Methods 16

2.4.1 Experimental Design and Water Levels 16

2.4.2 Groundwater Evapotranspiration $\quad 18$

2.4.3 Specific Yield 19

2.4.4 Biomass 20

2.5 Results 21

2.5.1 Lithology 21

2.5.2 Precipitation and Water Levels 22

2.5.3 Specific Yield 25

2.5.4 Groundwater Evapotranspiration $\quad 25$

2.5.5 Biomass 26

2.6 Discussion $\quad 27$

2.7 Conclusions $\quad 34$

2.8 References

2.9 Tables $\quad 40$

2.10 Figures 41

CHAPTER 3. HYROGEOCHEMICAL RESPONSE OF EXPERIMENTAL EVERGLADES TREE ISLANDS (FLORIDA, USA): INDENTIFYING FEEDBACK MECHANISMS ASSOCIATED WITH EARLY TREE GROWTH AND DIFFERING GEOLOGIC MATERIALS

3.1 Abstract $\quad 53$

3.2 Introduction $\quad 55$

$\begin{array}{ll}3.3 \text { Study Area } & 60\end{array}$

3.4 Methods 61

3.4.1 Monitoring and Sampling Design 61

3.4.2 Chemical Analysis 64

3.4.3 Surface Water, Groundwater, Source Waters and Stem Water Analysis $\quad 67$

3.4.4 Aboveground Tree Biomass 69 
$\begin{array}{ll}3.5 \text { Results } & 69\end{array}$

3.5.1 Temperature $\quad 69$

3.5.2 Nutrients $\quad 70$

3.5.3 Ions 71

3.5.4 SI and $\mathrm{pCO}_{2}$ Values $\quad 72$

3.5.5 Stable Isotopes 74

3.5.6 Aboveground Tree Biomass

3.6 Discussion 78

3.6.1 Effect of Groundwater Uptake by Trees on Groundwater Flow 78

3.6.2 Effect of Underlying Geologic Material 81

3.6.3 Effects of Forest Structure $\quad 83$

3.6.4 Mineral Formation $\quad 85$

3.7 Conclusion $\quad 86$

3.8 References $\quad 88$

3.9 Tables 93

3.10 Figures 95

CHAPTER 4. THE INFLUENCE OF VEGETATION ON THE HYDRODYNAMICS AND GEOMORPHOLOGY OF A TREE ISLAND IN EVERGLADES NATIONAL PARK (FLORIDA, USA) 111

4.1 Abstract 111

4.2 Introduction $\quad 112$

4.3 Study Area $\quad 116$

4.4 Methods 118

4.4.1 Precipitation, Groundwater, Surface Water and Soil Water Monitoring 118

$\begin{array}{ll}\text { 4.4.2 Aquifer Characteristics } & 119\end{array}$

4.4.3 Groundwater Fluxes $\quad 121$

4.4.4 Evapotranspirational Losses from Groundwater 121

4.4.5 Transpiration $\quad 122$

4.4.6 Groundwater and Surface Water Chemistry 125

4.5 Results 129

4.5.1 Rainfall and Water Levels 129

4.5.2 Soil Moisture and Aquifer Characteristics 130

4.5.3 Stand Level Transpiration (E) and Groundwater Evapotranspiration $\left(\mathrm{ET}_{\mathrm{GW}}\right) \quad 130$

4.5.4 Groundwater and Surface Water Chemistry 131

4.5.5 Water and Chloride Fluxes 134

4.6 Discussion 135

4.6.1 Hydrodynamics of a Hardwood Hammock 136

4.6.2 Hydrodynamics of a Bayhead and Bayhead Swamp 139

4.6.3 Transpiration as Driver of Carbonate Mineral Formation 141

4.6.4 Role of Groundwater-Surface Water Interactions on Phosphorus Sequestration at Satinleaf $\quad 145$

$\begin{array}{ll}4.7 \text { Conclusion } & 147\end{array}$

4.8 References 149

4.9 Tables 155 
CHAPTER 5. THE ROLE OF RECHARGE AND EVAPOTRANSPIRATION AS HYDRAULIC DRIVERS OF ION CONCENTRATIONS IN SHALLOW GROUNDWATER ON EVERGLADES TREE ISLANDS, FLORIDA (USA)

5.1 Abstract

5.2 Introduction

5.3 Study Area

5.4 Methods

5.4.1 Groundwater and Surface Water Monitoring $\quad 178$

$\begin{array}{ll}\text { 5.4.2 Slug Tests } & 180\end{array}$

5.4.3 Rainfall Monitoring and Estimating Recharge 181

5.5 Hydrologic Models $\quad 182$

5.5.1 Modeling Evapotranspiration $\quad 182$

5.5.2 Modeling Groundwater Inputs and Outputs 183

5.5.3 Modeling Groundwater Chloride Concentrations 184

5.6 Results

5.6.1 Precipitation and Water Levels 185

5.6.2 Groundwater and Surface Water Chloride Concentrations 186

5.6.3 Recharge and Hydraulic Conductivity 187

5.6.4 Evapotranspiration Results 187

5.6.5 Groundwater Flux Results 188

5.6.6 Chloride Modeling Results 189

5.6.7 Sensitivity Analysis 190

$\begin{array}{ll}5.7 \text { Discussion } & 190\end{array}$

5.7.1 Geologic Material 191

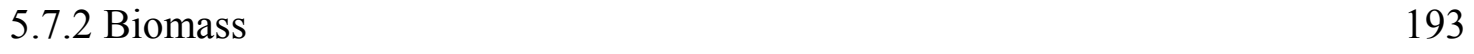

5.7.3 Hydrologic Properties: Effects of Mineral Formation 194

$\begin{array}{ll}\text { 5.7.4 Climate } & 195\end{array}$

5.7.5 Implications and Limitations 196

$\begin{array}{ll}5.8 \text { Conclusion } & 197\end{array}$

5.9 References 198

$\begin{array}{ll}5.10 \text { Table } & 202\end{array}$

$\begin{array}{ll}5.11 \text { Figures } & 203\end{array}$

CHAPTER 6. SUMMARY AND CONCLUSIONS 214

$\begin{array}{ll}\text { APPENDICES } & 220\end{array}$

Appendix 1 Author Guidelines for Reference Style 221

Appendix 2 Copyright Release $\quad 225$

$\begin{array}{ll}\text { VITA } & 227\end{array}$ 


\section{LIST OF TABLES}

TABLE

PAGE

Table 2.1 Linear regression results between surface water levels and groundwater in the center of the islands with differing geologic cores and locations (East (E) and West (W)). Regression results for the islands include: underlying geology, slope, standard error (STE) of the slope, intercept, standard error (STE) of the intercept and the square of the correlation coefficient $\left(\mathrm{R}^{2}\right)$.

Table 3.1 Mean and standard error of field parameters, major ion and nutrient concentrations, stable isotope values and SI values of groundwater in the Limestone Center (LC), Peat Center (PC) and EDGEs of the tree islands for the Planting-1 (P1) and Planting-2 (P2) tree islands. A two way ANOVA and post-hoc Tukey test $(\alpha=0.05)$ was used to determine significant difference between location and planting and within groups.

Table 3.2 The mean and standard error of chemical constituents in tree island groundwater (TI-GW), deep groundwater (DEEP GW) and Surface Water (SW). A one way ANOVA and post-hoc Tukey test $(\alpha=0.05)$ was used to determine significant difference between and within locations.

Table 4. 1 The sapwood area index for each species (Bursera simaruba (BS), Chrysophyllum oliviforme (CO), Coccoloba diversifolia (CD) and Eugenia axillaris (EA)) within each size class (Diameter at Breast Height $(\mathrm{DBH})<6,6-12,12 \mathrm{~cm}<\mathrm{DBH})$ in the stand.

Table 4. 2 Chemical constituents used to model the saturation index of calcite, aragonite and hydroxyapatite and the partial pressure of carbon dioxide $\left(\mathrm{pCO}_{2}\right)$ using PHREEQC.

Table 4. 3 The average hydraulic conductivity $\left(\mathrm{K}, \mathrm{m} \mathrm{d}^{-1}\right)$ and readily available specific yield ( $\mathrm{S}_{\mathrm{yr}}$, unitless) and standard deviation (Std) of underlying geology of all three communities at Satinleaf (Hardwood Hammock (HH), Bayhead (BH) and Bayhead Swamp (BHS).

Table 4. 4 The average values and standard error of temperature (Temp), conductivity, $\mathrm{pH}$, major ions $\left(\mathrm{HCO}_{3}{ }^{-}, \mathrm{Cl}^{-}, \mathrm{SO}_{4}{ }^{2-}, \mathrm{Na}^{+}, \mathrm{K}^{+}, \mathrm{Mg}^{2+}\right.$, and $\left.\mathrm{Ca}^{2+}\right)$, nutrients (TP, SRP and TOC), stable isotopes $\left(\delta \mathrm{D}, \delta^{18} \mathrm{O}\right)$, SI values (aragonite, calcite, and hydroxyapatite) and $\mathrm{pCO}_{2}$ in the groundwater in the Hardwood Hammock $(\mathrm{HH})$, Bayhead $(\mathrm{BH})$ and 
Bayhead Swamp (BHS) and marsh surface water from October 2008-June 2010. A One Way ANOVA and post-hoc Tukey test were used to identify significant differences in the $\mathrm{HH}, \mathrm{BH}$, and BHS groundwater chemistry.

Table 4.5 Spearman correlation matrix of chemical constituents and SI values of Satinleaf Tree Island groundwater $(n=28)$.

Table 5. 1 The overall average groundwater $\left[\mathrm{Cl}^{-}\right]$on the tree islands at LILA based on tree island type (Peat vs Limestone), location (Edge vs Center) and sampling event timing (May vs October). 


\section{LIST OF FIGURES}

FIGURE

PAGE

Figure 2. 1 Loxahatchee Impoundment Landscape Assessment (LILA) is located on the eastern edge of Water Conservation Area 1, in Boynton Beach, Florida.

Figure 2. 2 LILA is comprised of four macrocosms that mimic the Everglades; each macrocosm has two tree islands with an underlying geology of either peat or limestone. Of the 72 wells at LILA a total of 28 wells were monitored over the eight islands. GW=groundwater, $\mathrm{SW}=$ surface water.

Figure 2.3 Diurnal drawdown in groundwater levels from the center of a peat based island. Evapotranspiration from the groundwater $\left(\mathrm{ET}_{\mathrm{G}}\right)$ was determined according to Eq. 2. 1 using the slope between midnight and 4:00 am (r), the change in water level from midnight of the day of interest and the previous midnight $(\Delta \mathrm{S})$ and the specific yield.

Figure 2. 4 The average sediment profile at the center and edges of the peat and limestone islands. In macrocosm 3 (M3) a thick layer of clay was observed across the peat island and at the edges of the limestone island.

Figure 2. 5 Monthly rainfall amount averaged over 30 years (black) compared to the monthly rainfall amounts that occurred between 2007-2008 (striped) and 2008-2009 (gray). Rainfall amounts were below average from November through January in both years, and above average in September, October, February, and March 2007-2008 and above average in August and May 2008-2009.

Figure 2. 6 The daily surface water levels (colors) in the center of all four macrocosms and daily rainfall values (black) from the Loxahatchee weather station July 2007 through July 2009.

Figure 2. 7 Histogram of the hydraulic gradient between the surface water and the groundwater in the center of the peat (black) and limestone (gray) based tree islands. Positive values indicate groundwater discharge, while negative values indicate groundwater recharge by surface water.

Figure 2. 8 Surface water (blue) and groundwater levels from the center of the peat (green) and limestone (red) based tree islands in M1 from July 2007 through June 2009. The gray boxes indicate periods of 
groundwater recharge $(\mathrm{R})$ by surface water on the limestone tree island.

Figure 2.9 Groundwater (GW) levels were normalized to surface water (SW) to depict the water table across the limestone (left panel) and peat (right panel) tree islands. The horizontal solid line at the value of zero represents the surface water, while the vertical dashed lines represent the well locations. For July 2007-April 2008 (top row) the dominant direction of groundwater flow was from the center of the islands toward the edges. A hydraulic divide developed on the edges of islands for July 2008-April 2009 (bottom row). Blue arrows indicate direction of groundwater flow.

Figure 2. 10 The average monthly effective specific yield was variable for both the wells located on the edges $(\Delta)$ and centers $(\square)$ of the tree islands when the average monthly depth to the water table was less than $20 \mathrm{~cm}$. When the depth of the water table was greater than 20 $\mathrm{cm}$ deep, the average monthly effective specific yield increased for the wells located in the center of the tree islands.

Figure 2.11 Average daily evapotranspiration from groundwater $\left(\mathrm{ET}_{\mathrm{G}}\right)$ per month for the center of the peat (black) and limestone (gray) islands compared to the edges (striped).

Figure 2.12 Aboveground biomass $\left(\mathrm{t} \mathrm{ha} \mathrm{ha}^{-1}\right)$ predicted from mixed-species regression model based on height for four different combinations of substrate type and ground elevation in tree islands of macrocosms a) M1 and M4, and b) M2 and M3.

Figure 3.1 LILA is located at the northeastern edge of the Everglades (grey), on the boundary of Water Conservation Area 1 (WCA1), and north of Everglades National Park (ENP) where Shark Slough (SS) and Taylor Slough (TS) reside.

Figure 3.2 At least nine groundwater wells (cricles) were located on each tree island (Left). Surface (grey box) and groundwater were sampled on the peat (black circle) and limestone (white circle) at LILA (Left). Aerial schematic of sampled well locations on each island (Top Right); the two EDGE wells sampled were located at a lower ground elevation (lowland), while the one (Limestone Center, LC) to two (Peat Center, PC) CENTER wells and the one DEEP (PC) well sampled were located in the center of the island at a higher elevation (upland). Profile schematic depicts the well locations and depths across each tree island (Bottom Right). 
Figure 3.3 Average surface water level at LILA compared to the average ground elevation at the CENTER and EDGE of the tree islands and adjacent slough from July 2007 through June 2010.

Figure 3.4 Average daily surface water (SW, blue) and groundwater temperature in the center of the peat (PC, green) and limestone (LC, red) islands compared to the groundwater at the EDGE (dotted black) and DEEP (purple) groundwater.

Figure 3.5 The average and standard error groundwater concentrations of total phosphorus (TP) and soluble reactive phosphorus (SRP) from October 2007 through April 2010.

Figure 3.6 The average groundwater concentration of a) total organic carbon (TOC), b) $\mathrm{pCO}_{2}$, and c) SI value of calcite at the EDGE (gray), Peat Center (PC, green) and Limestone Center (LC, red) of the island.

Figure 3.7 Average groundwater concentration and standard error of chloride $\left(\mathrm{Cl}^{-}\right)$in the center (black) and edge (open) from October 2007 through April 2010.

Figure 3.8 The $\delta \mathrm{D}$ and $\delta^{18} \mathrm{O}$ value of rainfall (diamond) compared to surface water (asterisks). The linear regression of surface water values confirmed volume weighted average rainfall value (triangle).

Figure 3.9 The average $\delta^{18} \mathrm{O}$ compared to the $\mathrm{Cl}^{-}$concentration for surface water (asterisks) rainfall (triangle) and groundwater at the CENTER (black) and EDGE (open) of island as well as in the DEEP (purple) groundwater.

Figure 3.10 The average $\delta^{18} \mathrm{O}$ compared to the $\mathrm{Cl}^{-}$concentration of groundwater at the EDGE (black/gray) and CENTER (red) of the islands from the 2007-2010 wet (open) and dry (closed) sampling events.

Figure 3.11 The average $\delta^{18} \mathrm{O}$ values at the EDGE (Open), LC (red), PC (green) and DEEP (purple) groundwater.

Figure 3.12 Stem water (diamond), groundwater (circle), and soil water (square) values obtained at the EDGE (open) and CENTER (closed) as well as surface water (asterisks) of the Planting-1 (P1, left) and Planting-2 (P2, right) islands, compared to the meteoric water line (black line) and surface water values (star) for October 2008 (top)-April 2010 (bottom). Groundwater and soil water 
values were divided into those on the peat (green) and limestone (red) islands.

Figure 3.13 The average $\delta^{18} \mathrm{O}$ and standard error in the groundwater (circle) and soil water (square) for center of the peat (green, PC) and center of the limestone (red, LC) islands.

Figure 3.14 The average and standard error of the percent of groundwater utilized by trees from a) EDGE and center of limestone (LC) and peat (PC) and b) the Planting-1 (P1) and Planting-2 (P2) islands.

Figure 3.15 The average amount of aboveground biomass compared to the average groundwater water concentrations of a) potassium $\left.\left(\mathrm{K}^{+}\right), \mathrm{b}\right)$ oxygen-18 isotopes $\left(\delta^{18} \mathrm{O}\right)$, and c) Total Phosphorus (TP) in the Planting-1 (P1, black) and Planting-2 (P2, gray) islands.

Figure 3.16 Diagram of the predominate direction of groundwater flow, as indicated by the isotopic values $(\delta)$ of groundwater in the CENTER, EDGE and DEEP portions of the islands, as well as rainfall and surface water. a) When trees were planted the isotopic signature of the groundwater at the CENTER and EDGE of the islands was depleted but after three years of tree growth the groundwater in the b) Limestone Center (LC) and EDGE became enriched, while c) Peat Center (PC) remained fairly depleted.

Figure 4. 1 Satinleaf tree island is located in Everglades National Park, south Florida, USA. Groundwater wells $(\bigcirc)$ were monitored (left center) in all three vegetation community types on the island: Hammock $(\mathrm{HH})$, Bayhead (BH) and Bayhead Swamp (BHS) (bottom). Marsh groundwater was also monitored using shallow groundwater collectors $(\mathbf{\Delta})$ (left center)

Figure 4.2 Hays method (Eq 4. 3) used to determine $\mathrm{ET}_{\mathrm{GW}}$ from diurnal groundwater fluctuations on The Satinleaf Tree Island.

Figure 4. 3 A linear regression was derived between the sapwood area of cored trees (Bursera simaruba (BS), Chrysophyllum oliviforme (CO), Coccoloba diversifolia (CD) and Eugenia axillaris (EA)) and the Diameter at Breast Height (DBH) to determine the sapwood area of all species in the stand.

Figure 4. 4 Total monthly rainfall (striped) at the G-620 station adjacent to Satinleaf compared to the average monthly rainfall (gray) over a 25-year period at station S12D. Over the three year period there 
were three occasions when below average rainfall (BAR) was detected for sequential months.

Figure 4.5 A) Groundwater (GW) levels in the Hardwood Hammock (HH) community (black) and marsh surface water (SW) levels (gray) from July 2007 through September 2010. B) Average monthly normalized GW levels in the $\mathrm{HH}(\Delta)$, Bayhead $(\mathrm{BH}, \diamond)$ and Bayhead Swamp (BHS, •) communities. Positive values indicated the $\mathrm{GW}$ was elevated compared to the SW while negative values indicated GW levels were lower then SW levels.

Figure 4.6 The average daily transpiration $(\mathrm{E}, \mathbf{X})$ or groundwater evapotranspiration $\left(\mathrm{ET}_{\mathrm{GW}}, \Delta\right)$ per month and standard error for the $\mathrm{HH}$ community compared to the average daily Volumetric Soil Water Content (VSWC, black) per month.

Figure 4.7 The percent of groundwater (GW) taken up by phreatophytes through transpiration was negatively correlated to Volumetric Soil Water Content (VSWC, black).

Figure 4.8 In the Hardwood Hammock (HH) groundwater A) Total Phosphorus (TP) concentrations were negatively correlated with Total Organic Carbon (TOC), B) the saturation states of calcite and hydroxyapatite were positively correlated and C) Soluble Reactive Phosphorus (SRP) concentrations were negatively correlated to $\delta^{18} \mathrm{O}$ values.

Figure 4.9 Significant positive correlations were detected in the tree island groundwater $(\mathrm{GW})$ between $\mathrm{A})$ the concentration of calcium $\left(\mathrm{Ca}^{2+}\right)$ and chloride $\left(\mathrm{Cl}^{-}\right)$and $\left.\mathrm{B}\right)$ the saturation indices of calcite (SI $\mathrm{Salcite}_{\text {) }}$ and the concentration calcium, while a negative correlation was detected between $\mathrm{C}$ ) the calcite saturation indices and the partial pressure of $\mathrm{CO}_{2}\left(\mathrm{Log}\left(\mathrm{pCO}_{2}\right)\right.$ in the surface water $(\mathrm{SW})$.

Figure 4.10 A) Chloride concentrations and B) $\delta^{18} \mathrm{O}$ values in the marsh surface water $(\mathrm{SW}, \times)$ and the groundwater $(\mathrm{GW})$ in the Hardwood Hammock ( $\mathrm{HH}, \triangle)$, the Bayhead $(\mathrm{BH}, \bullet)$ and the Bayhead Swamp (BHS, •) communities from October 2008 through June (2010). The dry seasons are indicated by the gray boxes.

Figure 4. 11 Chloride concentration compared to $\delta^{18} \mathrm{O}$ values (A) and ratio of $\mathrm{Na}^{+}$to $\mathrm{Cl}^{-}$compared with $\mathrm{Mg}^{+2}$ to $\mathrm{Ca}^{+2}$ (B) for all groundwater $(\mathrm{GW})$ and surface water $(\mathrm{SW})$ sites. The Bayhead $(\mathrm{BH}, \diamond)$ and Bayhead Swamp (BHS, •) were substantially different from marsh 
GW (只) and SW $(\times)$, while the Hardwood Hammock $(\mathrm{HH}, \boldsymbol{\Delta})$ ranged between marsh and islands values (TOP). While isotopic values indicated that the $\mathrm{HH}$ community was interacting with surrounding marsh, the ionic ratios indicated $\mathrm{HH}$ community was being recharged by marsh groundwater for a portion of the year. ** $\delta^{18} \mathrm{O}$ values of rainfall were taken from Price et al. (2008), while chloride values of rainfall came from NADP (http://nadp.sws.uiuc.ed).

Figure 4. 12 The fluxes of A) water and B) chloride in the Hardwood Hammock on Satinleaf as a result of precipitation inputs $(\square)$, recharge and discharge of groundwater $(\mathrm{Q})(\bullet)$ and outputs of transpiration $(\mathrm{E})$ $(*)$. B) The concentration of chloride in rainfall was very low, while the transpiration had a large impact on concentrating ions over the year.

Figure 5. 1 LILA is located in Boynton Beach, South FL, USA (top left), just on the outskirts of the Everglades (middle left). Tree wells were monitored on the Peat (black) and Limestone tree (white) islands at LILA (right). Of the four macrocosms (M), M1 and M4 contained islands planted in 2006 (P1 islands), while M2 and M3 contained islands planted in 2007 (P2 islands). The groundwater levels on the island and surrounding surface water levels were used in a onedimensional analytical model to determine the inputs and outputs of water in the center the tree islands (bottom).

Figure 5.2 Rainfall (solid) and recharge (striped) for the wet (gray) and dry (black) seasons from 2007-2010, compared to the average seasonal 30-year rainfall.

Figure 5.3 Groundwater levels (black) in the center of a peat (a) and limestone (b) tree island at LILA compared to the surface water levels (light gray) and the modeled groundwater water levels (dark gray dash) from July 2007 through June 2010.

Figure 5. 4 Monthly $\left[\mathrm{Cl}^{-}\right]$in the surface water (SW) and groundwater (GW) in the center and shallow center wells and the edges of the tree islands.

Figure 5.5 The average hydraulic conductivity $(\mathrm{K})$ and standard deviation for the peat and limestone tree islands from Planting-1 (P1) and Planting-2 (P2).

Figure 5.6 The average daily evapotranspiration (ET) per month as determined by the hydrologic model, compared to the average 
daily groundwater evapotranspiration $\left(\mathrm{ET}_{\mathrm{GW}}\right)$ determined using the White Method by Sullivan et al. (2011).

Figure 5.7 a) The average monthly difference in recharge (R) and evapotranspiration $(\mathrm{ET}, \mathrm{mm}), \mathrm{b})$ monthly groundwater fluxes in $\left(\mathrm{Q}_{\text {in }}\right.$, gray, $\left.\mathrm{m}^{3}\right)$ and $\left.\mathrm{c}\right)$ daily groundwater $\left[\mathrm{Cl}^{-}\right]$in the Planting-1 (P1, black) and Planting-2 (P2, gray) islands.

Figure 5.8 a) The average monthly difference in recharge $(R)$ and evapotranspiration $(\mathrm{ET}, \mathrm{mm}), \mathrm{b})$ monthly fluxes of groundwater $\left(\mathrm{Q}_{\text {in }}\right.$, gray, $\left.\mathrm{m}^{3}\right)$ and $\left.\mathrm{c}\right)$ daily groundwater $\left[\mathrm{Cl}^{-}\right]$in the Limestone (black) and Peat (gray) islands.

Figure 5.9 Modeled daily groundwater $\left[\mathrm{Cl}^{-}\right]$(line) compared to the actual (triangle) groundwater $\left[\mathrm{Cl}^{-}\right]$using average rainfall $\left[\mathrm{Cl}^{-}\right]$(black dashed) and shallow groundwater $\left[\mathrm{Cl}^{-}\right]$(solid) for the recharge (R) $\left[\mathrm{Cl}^{-}\right]$and total monthly fluxes of groundwater in $\left(\mathrm{Q}_{\text {in }}\right.$, gray dashed).

Figure 5.10 The modeled groundwater chloride concentration ( $\left.\mathrm{GW}\left[\mathrm{Cl}^{-}\right]\right)$ compared to the actual $\left[\mathrm{Cl}^{-}\right]$for all of the islands.

Figure 5.11 Sensitivity analysis for a) hydraulic conductivity (K), b) Specific yield $\left(\mathrm{S}_{\mathrm{y}}\right)$ and $\left.\mathrm{c}\right)$ porosity $(\mathrm{n})$ for the groundwater chloride concentration $\left(\left[\mathrm{Cl}^{-}\right]\right)$predictions in the center of the tree islands, each parameter was altered positively (light gray) and negatively (dark gray) by $25 \%$. 


\section{CHAPTER 1. INTRODUCTION}

Recently, tree islands have been designated as indicators of Everglades ecosystem health because they harbor the highest species diversity in the Everglades but only comprise about $2 \%$ of the land cover (Davis and Ogden 1994). The reason tree islands harbor such high species diversity is two-fold: first, tree islands provide the elevated topographic refuge for flood intolerant species; second, they act as nutrient sinks in the oligotrophic system of the Everglades, allowing species with higher nutrient requirements to exist. Regrettably, since the 1940's there has been a marked decline in tree island cover across the Everglades (60\% Water Conservation Area 3 (WCA3) and 90\% WCA 2; Patterson and Finck, 1999; Sklar and van der Valk, 2002), which has been concurrent with a loss of the characteristic ridge-and-slough landscape pattern (Ogden, 2005). The loss of cover and topography has been in part attributed to surface water level management practices over the last century, which has led to extended high water levels that drowned trees and caused the accumulation of peat in sloughs. In other areas, extended low water levels have led to peat desiccation, oxidation, and the increased severity and occurrence of fires (Sklar et al., 1999; Brandt et al., 2000). The decrease in tree island surface area has also been attributed to the reduction of surface water flow that has modified sediment transport and decreased sediment input to the islands (Bazante et al., 2006).

To preserve and restore tree islands in the Everglades, efforts must be made to gain a better understanding of groundwater-surface water interactions across the ecosystem, as they have been shown to strongly influence the chemistry of shallow groundwater and 
thus location and patterns of vegetation in many wetlands (Ferone and Devito 2004, Glaser et al. 1981, Rietkerk et al. 2004). At the regional scale these interactions can be driven by variations in climate, geological material and the human dimension. At the local scale, small variations in vegetation stucture can play a critical role in groundwatersurface water interactions (Rodriguez-Iturbe, 2001; Jobbágy and Jackson, 2007; Muneepeerakul et al., 2008; Nosetto et al., 2008). Within the Everglades, elevated differential transpirations rates between tree islands and the surrounding marsh are thought to be a product of the contrast in vegetation (trees vs. sedges, grasses, rushes and macrophytes) and have been hypothesized to result in the advective convergence of regional groundwater and buildup of the associated ions and nutrients on tree islands over time (Wetzel et al., 2005; Ross et al., 2006). In addition, the accumulation of ions and nutrients through transpiration has been hypothesized to create a positive-negative feedback that reinforces tree island persistence on the landscape. The accumulation of resources enhances the productivity locally on the tree island, but the is at the expense of the surrounding marsh vegetation (Rietkerk and van de Koppel, 2008). While transpiration-driven groundwater-surface water interactions are thought to play an important role on tree islands, there is a lack of direct hydrologic evidence that the concentrations and distribution of ions and nutrients in shallow tree island groundwater is a result of plant-groundwater-surface interactions. 


\subsection{Objectives}

The primary goal of this dissertation is to define the relationships between groundwatersurface water interactions, plant-water uptake, and ion and nutrient concentrations on tree islands across the Everglades. The specific objectives addressed in this dissertation include the following:

I. to determine how evapotranspiration, precipitation, geologic material and seasonal surface water levels govern the hydrodynamics of tree islands;

II. to determine the sources of water utilized during transpiration and the effect of plant water uptake on the chemical composition of tree island groundwater; and

III. to determine if plant water uptake and tree island hydrodynamics control mineral formation by affecting the distribution and concentration of ions in tree island groundwater.

\subsection{Dissertation Organization}

Following this introduction are four main chapters written in manuscript form, consistent for publication in peer-reviewed, scientific journals. In keeping with this format the references were placed at the end of each chapter. The specific journals that each chapter was published in or will be submitted to are listed within the summaries below and the corresponding author guidelines for reference style can be found in Appendix 1.

The first two main chapters (Chapter 2 \& Chapter 3) present hydrogeologic and geochemical data from newly established tree islands at the Loxahatchee Impoundment 
Landscape Assessment (LILA). Chapter 2 (Sullivan et al. 2011, published in Hydrogeology Journal, for copyright release see appendix 2), presents groundwater and surface water level data on eight tree islands from 2007-2009. Diurnal fluctuations in the groundwater table were used to estimate groundwater evapotranspiration. Hydrologic evidence indicated the establishment of a water table depression under the tree islands that was concurrent with the observed increase in aboveground tree biomass. The strength of the depressions correlated to the underlying soil condition, with the largest depressions detected in the limestone and clay islands. The findings revealed that groundwater-surface water interactions on tree islands were more complex and dynamic than previously hypothesized.

In Chapter 3 (to be submitted to Biogeochemistry), three years (2007-2010) of groundwater, surface water, stem water and soil water chemistry data collected biannually (April/May and October) from the LILA tree islands were discussed in terms of the hydrogeochemical response of tree islands to early tree growth and geologic materials. All water samples were analyzed for the stable isotopes of oxygen and hydrogen, while groundwater and surface water samples were also analyzed for major ions and nutrients. Chloride concentrations, oxygen and hydrogen stable isotopes, and temperature of groundwater and surface water were employed as conservative tracers to identify plant-groundwater-surface water interactions. The effect of the soil type and aboveground biomass on tree island groundwater was determined by the distribution and accumulation of major ions and nutrients in the groundwater over time. The two main conclusions from this chapter were: 1) groundwater uptake by overlying trees led to the 
accumulation of ions and depletion of nutrients in tree island groundwater, and 2) inputs of regional groundwater were greater on limestone islands and were concurrent with the precipitation of calcium carbonate minerals.

Groundwater and surface water levels and chemistry, as well as sap flow and soil moisture data from three plant communities (hammock, bayhead and bayhead swamp) on a native tree island in the Everglades National Park (Satinleaf Tree Island) were presented in Chapter 4 (to be submitted to Hydrological Processes). Continuous estimates of groundwater evapotranspiration and transpiration rates on Everglades tree islands were determined on Satinleaf using diurnal water table fluctuations and sap flow measurements. Major ions, oxygen and hydrogen stable isotopes, and nutrient data from the groundwater were used to determine plant-groundwater-surface water interactions and explain the elevated concentration of phosphorus in tree island groundwater. Groundwater saturation indices, with respect to aragonite, calcite and hydroxyapatite, were modeled to determine the effect of plant-groundwater-surface water interactions on possible mineral formation. The four main findings of this work were: 1) elevated ionic strength of tree island groundwater compared to regional surface and groundwater was a result of transpiration, but was enhanced by phreatophytic uptake during the dry season; 2) the elevated ionic strength of the groundwater in the bayhead community was a result of inputs of groundwater from the hammock coupled with the transpiration of overlying trees, while the ionic strength of the groundwater in the bayhead swamp community was attributed to combined inputs of bayhead groundwater and regional groundwater from the Everglades; 3) the elevated ionic strength of the groundwater promoted the precipitation 
of calcium carbonate minerals in spite of elevated $\mathrm{pCO}_{2}$ levels, which may play an important role in soil stabilization in the hammock and soil formation in the bayhead and bayhead swamp areas; and 4) the elevated phosphorus concentrations in the hammock groundwater were most likely a result of the weathering of non-carbonate rich phosphorus minerals (i.e., hydroxyapatite) in the vadose zone.

In Chapter 5 (to be submitted to the Journal of Hydrology), the results of a hydrologic and chloride transport model prompted by the findings of the three previous chapters were used to gain a better understanding of ion accumulation in tree island groundwater. Groundwater and surface water level data and chloride chemistry from LILA were used to determine the role of precipitation, evapotranspiration and groundwater flow on the shallow groundwater chemistry in tree islands. The model was then used to explore the possible effects of varying underlying hydrologic properties, potentially caused by secondary formation of calcium carbonate minerals, on tree island hydrodynamics and ion concentrations. Modeling results indicated the ionic strength of the nascent LILA tree island groundwater was governed by the evapotranspiration-to-recharge ratio, hydrologic properties of the sediments and aboveground biomass.

The dissertation concludes (Chapter 6) with a summary of the four main chapters and suggested future research paths in relation to tree islands, biological and physical feedback mechanisms, and landscape patterning in wetlands. Appendices related to the author guidelines, copyright release and VITA are located at the end of the dissertation. Because of the large volume of data collected as part of this dissertation, all groundwater 
level, temperature, and chemistry data pertaining to LILA will be made available at the South Florida Water Management District's (SFWMD) by contacting the database coordinator for the Everglades Research Data Project (ERDP), while all surface water level data and rainfall data used are readily available to the public on SFWMD DBHYDRO database (http://my.sfwmd.gov/dbhydroplsq1/show_dbkey_info.main_menu). All water level and chemistry data pertaining to Satinleaf Tree Island will be made available on the Florida International University Long Term Ecological Research (LTER) Program's data products website (http://fce.lternet.edu/data/FCE/). 


\subsection{References}

Bazante, J, Jacobi, G., Solo-Gabriele, H. M., Reed, D., Mitchell-Brucker, S., Childers, D. L., Leonard, L., Ross, M., 2006. Hydrologic measurement and implications for tree island formation within Everglades National Park. Journal of Hydrology. 329, 606-619.

Brandt, L. A., Portier, K. M., Kitchens, W. M., 2000. Patterns of change in tree islands in Arthur R. Marshall Loxahatchee National Wildlife Refuge from 1950-1991. Wetlands. 20 (1), 1-14.

Daivs, S. M. and Ogden, J.C., 1994. Everglades: the ecosystem and it restoration. St. Lucie Press. Boca Raton, Fl.

Ferone, J.M., and Devito, K.J., 2004. Shallow groundwater-surface water interactions in pond-peatland complexes along Boreal Plains topographic gradient. Journal of Hydrology. 292, 75-95.

Glaser, P. H., Wheeler, G.A., Gorham, E., and Wright Jr., H.E., 1981. The patterned mires of the Red Lake peatland, Northern Minnesota: vegetation, water chemistry, and landforms. Journal of Ecology. 69 (2), 575-599.

Jobbágy, E. G., Jackson, R. B., 2007. Groundwater and soil chemical changes under phreatophytic tree plantations. Journal of Geophysical Research. 112, 1-15.

Muneepeerakul, C. P., Miralles-Wilhelm, F., Tamea, S., Rinaldo, A., Rodriquez-Iturbe, I., 2008. Coupled hydrologic and vegetation dynamics in wetland ecosystems. Water Resources Research. 40, W07421.

Nosetto, M. D., Jobbágy, E.G., Tóth, T., Jackson, R. B., 2008. Regional patterns and controls of ecosystem salinization with grassland afforestation along a rainfall gradient. Global Biogeochmical Cycles. 22, GB2015.

Ogden, J.C., 2005. Everglades ridge and slough conceptual ecological model. Wetlands. $25,810-820$.

Patterson, K., Finck, R., 1999. Tree Islands of the WCA 3A Aerial photointerpretation and trend analysis project summary report. Geonex Corporation, St. Petersburg, FL. Report to the South Florida Water Management District, West Palm Beach, FL.

Rietkerk, M., Dekker, S. C., Wassen, M. J., Verkroost, A. W. M., Bierkens, M. F. P., 2004. A putative mechanism for bog patterning. The American Naturalist. 163, 699-708. 
Rietkerk M., van der Koppel, J., 2008. Regular pattern formation in real ecosystems. Trends in Ecology and Evolution. 23, 169-176.

Rodriguez-Iturbe, I., Porporato, A., Laio, A., Ridolfi, L., 2001. Plants in water-controlled ecosystems: active role in hydrologic processes and response to water stress I. Scope and general outline. Advances in Water Resources. 24, 695-705.

Ross, M. S., Mitchell-Brucker, S., Sah, J. P., Stothoff, S., Ruiz, P. L., Reed, D. L., Jayachandran, K., Coultas, C. L., 2006. Interaction of hydrology and nutrient limitation in Ridge and Slough landscape of southern Florida. Hydrobiologia. 569, $37-59$.

Sklar, F., McVoy, C., Van Zee, R., Gawlik, D., Swift, D., Park, W., Fitz, C., Wu, Y., Rudnick, D., Fontaine, T., Miao, S., Ferriter, A., Krupa, S., Armentano, T., Tarboton, K., Rutchey, K., Dong, Q., and Newman, S.. 1999. Hydrologic needs: The effects of altered hydrology on the Everglades [Chapter 2]. In: Everglades Interim Report. West Palm Beach, Florida: South Florida Water Management District.

Sklar, F.H. and van der Valk, A., 2002. Tree islands of the Everglades: an overview. In Sklar, F.H., and van der Valk, A.G., Tree islands of the Everglades. Dordecht, The Netherlands: Kluwer Academic Publishers.

Sullivan, P. L, Price, R. M., Ross, M. S., Scinto, L.J., Stoffella, S. L., Cline, E., Dreschel, T. W., Sklar, F.H., 2011. Hydrologic processes on tree islands in the Everglades (Florida, USA): tracking the effects of tree establishment and growth, Hydrogeology Journal. 19, 367-378.

Wetzel, P. R., van der Valk, A. G., Newman, S., Gawlik, D. E., Gann, T. T., CoronadoMoliana, C. A., Childers, D. L., Sklar, F. H., 2005. Maintaining tree islands in the Florida Everglades: nutrient redistribution is the key. Front. Ecol. Environ. 3, 370-376. 
CHAPTER 2. HYDROLOGIC PROCESSES ON TREE ISLANDS IN THE EVERGLADES (FLORIDA, USA): TRACKING THE EFFECTS OF TREE ESTABLISHMENT AND GROWTH

Sullivan PL, Price RM, Ross MS, Scinto LJ, Stoffella SL, Cline E, Dreschel TW, Sklar FH (2011) Hydrologic processes on tree islands in the Everglades (Florida, USA): tracking the effects of tree establishment and growth. Hydrogeology Journal 19(16): 367378

\subsection{Abstract}

The hydrodynamics of tree islands during the growth of newly planted trees has been found to be influenced by both vegetation biomass and geologic materials. From July 2007 through June 2009, groundwater and surface water levels were monitored on eight recently planted tree islands at the Loxahatchee Impoundment Landscape Assessment (LILA) facility in Boynton Beach, Florida, USA. Over the two year study, stand development coincided with the development of water table depressions in the centers of each of the islands, which were bounded by hydraulic divides along the edges. The water table depression was greater in islands composed of limestone as compared to those composed of peat. The findings of this study suggest that groundwater evapotranspiration by trees create complex hydrologic interactions between the shallow groundwater in tree islands and the surrounding surface water and groundwater bodies. 


\subsection{Introduction}

Variation in groundwater evapotranspiration $\left(\mathrm{ET}_{\mathrm{G}}\right)$ rates may be one of the largest driving factors in groundwater-surface water interactions and thus the formation of landscape patterning across ecosystems of low topographic relief (Eppinga et al., 2008; Rietkerk et al. 2004; Wetzel et al. 2005). Groundwater-surface water interactions strongly influence the chemistry of shallow groundwater and the location and patterns of vegetation in wetlands (Ferone and Devito 2004; Glaser et al. 1981). The Great Vasyugan Bog, Siberia, and the Okavango Delta, Botswana, are examples of wetlands composed of raised ridges or islands that coincide with the presence of elevated ion and nutrient concentrations in groundwater and higher order vascular plants, compared to the surrounding hollows and sloughs (Eppinga et al. 2008; McCarthy 1998). A combination of positive and negative feedback mechanisms has been proposed for the formation of self-organizing patterns found in many wetlands (Rietkerk et al. 2004; Rietkerk and van de Koppel 2008). The hypothesis behind these feedbacks is that areas with high $\mathrm{ET}_{\mathrm{G}}$ rates would lower the water table, creating an inward convective transport of nutrients and ions, which could increase the growth rate of biomass, and lead to an accelerated rate of soil accretion. The elevated ion and nutrient concentrations have a positive feedback on local biomass while negatively impacting vegetation at a greater distance by inhibiting their access to resources (Rietkerk and van der Koppel 2008). This hypothesis is supported by the findings of Engel et al. (2005) in the Pampas of South America, where sap flow measurements and diurnal water table fluctuations suggested that the ratio of $\mathrm{ET}_{\mathrm{G}}$ to precipitation was greater in the tree plantation than in the surrounding grasslands. Furthermore, the increased $\mathrm{ET}_{\mathrm{G}}$ coincided with a lowering of the water table and the 
development of elevated ion concentrations under the plantation (Jobbágy and Jackson 2007).

Similar feedback patterns may have led to the ridge-slough-tree island topography of the Florida Everglades, USA (Figure 2. 1), where some of the highest soil and groundwater nutrient concentrations have been detected in tree islands. Gann et al. (2005) detected total soil phosphorus concentrations that were six-fold higher in tree islands $\left(446 \mathrm{~g} \mathrm{~kg}^{-1}\right)$ compared to the adjacent marsh ( $\left.78 \mathrm{~g} \mathrm{~kg}^{-1}\right)$. In addition, Ross et al. (2006) detected pore water concentrations of soluble reactive phosphorus (SRP) to be two to three orders of magnitude higher in the tree islands compared to the surrounding marsh. Potential sources suggested for the high phosphorus concentrations detected in tree islands are the capture of dust from the atmosphere by the tree canopy, inputs of bird guano and bones (Coultas et al. 2008), and high $\mathrm{ET}_{\mathrm{G}}$ rates that increased inputs of high nutrient groundwater (Wetzel et al. 2005). High rates of $\mathrm{ET}_{\mathrm{G}}$ relative to recharge were again suggested as a driving factor when a diurnal drawdown in the water table was observed between sunrise and sunset on tree islands in the Everglades during the December - May dry season (Ross et al. 2006). Furthermore, the use of oxygen and hydrogen stable isotopes of stem water, soil water and groundwater in a hardwood hammock tree island indicated that trees on such islands relied on groundwater during the dry season (Ewe et al. 1999). Less than $1 \%$ of the water utilized by trees was groundwater during the wet season, but during the dry season, groundwater constituted $86 \%$ of the water utilized. While nutrient concentrations, diel groundwater fluctuations, and groundwater isotopic values suggest a link between overlying vegetation and tree island hydrodynamics, the 
impact of the $\mathrm{ET}_{\mathrm{G}}$ on tree island groundwater-surface water interactions has yet to be clarified.

Over the last century, the construction of canals, dikes and levees across the Everglades has led to drastic hydrologic changes, which have been linked to a sixty percent and ninety percent reduction in tree island cover in Water Conservation Areas (WCA) 3 and 2, respectively (Sklar and van der Valk 2002) (Figure 2. 1). While such losses are sometimes attributable to fire, in many cases they result from extended periods of high surface water levels, which drowned trees and caused the loss of peat from the islands and ridges, and resulted in the accumulation of peat in sloughs (Sklar and van der Valk 2002). The loss of tree islands is a major concern in efforts to restore the Everglades because they harbor the highest plant and animal species diversity of the region (Gawlik et al. 2002). In addition, tree islands provide a topographic refuge for plant species that are not flood tolerant and have high nutrient requirements (Davis and Ogden 1994).

The majority of the remaining tree islands in the Everglades are located in and around Shark Slough in the southern Everglades, the western edge of Water Conservation Area 3, and in Loxahatchee National Wildlife Refuge (LNWR, WCA-1) in the northern Everglades (Brandt et al. 2002; Wetzel et al. 2005). Though tree islands located in the northern and southern portions of the Everglades contain many of the same tree species, their underlying geology differs. In the southern Everglades, the limestone bedrock is very close to the soil surface. Most of the tree islands are thought to originate from limestone outcrops or mineral sediment mounds (Ross and Jones 2004). These tree 
islands are generally teardrop in shape and form a raised head and elongated tail oriented in the direction of surface water flow. In LNWR, a thick layer of peat, 1.5-3.5 m deep, overwhelms any sign of the minor topographic change in the limestone bedrock. Tree islands in LNWR are of two types; typically small and round, or large and elongated in the direction of flow but without distinct tails (Brandt et al. 2000). The former group of islands are known as "battery" tree islands that develop when a large piece of peat detaches from the bottom of a slough during high water levels (Stone et al. 2002). Although extensive studies have been conducted to define tree island vegetation, shape, morphology, and surface water dynamics, the relationship between tree island hydrodynamics and the underlying geologic composition has not been well established.

The main objective of this research was to investigate the hydrodynamics of tree islands in their early stages of development. The project was conducted on constructed tree islands that were planted with tree saplings. Groundwater and surface water levels were monitored over two years. Two types of tree islands were investigated: those that were constructed of peat, and others that were constructed of limestone rubble with overlying peat. The effects of standing live biomass on $\mathrm{ET}_{\mathrm{G}}$ rates and groundwater levels were also investigated.

\subsection{Study Site}

Constructed in 2003, the Loxahatchee Impoundment Landscape Assessment (LILA) Facility represents a large physical model of the Everglades. The LILA is located at the 
Arthur R. Marshall Loxahatchee National Wildlife Refuge, Boynton Beach, Florida (N26 $\left.29.600^{\prime}, \mathrm{W} 80^{\circ} 13.000^{\prime}\right)$ and spans just over 34 ha (Figure 2. 1). The LILA consists of four 8 ha macrocosms (M1 through M4), which mimic the Everglades ridge-andslough and tree island landscape features. Each macrocosm contains two tree islands with different underlying geologic material, one consisting entirely of peat (Peat Islands) and one having a limestone rubble core overlaid by a thin layer of peat (Limestone Islands; van der Valk et al., 2008) (Figure 2. 2). The soil survey of the area classifies the peats in the LILA vicinity as $80 \%$ Okeelanta muck and 20\% minor components (Natural Resources Conservation Service 2010). Each of the islands at LILA is approximately $43 \times 71 \mathrm{~m}$ in size. The limestone tree islands were constructed of local limestone rubble extending approximately $7 \mathrm{~m}$ to the north and south and $24 \mathrm{~m}$ to the east and west of the center of the islands. The limestone rubble was buried about $31 \mathrm{~cm}$ beneath the peat and extended to a depth about $91 \mathrm{~cm}$ (van der Valk et al. 2008). Over 700 saplings were planted on each tree island consisting of eight species common to the Everglades (Stoffella et al. 2010). Tree islands in M1 and M4 were planted in March 2006 (Planting1), while the tree islands in M2 and M3 were planted in March 2007 (Planting-2).

The climate of the region is characterized by distinct wet (mid-May through October) and dry (November to mid-May) seasons with a thirty-year annual average of $133 \mathrm{~cm}$ of precipitation (Ali et al. 2000). During the wet season, precipitation can be described as bimodal, with peaks in June and August. The surface water levels in LILA are controlled to mimic those of the Everglades, with the highest surface water levels occurring from 
September to January, flooding the tree islands, and the lowest surface water levels occurring from April to June.

\subsection{Materials and Methods}

\subsubsection{Experimental Design and Water Levels}

Nine wells were drilled or augered into each of the eight tree islands; six wells were located on the edge of the islands while three were located in the center. The lithology of the sediments encountered during drilling was characterized. The wells had an average depth of $1.34 \pm 0.15 \mathrm{~m}$ and an average bottom elevation of $3.49 \pm 0.08 \mathrm{~m}$ (relative to the National Geodetic Vertical Datum of 1929, NGVD29). Each PVC-encased well had a diameter of $3.8 \mathrm{~cm}$ and a $0.6 \mathrm{~m}$ screen interval at the bottom. Two edge wells and one center well were equipped with In-Situ Level Troll $500^{\mathrm{TM}}$ pressure transducers. Water levels in these wells were used to determine the effects of the proximity to the island's edge and the aboveground biomass on the water table and on $\mathrm{ET}_{\mathrm{G}}$ rates.

A total of 28 wells were monitored from July 2007 to July 2009 (Figure 2. 2). Groundwater levels were recorded at 15 minute intervals with the pressure transducers having an accuracy of $3.5 \mathrm{~mm}$. Water pressure was corrected for water specific gravity ( 0.99 as determined by a hydrometer) using the software provided by In-Situ. The

elevation of the top of the PVC pipe was determined using a Wild Nak-2 ${ }^{\mathrm{TM}}$ level and stadia rod, which provided a $3 \mathrm{~mm}$ level of accuracy. The distance from the top of the PVC pipe to the bottom of the pressure transducer was measured to within $2 \mathrm{~mm}$. 
Surface water stage was monitored at the eastern and western ends of each of the four 8 ha macrocosm, comprising a total of eight stations (SFWMD DBHYDRO, http://my.sfwmd.gov/dbhydroplsq1/show_dbkey_info.main_menu, Figure 2. 2). Surface water stages were maintained according to an established hydrograph and surface water levels were recorded every 15 minutes. Daily average surface water levels were computed from the 15 minute values. Surface water levels at the center of the two tree islands in each macrocosm were estimated from a linear interpolation between the surface water stages on the eastern and western ends of the macrocosms. Hydraulic gradients were determined between the surface water level and groundwater levels for the center of each of the tree islands. Positive hydraulic gradients indicated groundwater discharging to the surface water while negative values indicated surface water recharging to the groundwater.

Daily rainfall values were collected from the station LXWS (26²9'56.257', $80^{\circ} 13^{\prime}$ 20.159”, SFWMD DBHYDRO, http://my.sfwmd.gov/dbhydroplsql/show_dbkey _info.main_menu), located about 1 km from LILA, from July 2007 through June 2009. Daily values were summed to determine monthly totals. The monthly totals were compared to 30-year average values obtained from rain gauge LWD.L28 $\left(26^{\circ} 29^{\prime} 44.257^{\prime \prime}\right.$, $\left.80^{\circ} 12^{\prime} 10.157^{\prime \prime}\right)$, located $1.8 \mathrm{~km}$ from LILA. 


\subsubsection{Groundwater Evapotranspiration}

White (1932) determined that a diurnal drawdown of the water table during daylight hours was a product of phreatophytic plants taking up groundwater and could be used to determine the average daily $\mathrm{ET}_{\mathrm{G}}$ rate. The White method required that three assumptions be made: first, transpiration was negligible between midnight and 4:00 am; second, the diurnal water table fluctuations were a result of groundwater uptake by plants and not a phenomena of pumping or recharge of the aquifer; and third, reasonable values of specific yield were obtained (Healy and Cook 2002; Loheide et al. 2005). The White method utilized the equation:

$$
\mathrm{ET}_{\mathrm{G}}=\mathrm{S}_{\mathrm{y}}(\Delta \mathrm{s} / \mathrm{t} \pm \mathrm{r})
$$

where the average daily loss of groundwater through evapotranspiration $\left(\mathrm{ET}_{\mathrm{G}}\right)$ was the product of the specific yield $\left(\mathrm{S}_{\mathrm{y}}\right)$, and the sum of the change in storage $(\Delta \mathrm{s})$ per unit time (t) and the net recovery rate of the water table (r). The change in storage term was calculated by taking the difference between the water level at midnight on the day of interest and the water level at midnight, 24 hours later. Positive values indicated that there was a decline in the overall trend in the water table, while negative values indicated a rise in the water table. The net recovery rate of the water table was determined as the slope of the linear regression of the groundwater levels between midnight and 4:00 am (Figure 2. 3). 


\subsubsection{Specific Yield}

Laboratory and field methods were used to determine the readily available specific yield of the tree island sediments. Polycarbonate tubes with a diameter of $5.08 \mathrm{~cm}$ were inserted in the center of the peat-based tree islands to collect soil cores. Three cores were obtained from a depth of 5-25 cm and two obtained from a depth of $25-45 \mathrm{~cm}$ for a total five of cores that had an average length of $15.06 \mathrm{~cm}$. In the laboratory, each core was slowly submerged in water from the bottom to the top of the soil profile. Care was taken to ensure the entire column was saturated. Each core was oriented vertically and allowed to drain for 12 hours. This time duration was chosen to attain the amount of water released over the diurnal fluctuation time period (Meyboom 1967). The $\mathrm{S}_{\mathrm{y}}$ was calculated based on the following expression (Meinzer 1923):

$$
\mathrm{S}_{\mathrm{y}}=\mathrm{V}_{\mathrm{d}} / \mathrm{V}_{\mathrm{t}}
$$

where the readily available specific yield $\left(\mathrm{S}_{\mathrm{y}}\right)$ was the ratio of the volume of water that drained by weight $\left(\mathrm{V}_{\mathrm{d}}\right)$, compared to the total volume of each core $\left(\mathrm{V}_{\mathrm{t}}\right)$. Each core was tested twice $(\mathrm{n}=10)$ and the results were averaged to determine a mean $\mathrm{S}_{\mathrm{y}}$, and standard error.

Specific yield has been shown to increase with the depth of the water table in aquifers with a shallow water table, only reaching a stable value when the depth of the water table was approximately 2-3 m deep (Loheide et al. 2005; Nachabe 2002). To take this variability into account, the effective specific yield was also calculated using a modified 
version of the Water Table Fluctuation Method (Gerla 1992; Rosenberry and Winter 1997):

$$
\mathrm{S}_{\mathrm{ye}}=\mathrm{P} / \Delta \mathrm{h}
$$

where the effective specific yield $\left(\mathrm{S}_{\mathrm{ye}}\right)$ was equal to the ratio of precipitation inputs $(\mathrm{P})$ to the change in groundwater level $(\Delta \mathrm{h})$. Precipitation data from rain gauge LXWS were used to determine $\mathrm{P}$, while groundwater level data from each of the wells were used to determine the $\Delta \mathrm{h}$. Equation 3 required the assumptions that evapotranspiration, runoff, and subsurface flow were negligible over time and that the soil was above field capacity (Healy and Cook 2002). The effective specific yield was determined per rain event and averaged to obtain a monthly $\mathrm{S}_{\mathrm{ye}}$ per well. The average monthly $\mathrm{S}_{\mathrm{ye}}$ per well was then used in the White equation to calculate the average monthly $\mathrm{ET}_{\mathrm{G}}$ per well.

\subsubsection{Biomass}

Allometric biomass equations were developed by collecting plant attributes (height, basal diameter and crown dimensions) and biomass data from individuals comprising the range of heights present in LILA tree islands (up to $5 \mathrm{~m}$ ). The complete procedure and data analysis used to develop the equations is described in Stoffella et al. (2009). In the present work, a mixed-species regression model derived solely from total height (which was measured on all individuals at 6-month intervals with a telescoping height pole) was used to estimate a change in biomass with time. To compare biomass between the edges 
and centers of the islands, the biomass of each tree located within a $7 \mathrm{~m}$ radius around the monitoring wells was summed and divided by the area of the circle thereby circumscribed. On each island, two monitoring wells located on the edges of the islands were averaged to determined edge biomass while the biomass around the center monitoring well was used to represent the center biomass. The biomass at the center and the edges of islands were then averaged across all islands of similar geology and year of planting.

\subsection{Results}

\subsubsection{Lithology}

The underlying substrate in the center of the peat and limestone tree islands substantially differed within the first meter of the ground surface (Figure 2. 4). At the center of the limestone islands, peat was detected to an average depth of $11 \mathrm{~cm}$, and was underlain by limestone rubble that extended to an average depth of $59 \mathrm{~cm}$ (Stoffella et al. 2010). In all other areas on the limestone and peat islands, the peat extended from the surface to a depth of at least $60 \mathrm{~cm}$. Though most of the islands followed a similar lithologic pattern, clay was detected under the tree islands in M3. Over the entire expanse of the peat island in M3 (M3P), clay was detected at average depth of $67 \mathrm{~cm}$ and extended to $180 \mathrm{~cm}$. On the limestone island (M3L), clay was only detected at the edges at an average depth of $171 \mathrm{~cm}$, extended to $180 \mathrm{~cm}$, and was overlain by $50 \mathrm{~cm}$ of sand. A combination sand and shell unit was detected under all of the islands at a starting depth of $60-80 \mathrm{~cm}$ (except M3P and M3L) and extended to a depth of at least $190 \mathrm{~cm}$ (Figure 2. 4). The deep unit 
consisted of coarse and fine sand with areas of compacted shell and is likely part of the Pamlico Sand Formation (Parker et al. 1955; Stone et al. 2002). Data from well logs in the surrounding area suggest that the depth to bedrock is approximately $3 \mathrm{~m}$ (Parker et al. 1955).

\subsubsection{Precipitation and Water Levels}

The total annual rainfall from July 2007 through June 2008 was $148.69 \mathrm{~cm}$, slightly higher than the annual rainfall from July 2008 through June 2009, which totaled 133.83 $\mathrm{cm}$. The total annual rainfall in both years was below the thirty-year annual average of $160.20 \mathrm{~cm}$ (Figure 2. 5). The largest amount of rainfall occurred between the end of May and October, typical of South Florida's wet season. In both years, the rainfall from November through January was substantially lower than the 30 -year average.

From July 2007 through June 2009, the surface water levels ranged from $4.23 \mathrm{~m}$ to 5.15 $\mathrm{m}$ (Figure 2. 6). Surface water levels followed the seasonal rainfall patterns (Figure 2. 6). The highest surface water levels occurred between September and December and the lowest levels typically occurred between March and June. Surface water levels in some of the macrocosms were occasionally lowered for short periods of time for experimental purposes. On average, the edges of the tree islands were inundated by surface water for 150 days from July 2007 to June 2008, and 186 days from July 2008 to June 2009. 
The response of the water table to surface water levels was similar on islands with similar geologic substrates (Table 2. 1). Linear regressions between the surface water levels and the groundwater levels on three of the peat islands (excluding M3P) indicated an almost one-to-one relationship between the two water bodies with an average slope of 1.03 (average $\mathrm{R}^{2}=0.96$ ). For the limestone islands, the slope of a linear regression between groundwater levels (independent variable) and surface water averaged 0.86 (average $\mathrm{R}^{2}=0.82$ ). The groundwater levels in peat tree island M3P, which contained some clay, responded to surface water levels similarly to the limestone islands, with a slope of 0.69 $\left(\mathrm{R}^{2}=0.65\right)$.

Throughout the two-year study, the hydraulic gradient in the peat islands was always positive, ranged from 0.00 to 0.23 , and averaged 0.05 (Figure 2. 7). The average hydraulic gradient in the limestone islands (0.03) was similar to the peat islands but ranged from -0.24 to 0.47 . The hydrologic responses of the peat tree islands were similar with the exception of M3P where the hydraulic gradient ranged from -0.11 to 0.27 , and averaged 0.02 . The hydrologic responses of all four limestone tree islands were similar. This paper will focus on the groundwater-surface water interactions on the peat and limestone tree islands in M1 (Figure 2. 8), with the understanding that similar responses were observed in the tree islands of the other three macrocosms.

From July 2007 through June 2009, the average daily groundwater level in the centers of the peat and limestone tree islands in M1 reached a maximum of $5.19 \mathrm{~m}$ (NGVD29). Minimum daily groundwater levels of $4.39 \mathrm{~m}$ and $4.12 \mathrm{~m}$ were observed in the peat and 
limestone tree islands, respectively. During this same period the surface water levels ranged from $4.26 \mathrm{~m}$ to $5.15 \mathrm{~m}$ and averaged $4.60 \mathrm{~m}$ for $2007-2008$ and $4.70 \mathrm{~m}$ for 2008 2009. The highest water levels occurred between August and November, while lowest water levels typically occurred between March and May. Though groundwater levels in the center of the peat island were always elevated compared to surface water, the groundwater level in the center of the limestone island was lower than the surface water when the surface water level and precipitation inputs were low (Figure 2. 8).

Groundwater levels from three wells on each island were normalized to the surface water levels and graphed to characterize the shape of the water table (Figure 2. 9). From July 2007 through June 2008, the water table was typically elevated in the center compared to the edges in both the peat and limestone tree islands (Figure 2. 9). From July 2007 through June 2009, the groundwater levels at the edges of the islands were always elevated compared to the surface water. However, from July 2008 through June 2009, the groundwater levels were lower in the center compared to the edges, which caused a hydraulic divide to be established along the edge of the tree islands (Figure 2. 9). The hydraulic divide first appeared on the limestone islands 1.3 years after the trees were planted, but was not sustained year-round until 2.3 years after planting. On the peat islands the hydraulic divide did not occur until 2.5 years after planting. The development of a water table depression in the center on the islands led to a shift in the dominant direction of horizontal groundwater flow. During this period, groundwater flowed from the edges of the islands to the center of the islands as well as toward the surrounding surface water (Figure 2. 9). The greatest water table drawdown occurred in the center of 
the limestone islands, averaging $6.33 \mathrm{~cm}$ lower than the edges and ranging from 0.16 to $18.05 \mathrm{~cm}$. The center of the peat island had a much lower average drawdown of $1.21 \mathrm{~cm}$ compared to the edges and ranged from 0.12 to $2.01 \mathrm{~cm}$.

\subsubsection{Specific Yield}

The average $S_{y}$ obtained from the soil cores on the peat based tree islands was $0.15 \pm$ 0.04 and ranged from 0.01 to 0.38 . The $\mathrm{S}_{\mathrm{ye}}$ values were similar to those obtained from the soil cores with an average of 0.15 and ranged from 0.01 to 0.40 (Figure 2. 10). The average $S_{\text {ye }}$ for the center of the peat tree islands was elevated compared to the center of the limestone tree islands with values of $0.13 \pm 0.01$ and $0.10 \pm 0.01$, respectively. When the $\mathrm{S}_{\mathrm{ye}}$ values were grouped according to location (edge or center), the $\mathrm{S}_{\mathrm{ye}}$ in the center of the tree islands increased with depth to water for water table depths greater than $20 \mathrm{~cm}$ below the ground surface (Figure 2. 10). Values of $S_{\text {ye }}$ increased from 0.03 to 0.20 when the water table declined from $20 \mathrm{~cm}$ to $60 \mathrm{~cm}$ below the ground surface. When the depth to the water table was less than $20 \mathrm{~cm}$ below the ground surface, no relationship was detected between the depth to water and the $S_{\mathrm{ye}}$ at either the center or the edges of the islands.

\subsubsection{Groundwater Evapotranspiration}

The average daily $\mathrm{ET}_{\mathrm{G}}$ values per month for all wells averaged $3.69 \mathrm{~mm} \mathrm{~d}^{-1}$ and ranged from 0.27 to $14.23 \mathrm{~mm} \mathrm{~d}^{-1}$. During the first year of this study, the average $\mathrm{ET}_{\mathrm{G}}$ was $4.02 \mathrm{~mm} \mathrm{~d}^{-1}$ with the most elevated values detected in September, May and June, and the 
lowest values detected in November and December. During the next year, the average $\mathrm{ET}_{\mathrm{G}}$ was slightly lower with an average $\mathrm{ET}_{\mathrm{G}}$ of $3.47 \mathrm{~mm} \mathrm{~d}^{-1}$. During this period the highest values were detected in April, May, and August while the lowest values were detected in December, January and February. When the $\mathrm{ET}_{\mathrm{G}}$ values were grouped according to both location (edge vs center) and underlying sediments, the average annual $\mathrm{ET}_{\mathrm{G}}$ was similar on the edge of the peat and limestone tree islands, with values of $3.84 \mathrm{~mm} \mathrm{~d}^{-1}$ and $3.87 \mathrm{~mm} \mathrm{~d}^{-1}$, respectively.

As a result of annual high water levels that inundated the edges of the islands from September through December, $\mathrm{ET}_{\mathrm{G}}$ values could not be calculated using the White method, for wells in those locations. Therefore, the $\mathrm{ET}_{\mathrm{G}}$ of the center and edges of the islands could only be compared for months when data were available from all locations. The average annual $\mathrm{ET}_{\mathrm{G}}$ for the center of the limestone islands, $4.02 \mathrm{~mm} \mathrm{~d}^{-1}$, was elevated compared to the center of the peat islands, $3.06 \mathrm{~mm} \mathrm{~d}^{-1}$. Typically the center of the limestone islands had the elevated average daily $\mathrm{ET}_{\mathrm{G}}$ value per month compared to the edges, which were elevated compared to the center of the peat islands (Figure 2. 11).

\subsubsection{Biomass}

The accrual of aboveground tree biomass on all islands showed a strong seasonal pattern with relatively little growth occurring between September and March followed by higher growth from March to September. In addition, the rate of biomass accumulation increased on all islands during the last year. From March 2007 through September of 
2009 , the aboveground biomass more than doubled on the edges of the islands while in the center of the islands the biomass increased by nearly six-fold. From March 2007 to March 2008, the average aboveground biomass on the edges of the limestone islands was similar to that of the center, with a difference of 0.01 tonnes per hectare $\left(\mathrm{t} \mathrm{ha}^{-1}\right)$ on the Planting-1 islands and $0.12 \mathrm{t} \mathrm{ha}^{-1}$ on the Planting-2 islands (Figure 2. 12). During this same period the average aboveground biomass in the center of the Planting-1 peat islands was substantially elevated compared to the edge, with a difference of $0.77 \mathrm{tha}^{-1}$, while little difference in the aboveground biomass was detected between the center and edge of the Planting-2 peat islands (Figure 2. 12). From September 2008 to September 2009, the biomass in the center of all of the islands was elevated compared to the edges by at least $0.60 \mathrm{tha}^{-1}$, with the greatest difference detected between the center and edge of the peat islands (Figure 2. 12).

\subsection{Discussion}

Soil cores and depth to bedrock probes of the heads of tree islands indicate that 1.5-3.5 m of peat separate the top of the tree islands from the underlying bedrock in the northern Everglades, while only $25-90 \mathrm{~cm}$ peat overlies the mineral substrate or bedrock in the central and southern Everglades (Brandt et al. 2002; Mason and van der Valk 2002; Schwadron 2006; Stone et al. 2002). With similar thickness in the overlying peat, the peat trees islands at LILA mimic those of the Water Conservation Area 3, located in the central portion of the Everglades (Mason and van der Valk 2002). Furthermore, the limestone islands at LILA may be similar to a number of fixed islands in Everglades 
National Park, such as Crandon and Sour Orange hammocks. On these islands $25-50 \mathrm{~cm}$ of organic coarse loamy soil separated the top of the islands from a $40-75 \mathrm{~cm}$ thick mineralized or calcrete layer that was underlain by $50 \mathrm{~cm}$ thick layer of dense black earth midden before reaching bedrock (Coultas et al. 2008; Graf 2008). Although the thickness of overlying peat, presence of a calcrete layer, and depth to bedrock vary widely between tree islands of the Everglades, the variability in tree island stratigraphy is captured in the constructed islands at LILA.

The range in the hydraulic gradients from the limestone tree islands at LILA (-0.24 to 0.47) was greater than values previously reported in the Everglades. The highest published hydraulic gradient was 0.10 measured adjacent to a levee road (Harvey et al. 2004). However, the average hydraulic gradients measured on the peat (0.05) and limestone (0.03) tree islands at LILA were similar to a value of 0.02 reported in the interior of the Water Conservation Area 2 (Harvey et al. 2000) but significantly greater than a hydraulic gradient of 0.005 reported for Taylor Slough (Harvey et al. 2004). The large variability in the hydraulic gradients observed in the tree islands at LILA were most likely the result of managed surface water level, which was sometimes raised or lowered quickly to accommodate other studies or to stay on the operational hydrograph.

The $\mathrm{S}_{\mathrm{ye}}$ values at LILA varied greatly $(0.10-0.27)$ when the water table was within $20 \mathrm{~cm}$ of the ground surface, while the $S_{\text {ye }}$ values increased from 0.03 to 0.20 with water table depth deeper than $20 \mathrm{~cm}$. Though slightly elevated, specific yield modeling results of Everglades peat showed similar patterns to those at LILA. When the water table was 
within $15-20 \mathrm{~cm}$ of the ground surface, the specific yield values were highly variable and ranged from $0.1-0.5$, but when the depth of the water table was greater than $20-30 \mathrm{~cm}$, the specific yield increased with depth to 0.2 (Sumner 2007). The readily available specific yields of mineral soils were also found to increase with water table depth when the water table was within $1 \mathrm{~m}$ of the ground surface (Lohiede et al. 2005), though the reverse was observed in peat soils (Boelter 1965; Heloitis 1989). The increase in $\mathrm{S}_{\mathrm{ye}}$ with water table depth, at depths greater than $20 \mathrm{~cm}$, on the islands at LILA may be attributed to the sandshell layer that underlies the peat for all of the islands.

The $\mathrm{ET}_{\mathrm{G}}$ rates at LILA followed a seasonal pattern and monthly mean akin to those of a forested area with a shallow water table examined in Hillsborough County, Florida (Nachabe et al. 2005); using the White method, these authors found that the average daily $\mathrm{ET}_{\mathrm{G}}$ per month in the forest ranged from 0.1 to $7.8 \mathrm{~mm} \mathrm{~d}^{-1}$, with the highest rates detected in May through July. Lysimeter data for the Everglades Nutrient Removal project, $25 \mathrm{~km}$ from LILA, showed seasonal evapotranspiration patterns analogous to the $\mathrm{ET}_{\mathrm{G}}$ rates at LILA, with the highest rates detected between May and July, but with a much smaller range, exhibiting values of $1.9 \mathrm{~mm} \mathrm{~d}^{-1}$ to $5.8 \mathrm{~mm} \mathrm{~d}^{-1}$ (Abtew 1996). Using the energy budget method, German and Sumner (2002) calculated rates of evapotranspiration that ranged from 1.69 to $5.92 \mathrm{~mm} \mathrm{~d}^{-1}$ during a drought year in a sawgrass area of Blue Cypress Marsh, located north of Loxahatchee. The average daily $\mathrm{ET}_{\mathrm{G}}$ per month detected in the summer of 2008 at LILA were elevated compared to data reported by Abtew (1996) and German and Sumner (2002). The large range in specific yield values that 
occurred when the water table was close to the ground surface may have led to an over estimation of $\mathrm{ET}_{\mathrm{G}}$ during the wet season.

The greater $\mathrm{ET}_{\mathrm{G}}$ rates in the center of the limestone tree islands compared to the peat islands may be attributed to variations in the overlying biomass. Stoffella et al. (2010) found that the height of the trees increased on the peat tree islands with increasing elevation. Furthermore, they noted from aerial photos that fewer ruderal herbs and shrubs persisted in the center of the peat tree islands compared to the limestone. The lower $\mathrm{ET}_{\mathrm{G}}$ rates in the center of the peat islands may be attributed to increased shading, lower air and soil temperatures, the development of a litter layer and the reduced air flow associated with the greater aboveground tree biomass (Holmgren et al. 1997; Le Maitre et al. 1999).

In addition to the amount of aboveground biomass more than doubling from 2007-2008 to 2008-2009, the distribution of the aboveground biomass also changed. In 2007-2008 the aboveground biomass was equally distributed between the edge and center for most of the islands while for 2008-2009 the center of the islands had at least 1.5 times more aboveground biomass compared to the edges. Over the same time period, a shift occurred in the groundwater flow direction in the islands. For 2007-2008 groundwater consistently flowed radially away from the center of the islands toward the edges where it discharged to the surface water. In 2008-2009, the water table in the center of the islands was depressed compared to the edges, which created a hydraulic divide along the edge of the islands. From this divide, groundwater flowed in two directions; one from the edges of 
the island toward its center, and the other from the edges of the island to the surface water (Figure 2. 9). Though the average monthly $\mathrm{ET}_{\mathrm{G}}$ rates slightly decreased from 2007-2008 to 2008-2009 on both island types, the aboveground biomass increased. The increase in aboveground biomass was particularly high in the center of the peat tree islands where biomass increased $5.7 \mathrm{tha}^{-1}$ on Planting-1 islands and $1.8 \mathrm{t} \mathrm{ha}^{-1}$ on Planting-2 (Figure 2. 12) An increase in aboveground biomass would be expected to increase transpiration, but could have also increased shading, reduced soil temperatures and increased humidity, all of which would reduce evaporation. Lauenroth and Bradford (2006) found that as the biomass in a short grass steppe in Colorado increased, the ratio of evaporation to evapotranspiration decreased significantly while the ratio of transpiration to evapotranspiration increased.

Though the average monthly $\mathrm{ET}_{\mathrm{G}}$ rates on the islands at LILA were similar from the first to the second year of the study, there was a large increase in the biomass specifically in the center of the islands, which may suggest that the ratio of transpiration to evaporation increased. The likely increase in transpiration rates is further supported by the drawdown detected in the water table in the center of the tree islands. Given that the White method was used to calculate evapotranspiration from below the water table, an increase in $\mathrm{ET}_{\mathrm{G}}$ in the center of the island would not be captured if the trees relied more on unsaturated zone groundwater. These results suggest that measuring $\mathrm{ET}_{\mathrm{G}}$ by the White method may not be sufficient for comparing interactions within the ridge-slough-tree island continuum. In the future, the estimation of $\mathrm{ET}_{\mathrm{G}}$ in the tree islands could be improved by taking sap flow measurements. 
The larger drawdown in the water table in the limestone islands compared to the peat islands may be attributed to the hydraulic properties of the island sediments. Harvey et al. (2004) found that the hydraulic conductivity of peat in Water Conservation Area 2, just southwest of LILA, was substantially lower than that of the underlying limestone bedrock with average values of $60 \mathrm{~cm} \mathrm{day}^{-1}$ and $9000 \mathrm{~cm} \mathrm{day}^{-1}$, respectively. The limestone rubble cores on the tree islands at LILA, likely do not reflect that of the underlying bedrock and may have a hydraulic conductivity lower than that of the peat because of the mixture of peat and limestone rubble. Kamann et al. (2007) found that the permeability of a pebble layer decreased with increased proportions of sand, with the pebbles reaching a permeability less than that of the sand when mixtures were comprised of less than $60 \%$ pebbles. A potentially lower hydraulic conductivity of the limestone islands compared to the peat islands may explain the larger drawdown observed in the center of the limestone islands.

Local, intermediate and regional groundwater flow paths have been attributed to topography, geology (i.e., hydraulic conductivity) and precipitation, where topographic highs tend to dominate local flow patterns (Sopocleous 2002; Tóth 1963). Although the tree islands are only slightly raised above the surrounding landscape $(\leq 1 \mathrm{~m})$, the data from LILA suggest that complex and dynamic groundwater flow patterns can develop within them. The development of the hydraulic divide along the edges of the tree islands suggests reduced groundwater-surface water interactions at a shallow (local) depth. The observed cone of depression in the center of the islands supports the possibility of a 
slightly deeper (intermediate) flow path of groundwater from beneath the slough into the tree island induced by the transpiration of trees, similar to what has been suggested by Ross et al. (2006). The results of the present study also suggest that the hydrologic conditions in tree islands are dependent upon the inputs of precipitation and outputs of $\mathrm{ET}_{\mathrm{G}}$, as well as water levels and geologic materials. Future modeling efforts would assist in providing a better understanding of these relationships.

The hydrodynamic conditions observed in the two years of this study lends support to the hypothesis that variations in $\mathrm{ET}_{\mathrm{G}}$ across ecosystems can be a large driving factor in landscape patterning, especially in the Everglades (Eppinga et al. 2008; Rietkerk et al. 2004; Wetzel et al. 2005). In addition to the change in groundwater flow patterns, the variation in the underlying geologic materials played a large role in the size of the water table drawdown, particularly in the limestone islands. Similar to the islands at LILA, the underlying geology of the tree islands in the Everglades varies from the north to south and may in part explain the southerly increase in nutrient and ion concentrations detected in tree islands (Wetzel et al. 2011). The observed water table drawdown in the center of the tree islands at LILA indicates $\mathrm{ET}_{\mathrm{G}}$ is a dominant process that creates a natural sink in the center of the islands where the exclusion of ions through transpiration and advective transport could lead to the concentration of ions and nutrients within the center of the tree islands. 


\subsection{Conclusions}

In summary, the data from LILA suggest that overlying vegetation and underlying geologic materials play a large role in the hydrologic conditions of tree islands. For 20072008, the groundwater levels indicate that the dominant direction of groundwater flow was from the center of the islands to the edges. Between the first and second year of the study, the amount of aboveground biomass nearly doubled. With this doubling of biomass, a water table depression developed in the center of all of the islands and created a hydraulic divide along the edge of the island, which led to varying groundwater flow paths. The groundwater drawdown was larger in the limestone islands compared to the peat islands. The fast response in the water table with the growth of juvenile trees was unexpected, but provides insight into the formation and possible reconstruction of tree islands of the Everglades. 


\subsection{References}

Abtew W (1996) Evapotranspiration measurements and modeling for three wetland systems in south Florida. Water Resour Bull 32(3):465-473

Ali A, Abtew W, Van Horn S, Khanal N (2000) Temporal and spatial characterization of rainfall over Central and South Florida. J Am Water Resour Assoc 36(4):833-848

Boelter HD (1965) Hydraulic conductivity of peats. Soil Sci 100(4):227-231

Brandt LA, Portier KM, Kitchens WM (2000) Patterns of change in tree islands in Arthur R. Marshall Loxahatchee National Wildlife Refuge from 1950-1991. Wetlands 20(1):1-14

Brandt LA, Siliveria JE, Kitchens WM (2002) Tree islands of Arthur R. Marshall Loxahatchee National Wildlife Refuge. In: Sklar FH, van der Valk AG (eds) Tree islands of the Everglades. Kluwers, Dordecht, The Netherlands

Coultas CL, Schawrdon M, Galbraith JM (2008) Petrocalcic horizon formation and prehistoric people's effect on Everglades tree island soils, Florida. Soil Surv Horiz 49(1):16-21

Daivs SM, Ogden JC (1994) Everglades: the ecosystem and it restoration. St. Lucie, Boca Raton, FL

Engel VC, Jobbágy EG, Stieglitz M, Williams M, Jackson RB (2005) Hydrological consequences of Eucalyptus afforestation in the Argentine Pampas. Water Resour Res 41 ,W10409, 14 pp

Eppinga MB, Rietkerk M, Borren W, Lapshina ED, Bleuten W, Wassen MJ (2008) Regular surface patterning of peatlands: confronting theory with field data. Ecosystems 11:520-536

Ewe SML, da Silveira Lobo Sternberg L, Busch DE (1999) Water-use patterns of woody species in pineland and hammock communities of South Florida. For Ecol Manage 118:139-148

Ferone JM, Devito KJ (2004) Shallow groundwater-surface water interactions in pondpeatland complexes along Boreal Plains topographic gradient. J Hydrol 292:7595

Gann TGT, Childers DL, Randeaau DN (2005) Ecosystem structure, nutrient dynamics, and hydrologic relationships in tree islands of the southern Everglades, Florida, USA. For Ecol Manage 214:11-27 
Gawlik DE, Gronemyer P, Powell RA (2002) Habitat-use patterns of avian seed dispersers in the central Everglades. In: Sklar FH, van der Valk AG (eds) Tree islands of the Everglades. Kluwer, Dordecht, The Netherlands

Gerla PJ (1992) The relationship of water table changes to the capillary fringe, evapotranspiration, and precipitation in intermittent wetlands. Wetlands 12(2):9198

German ER, Sumner DM (2002) Evapotranspiration rates from two different sawgrass communities in South Florida during drought conditions. Second Federal Interagency Hydrologic Modeling Conference, Las Vegas, NV, 28 July-1 August $2002,12 \mathrm{pp}$

Glaser PH, Wheeler GA, Gorham E, Wright HE Jr (1981) The patterned mires of the Red Lake peatland, northern Minnesota: vegetation, water chemistry, and landforms. J Ecol 69(2):575-599

Graf MT, Schwadron M, Stone PA, Ross M, Chmura GL (2008) An enigmatic carbonate layer in Everglades tree island peats. EOS Trans AGU 89(12):117-124

Harvey WJ, Jackson JM, Mooney RH, Choi J (2000) Interaction between ground water and surface water in Taylor Slough and Vicinity, Everglades National Park, South Florida. US Geol Surv Open-File Rep 00-483

Harvey WJ, Krupa SL, Krest JM (2004) Ground water recharge and discharge in the central Everglades. Ground Water 47(7):1090-1102

Healy WR, Cook PG (2002) Using groundwater levels to estimate recharge. Hydrogeol J 10:91-109

Heliotis FD (1989) Water storage capacity of wetland used for wastewater treatment. J Environ Eng 115(4):822-834

Holmgren M, Scheffer M, Huston AM (1997) The interplay of facilitation and competition of plant communities. Ecology 78(7):1966-1975

Jobbágy EG, Jackson RB (2007) Groundwater and soil chemical changes under phreatophytic tree plantations. J Geophys Res 112(G0213):1-15

Kamann PJ, Ritzi RW, Dominic DF, Conrad CM (2007) Porosity and permeability in sediment mixtures. Ground Water 45(4):429-438

Lauenroth WK, Bradford JB (2006) Ecohydrology and the partition AET between transpiration and evaporation in semiarid steppe. Ecosystems 9:756-767

Le Maitre DC, Scott DF, Colvin C (1999) A review of information on interactions between vegetation and groundwater. Water S A 25(2):137-152 
Loheide SP II, Butler JJ Jr, Gorelick SM (2005) Estimating groundwater consumption by phreatophytes using diurnal water table fluctuations: a saturated-unsaturated flow assessment. Water Resour Res 40, W07030

Mason DH, van der Valk A (2002) Vegetation, peat elevation, and peat depth on two tree islands in Water Conservation Area-3A. In: Sklar FH, van der Valk AG (eds) Tree islands of the Everglades. Kluwer, Dordecht, The Netherlands

McCarthy TS, Ellery WN, Danergfield JM (1998) The role of biota in the initiation and growth of islands on the floodplain of the Okavanga Alluvial Fan, Bostwana. Earth Surf Process Land 23:281-316

Meinzer OE (1923) The occurrence of groundwater in the United States with a discussion of principles. US Geol Surv Water Suppl Pap 489

Meyboom P (1967) Groundwater studies in the Assiniboine River drainage basin: part II, hydrologic characteristics of phreatophytic vegetation in south-central Saskatchewan. Geol Surv Canada Bull 139

Nachabe MH (2002) Analytical expressions for transient specific yield and shallow water table drainage. Water Resour Res 38(10):1193-1204

Nachabe M, Shah N, Ross M, Vomacka J (2005) Evapotranspiration of two vegetation covers in shallow water table environment. Soil Sci Soc Am J 69:429-499

Natural Resources Conservation Survey (2010) Web soil survey, national cooperative soil survey. National Resources Conservation Survey, Washington, DC. http://websoilsurvey.nrcs.usda.gov/app/WebSoilSurvey.aspx. Cited 21 March 2010

Parker GG, Ferguson GE, Love SK et al (1955) Water resources of southeastern Florida with special reference to the geology and ground water of the Miami area. US Geol Surv Water Suppl Pap 1255

Rietkerk M, van der Koppel J (2008) Regular pattern formation in real ecosystems. Trends Ecol Evol 23(3):169-176

Rietkerk M, Dekker SC, Wassen MJ, Verkroost AWM, Bierkens MFP (2004) A putative mechanism for bog patterning. Am Naturalist 163(5):699-708

Rosenberry DO, Winter TC (1997) Dynamics of water-table fluctuations in an upland between two prairie-pothole wetlands in North Dakota. J Hydrol 191:266-289

Ross MS, Jones DT (2004) Tree islands in the Shark Slough landscape: interactions of vegetation, hydrology and soils. Final report, Submitted to the Everglades National Park, Homestead, FL, 196 pp 
Ross MS, Mitchell-Brucker S, Sah JP, Stothoff S, Ruiz PL, Reed DL, Jayachandran K, Coultas CL (2006) Interaction of hydrology and nutrient limitation in ridge and slough landscape of southern Florida. Hydrobiology 569:37-59

Schwadron M (2006) Everglades tree islands prehistory: archeological evidence for regional Holocene variability and early human settlement. Antiquity 80(310)

Sklar FH, van der Valk A (2002) Tree islands of the Everglades: an overview. In: Sklar FH, van der Valk AG (eds) Tree islands of the Everglades. Kluwer, Dordecht, The Netherlands

Sophocleous M (2002) Interactions between groundwater and surface water: the state of science. Hydrogeol J 10:52-67

Stoffella SL, Ross MS, Sah J, Ruiz P, Lopez 1, Colbert N, Dodge C, Heinrich J Trujillo D (2009) Estimating biomass production and nutrient concentrations of tree species growing along hydrologic gradient on LILA tree islands Biomass Estimation. Report to the South Florida Water Management District. SFWMD, West Palm Beach, FL, 12 pp

Stoffella SL, Ross MS, Sah JP, Price MP, Sullivan PL, Cline AE, Scinto LJ (2010) Survival and growth responses of eight Everglades tree species along an experimental hydrologic gradient on two tree island types. Appl Veg Sci. doi:10.1111/j.1654-109X.2010.01081.x

Stone PA, Gleason PJ, Chmura GL (2002) Bayhead Tree Islands on deep peats of the northeastern Everglades, chapter 3. In: Sklar FH, van der Valk AG (eds) Tree islands of the Everglades. Kluwer, Dordecht, The Netherlands

Sumner DM (2007) Effects of capillarity and microtopography on wetlands specific yield. Wetlands 27(3):693-701

Tóth J (1963) A theoretical analysis of groundwater flow in a small drainage basin. J Geophys Res 68(16):4795-4812

van der Valk AG, Wetzel P, Cline E, Sklar FH (2008) Restoring Tree Islands in the Everglades: experimental studies of tree seedling survival. Restor Ecol 16(2):281289

Wetzel PR, van der Valk AG, Newman S, Gawlik DE, Gann TT, Coronado-Moliana CA, Childers DL, Sklar FH (2005) Maintaining tree islands in the Florida Everglades: nutrient redistribution is the key. Front Ecol Environ 3(7):370-376

Wetzel PR, Sklar FH, Coronado CA, Troxler TG, Krupa SL, Sullivan PL, Ewe S, Price RM, Newman S, Orem WH (2011). Biogeochemical processes on tree islands in the Greater Everglades: Initiating a new paradigm. Critical Reviews in Environmental Science and Technology 41:670-701 
White WN (1932) A method of estimating ground-water supplies based on discharge by plants and evaporations from soils: results of investigations in Escalante Valley, Utah. US Geol Surv Water Suppl Pap 659-A 


\subsection{Tables}

Table 2. 1 Linear regression results between surface water levels and groundwater in the center of the islands with differing geologic cores and locations (East (E) and West (W)). Regression results for the islands include: underlying geology, slope, standard error (STE) of the slope, intercept, standard error (STE) of the intercept and the square of the correlation coefficient $\left(\mathrm{R}^{2}\right)$.

\begin{tabular}{l|l|l|l|l|l|l} 
Site & Island Type & Slope & STE-Slope & Intercept & STE-Intercept & $\mathrm{R}^{2}$ \\
\hline M3E & Peat & 0.69 & 0.02 & 1.45 & 0.09 & 0.65 \\
\hline M1E & Limestone & 0.82 & 0.02 & 0.80 & 0.09 & 0.72 \\
\hline M4E & Limestone & 0.83 & 0.02 & 0.80 & 0.08 & 0.75 \\
\hline M2W & Limestone & 0.86 & 0.01 & 0.48 & 0.07 & 0.93 \\
\hline M3W & Limestone & 0.95 & 0.01 & 0.21 & 0.07 & 0.89 \\
\hline M4W & Peat & 0.99 & 0.01 & 0.00 & 0.05 & 0.94 \\
\hline M2E & Peat & 1.01 & 0.01 & -0.16 & 0.03 & 0.97 \\
\hline M1W & Peat & 1.10 & 0.01 & -0.55 & 0.04 & 0.97
\end{tabular}




\subsection{Figures}

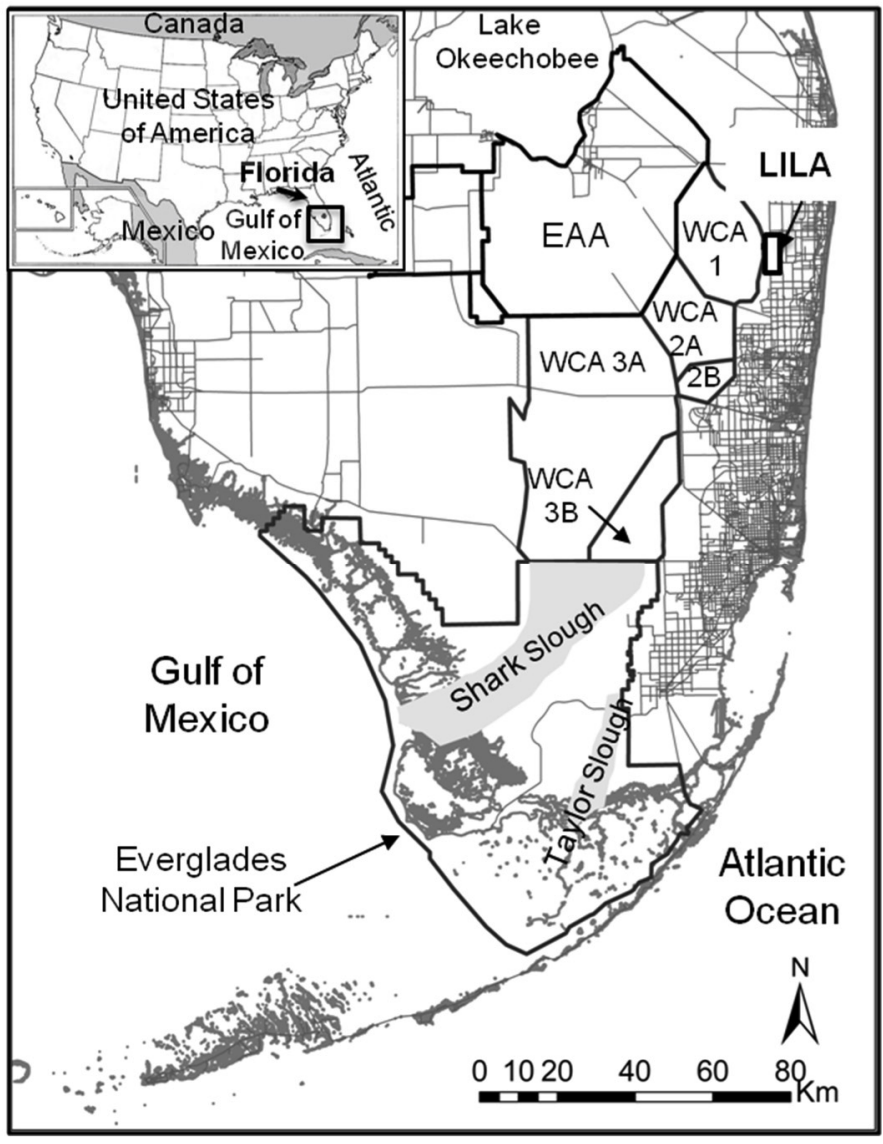

Figure 2. 1 Loxahatchee Impoundment Landscape Assessment (LILA) is located on the eastern edge of Water Conservation Area 1, in Boynton Beach, Florida. 


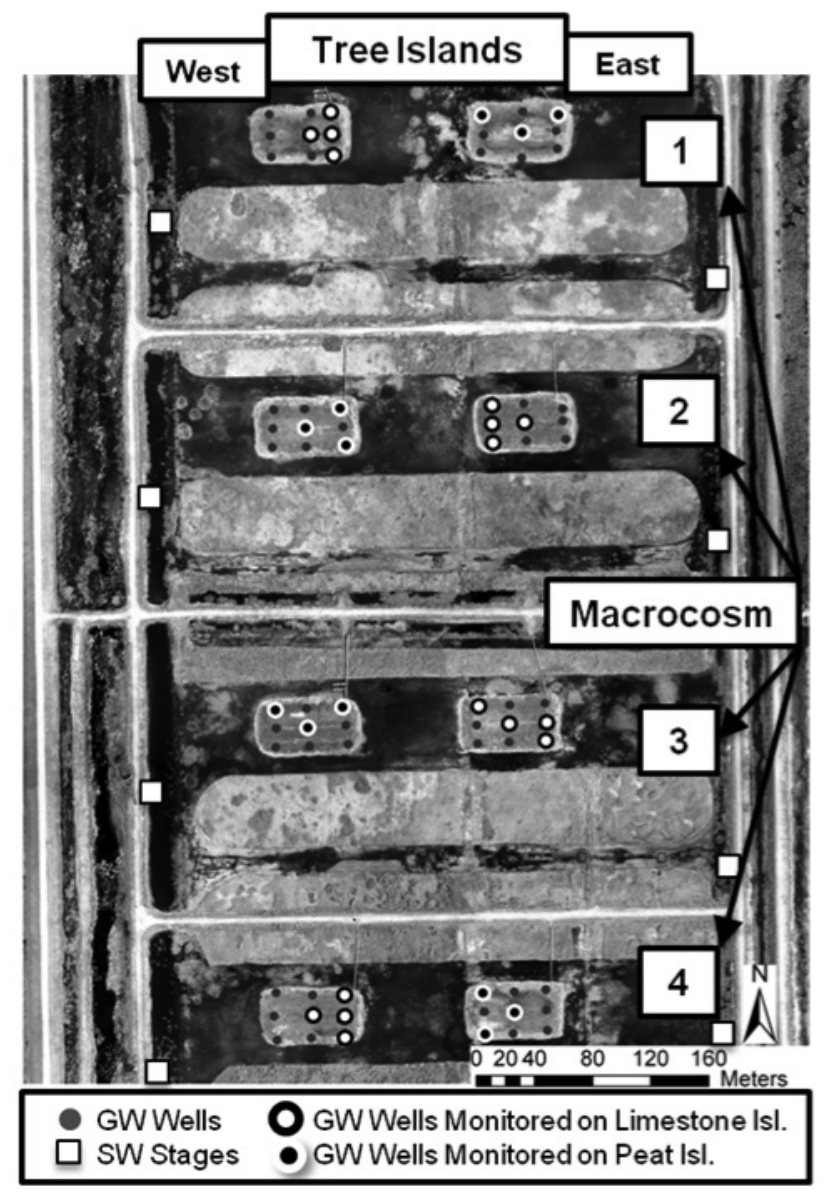

Figure 2. 2 LILA is comprised of four macrocosms that mimic the Everglades; each macrocosm has two tree islands with an underlying geology of either peat or limestone. Of the 72 wells at LILA a total of 28 wells were monitored over the eight islands. $\mathrm{GW}=$ groundwater, $\mathrm{SW}=$ surface water. 


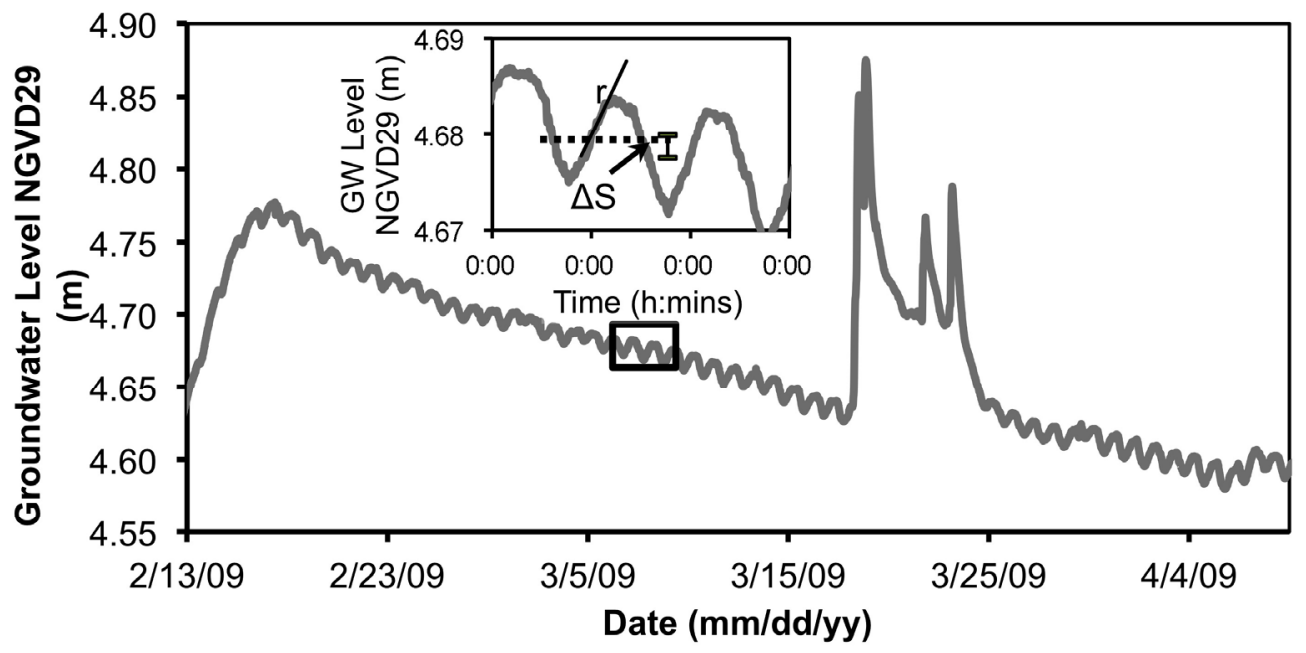

Figure 2. 3 Diurnal drawdown in groundwater levels from the center of a peat based island. Evapotranspiration from the groundwater $\left(\mathrm{ET}_{\mathrm{G}}\right)$ was determined according to Eq. 2. 1 using the slope between midnight and 4:00 am (r), the change in water level from midnight of the day of interest and the previous midnight $(\Delta \mathrm{S})$ and the specific yield. 


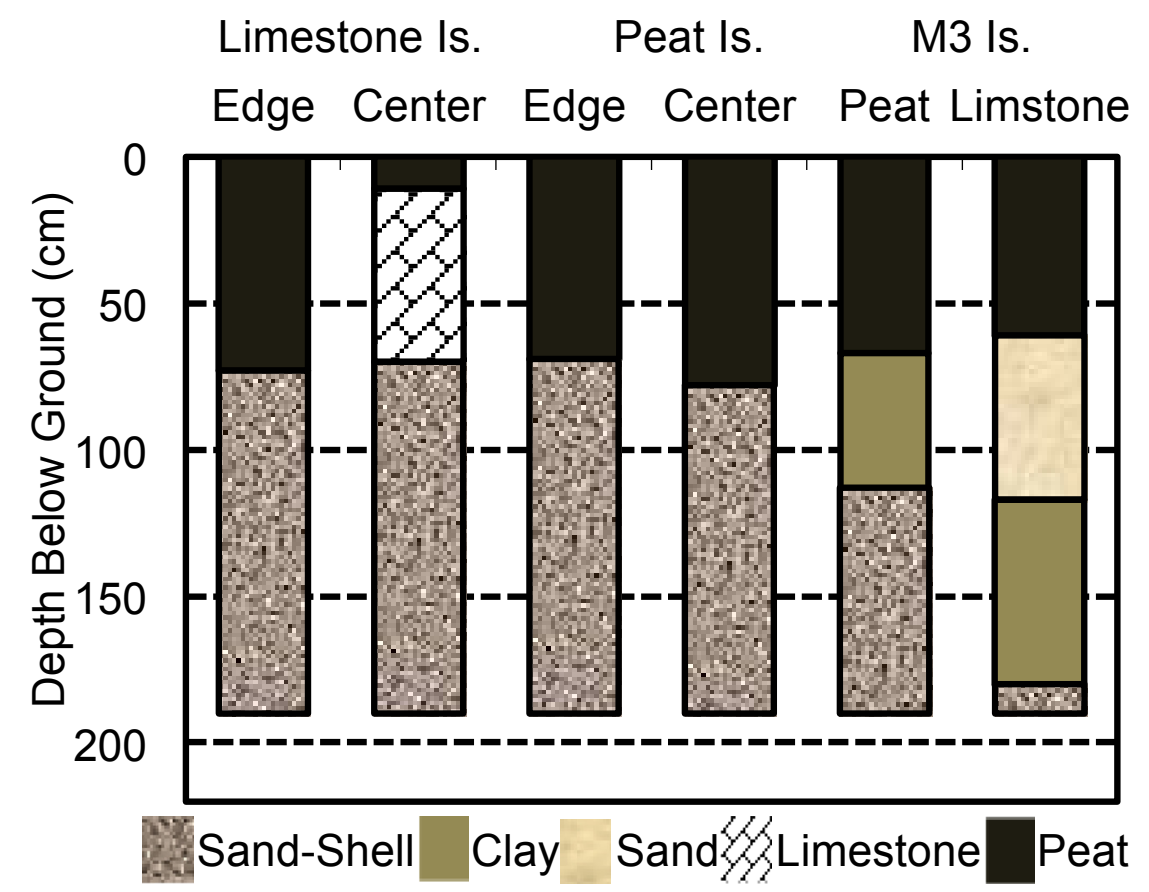

Figure 2. 4 The average sediment profile at the center and edges of the peat and limestone islands. In macrocosm 3 (M3) a thick layer of clay was observed across the peat island and at the edges of the limestone island. 


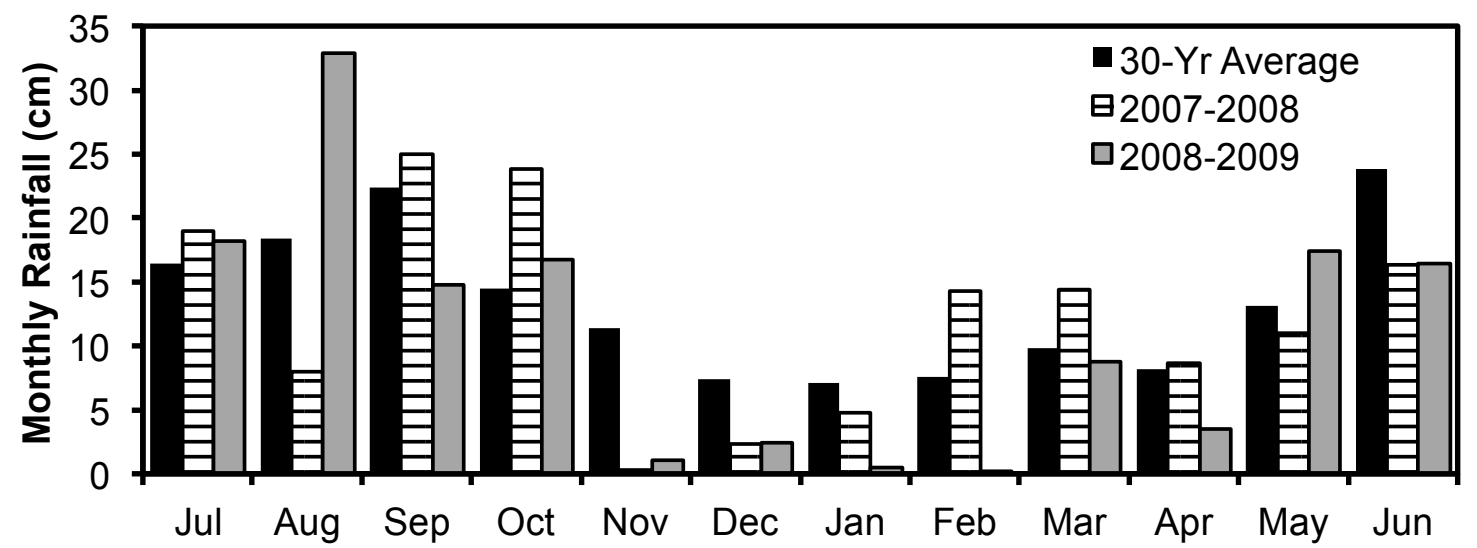

Figure 2. 5 Monthly rainfall amount averaged over 30 years (black) compared to the monthly rainfall amounts that occurred between 2007-2008 (striped) and 2008-2009 (gray). Rainfall amounts were below average from November through January in both years, and above average in September, October, February, and March 2007-2008 and above average in August and May 2008-2009. 


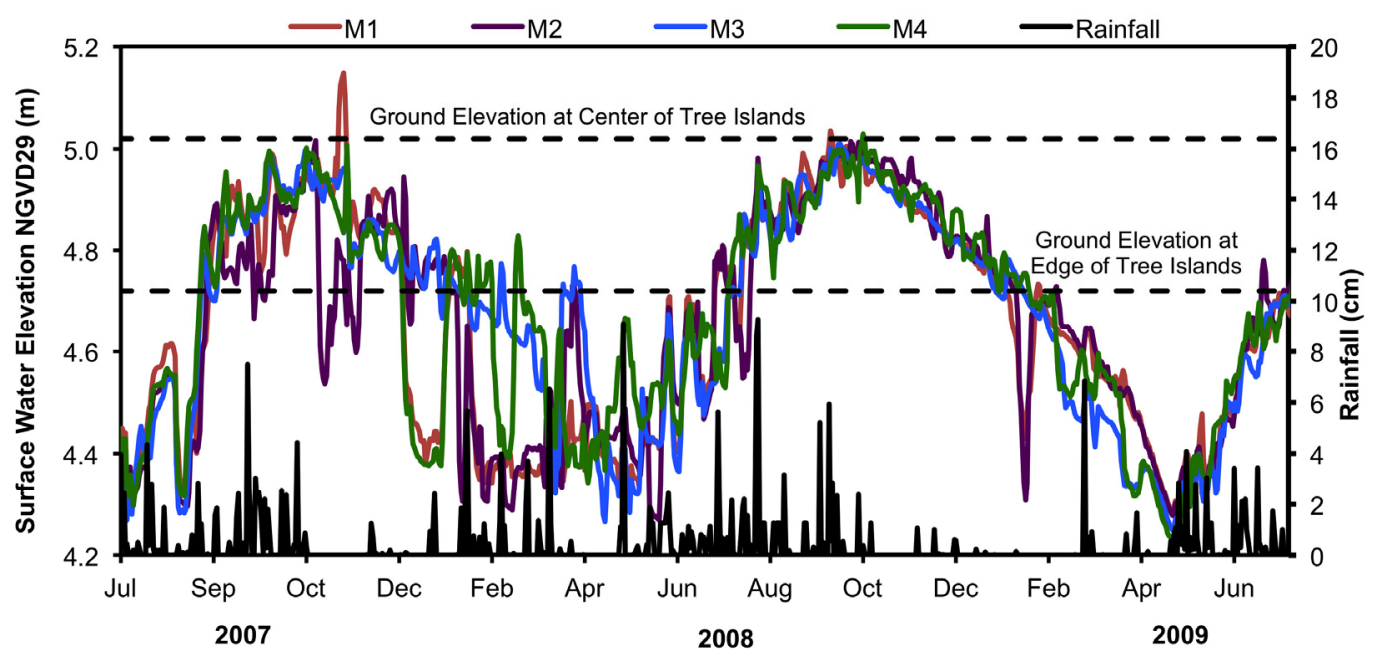

Figure 2. 6 The daily surface water levels (colors) in the center of all four macrocosms and daily rainfall values (black) from the Loxahatchee weather station July 2007 through July 2009. 


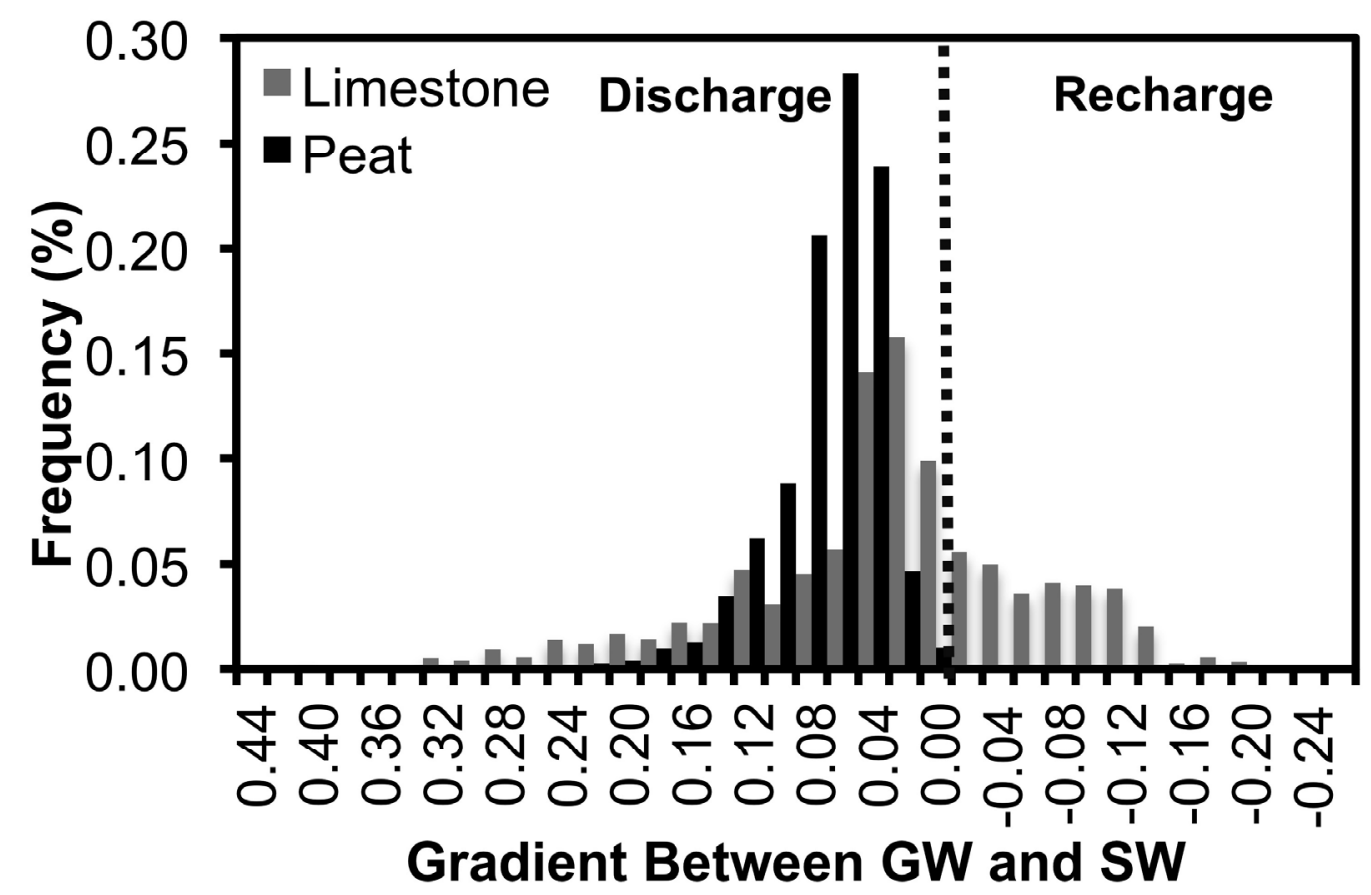

Figure 2. 7 Histogram of the hydraulic gradient between the surface water and the groundwater in the center of the peat (black) and limestone (gray) based tree islands. Positive values indicate groundwater discharge, while negative values indicate groundwater recharge by surface water. 


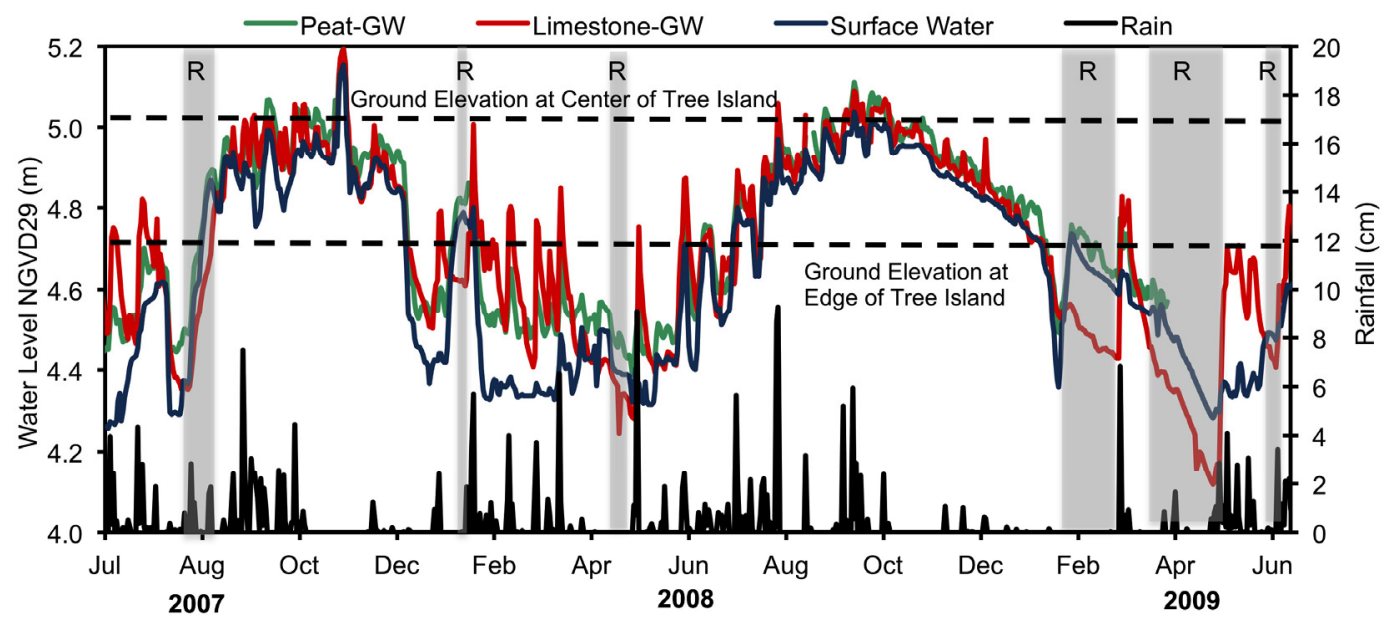

Figure 2. 8 Surface water (blue) and groundwater levels from the center of the peat (green) and limestone (red) based tree islands in M1 from July 2007 through June 2009. The gray boxes indicate periods of groundwater recharge (R) by surface water on the limestone tree island. 


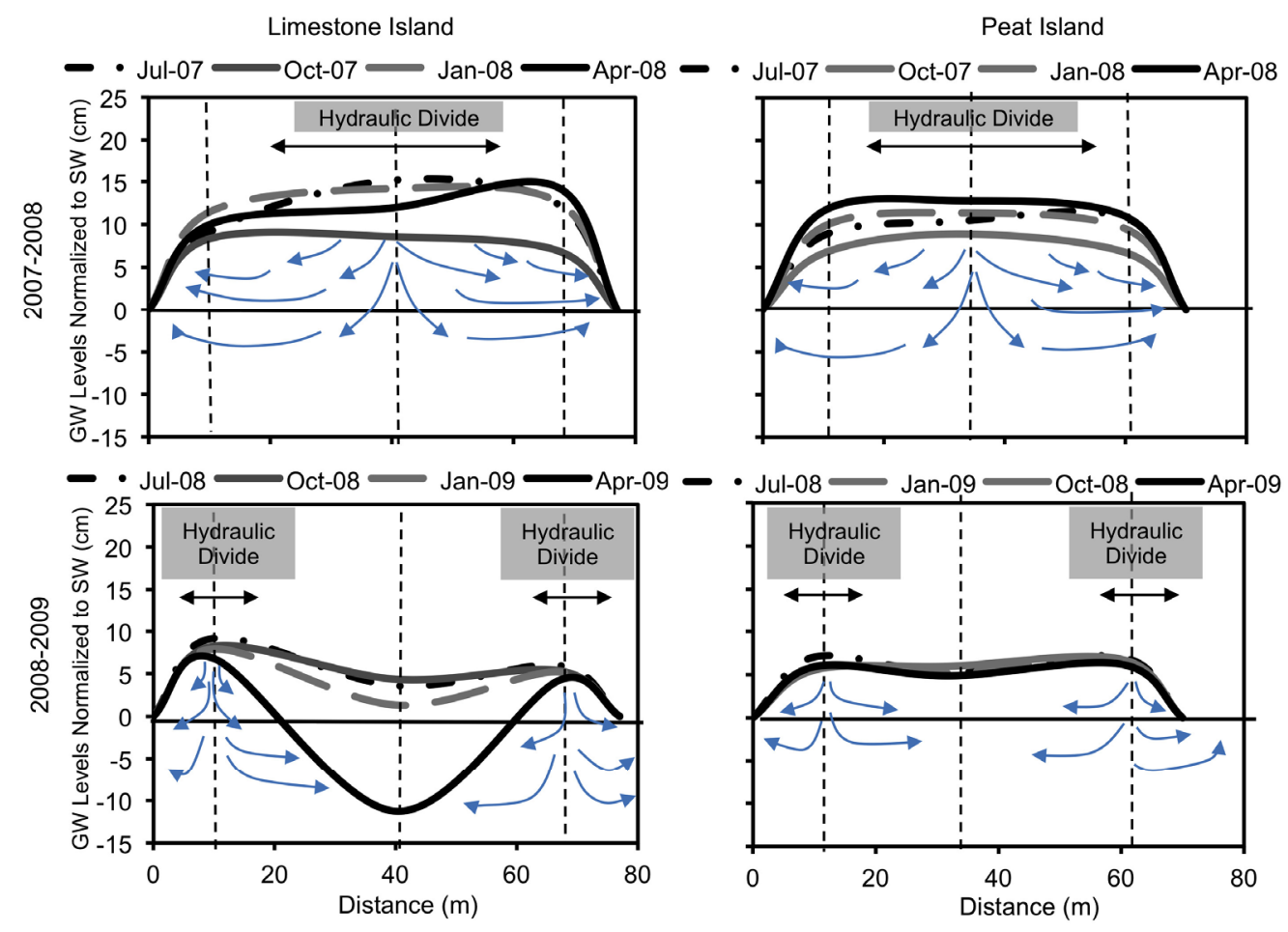

Figure 2. 9 Groundwater (GW) levels were normalized to surface water (SW) to depict the water table across the limestone (left panel) and peat (right panel) tree islands. The horizontal solid line at the value of zero represents the surface water, while the vertical dashed lines represent the well locations. For July 2007-April 2008 (top row) the dominant direction of groundwater flow was from the center of the islands toward the edges. A hydraulic divide developed on the edges of islands for July 2008-April 2009 (bottom row). Blue arrows indicate direction of groundwater flow. 


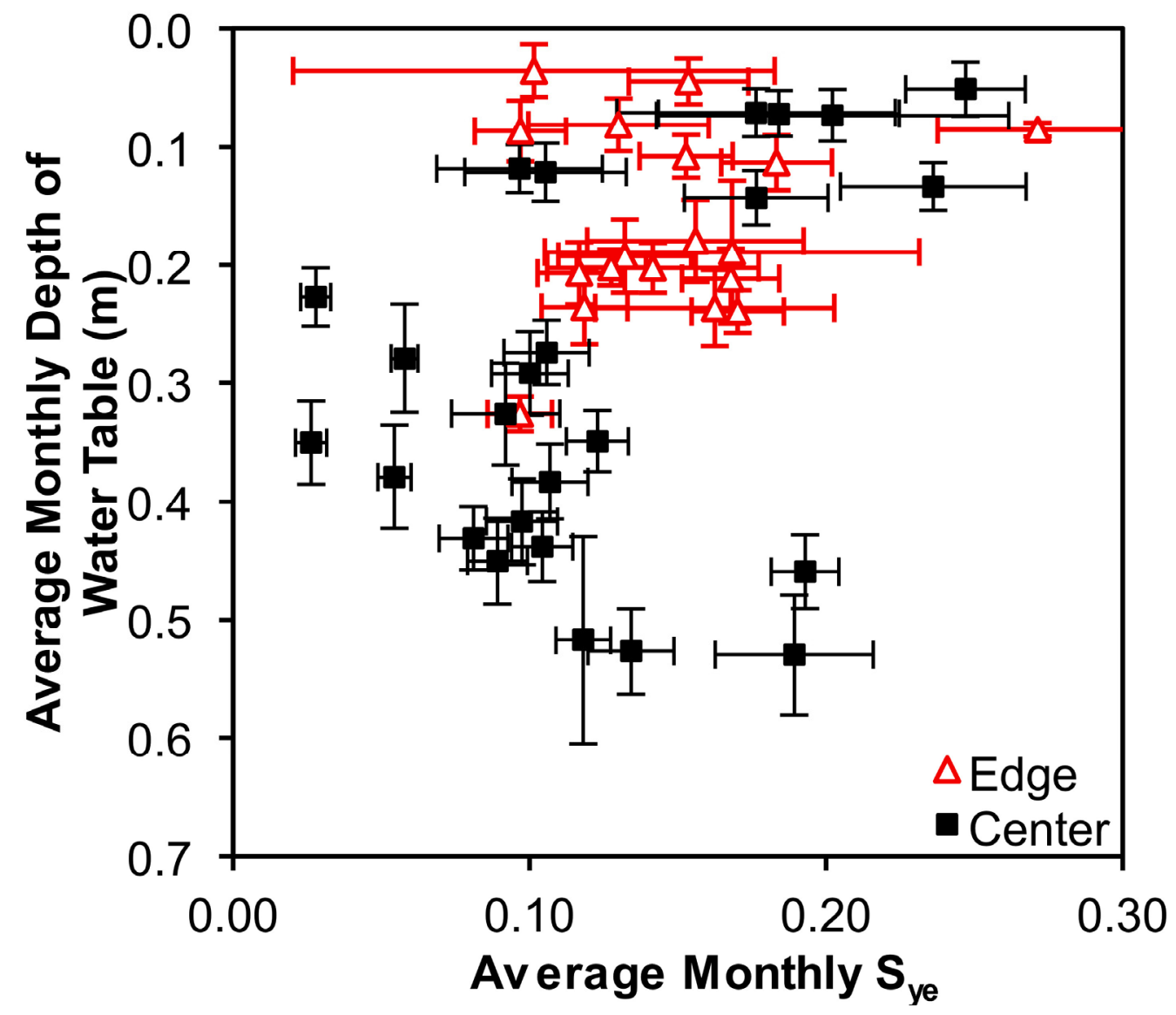

Figure 2. 10 The average monthly effective specific yield was variable for both the wells located on the edges $(\Delta)$ and centers $(\square)$ of the tree islands when the average monthly depth to the water table was less than $20 \mathrm{~cm}$. When the depth of the water table was greater than $20 \mathrm{~cm}$ deep, the average monthly effective specific yield increased for the wells located in the center of the tree islands. 


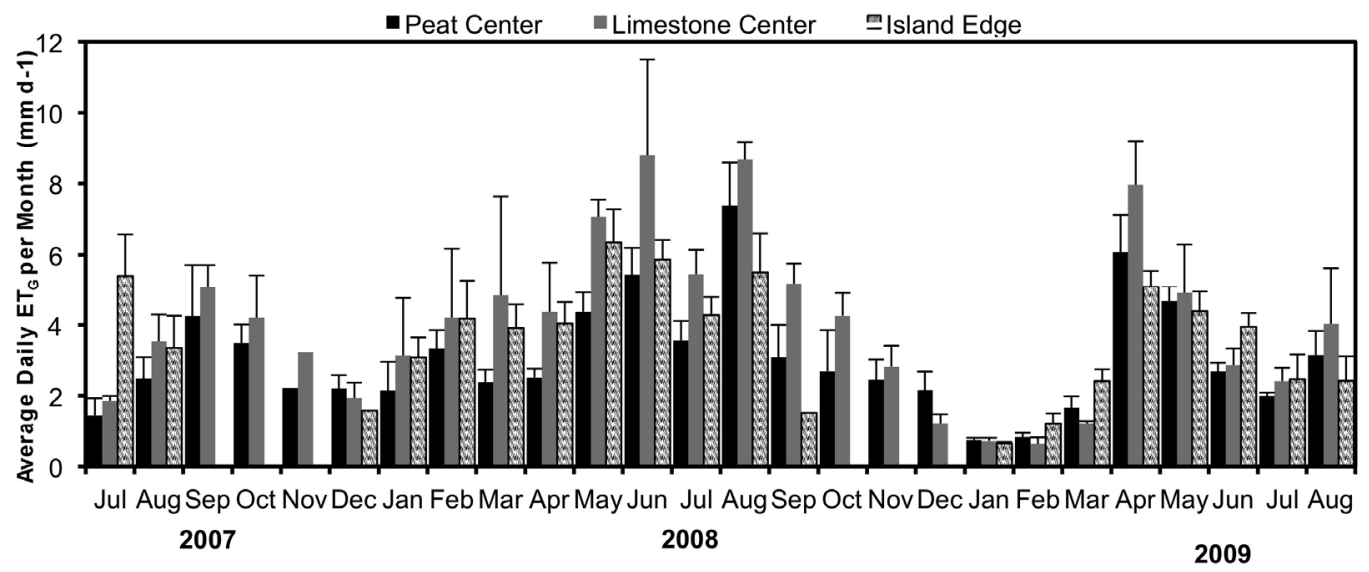

Figure 2. 11 Average daily evapotranspiration from groundwater $\left(\mathrm{ET}_{\mathrm{G}}\right)$ per month for the center of the peat (black) and limestone (gray) islands compared to the edges (striped). 


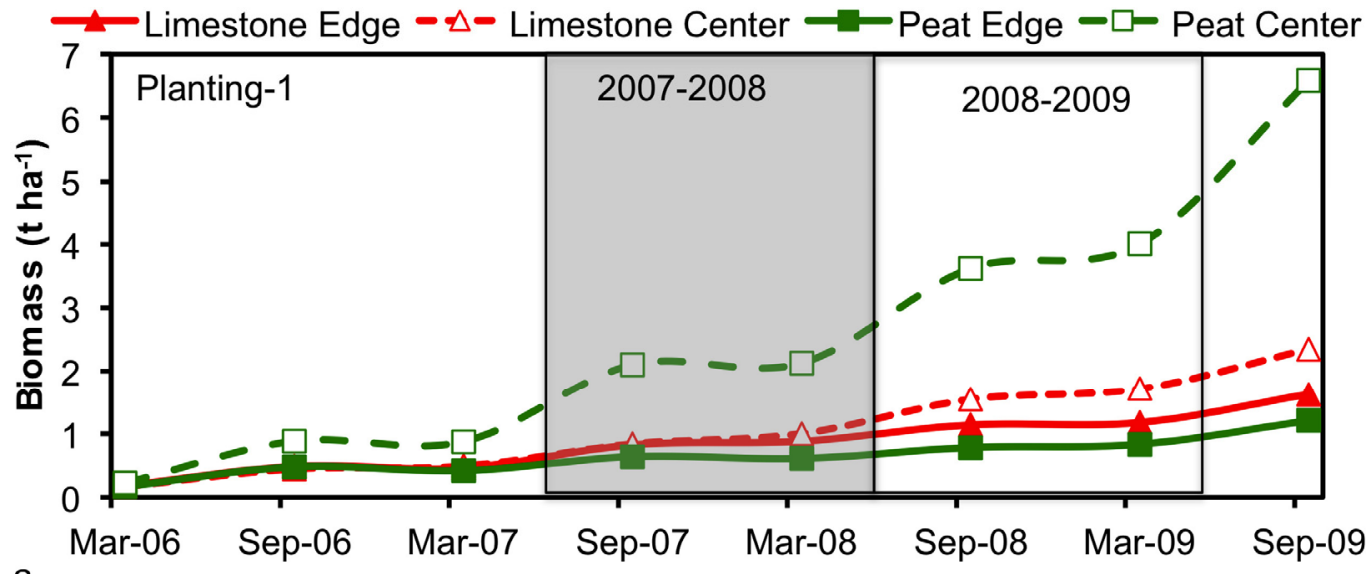

a.

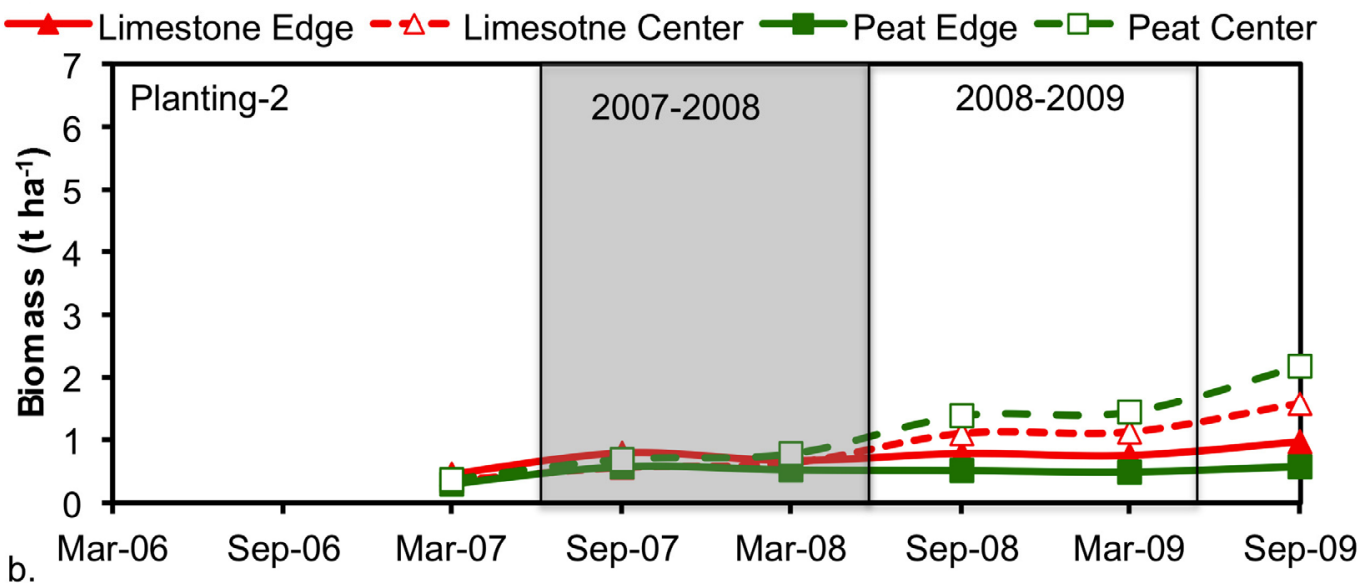

Figure 2. 12 Aboveground biomass $\left(\mathrm{t} \mathrm{ha}^{-1}\right)$ predicted from mixed-species regression model based on height for four different combinations of substrate type and ground elevation in tree islands of macrocosms a) M1 and M4, and b) M2 and M3. 
CHAPTER 3. HYDROGEOCHEMICAL RESPONSE OF EXPERIMENTAL EVERGLADES TREE ISLANDS (FLORIDA, USA): INDENTIFYING FEEDBACK MECHANISMS ASSOCIATED WITH EARLY TREE GROWTH AND DIFFERING GEOLOGIC MATERIALS

\subsection{Abstract}

Preserving the biological and physical feedback mechanisms that create and promote the spatial heterogeneity of wetlands is critical to maintaining biodiversity and ecosystem function. Like many wetlands, the Everglades ridge-slough-tree island topography has homogenized over the last century. Preventing additional loss of tree islands and fostering their recovery is important, because tree islands harbor some of the highest species diversity in the Everglades. To accomplish this goal, a better understanding of the physical and biological feedback mechanisms that maintain tree islands across the landscape is needed. A transpiration-driven nutrient accumulation mechanism has been identified as one feedback mechanism that may help sustain tree islands. Unfortunately, direct hydrologic data identifying the effect of transpiration by overlying trees on the hydrodynamics of tree islands is lacking. Furthermore, a clear understanding of the effects of underlying geologic materials and overlying forest structure on tree island hydrodynamics is still needed for the construction of management plans. The objective of this study was to identify how tree growth and geologic materials affect the hydrodynamics and shallow groundwater chemistry on constructed Everglades tree islands. Groundwater, surface water, stem water and soil water chemistry were monitored 
biannually on eight recently planted tree islands with different geologic materials (predominately peat or peat and limestone) from 2007 through 2010. All water samples were analyzed for oxygen and hydrogen stable isotopes, while groundwater and surface waters were also analyzed for major ions, and total and dissolved nutrient concentrations. The temperature of groundwater and surface water was monitored year-round, while tree height was measured biannually. Aboveground biomass was estimated using allometric biomass equations, derived from tree height, to determine the interaction between underlying groundwater geochemistry and aboveground biomass. The results provide direct hydrologic evidence that transpiration of overlying trees led to the advective movement of water and associated ions toward the center of the tree islands. The data also indicated that the limestone tree islands had an increased interaction with surrounding regional water compared to the peat tree islands. The observed increase in aboveground biomass over time was concurrent with the accumulation of ions and reduction in nutrient concentrations in the tree island groundwater. The increase in ion concentrations led to geochemical conditions that favored the precipitation of calcium carbonate minerals in the center of the limestone islands. In conclusion, forest structure and underlying geologic materials were found to mediate the feedback between transpiration, groundwater-surface water interactions and ion accumulation on tree islands. 


\subsection{Introduction}

Understanding the biological and physical feedback mechanisms responsible for spatial heterogeneity across wetlands is critical for implementing practices to preserve ecosystem function and for the management and restoration of wetlands in the face of climate change (Gibbs 2000). The regular hummock-hollow landscape patterning found in many of these wetlands has been attributed to physical forces such as divergence of water flow and redistribution of sediments (Larsen et al. 2007; Weerman et al. 2010), or water ponding driven by variations in hydraulic conductivity (Cheng et al. 2011; Swanson and Grigal 1988). Spatial patterning across wetlands has also been attributed to physio-biological process for instance, varying rates of peat or soil accretion (Eppinga et al. 2009; Larsen et al. 2007). Recently, a transpiration-driven nutrient accumulation mechanism has been attributed to the regular spatial patterning of some of the world's largest wetland areas, such as the Okavango delta and West Siberian Basin, (Eppinga et al. 2008; McCarthy et al. 1993; McCarthy et al. 1998). It also may be relevant in many other wetlands such as the Pripyat basin and Glacial Lake Agassiz (Eppinga et al. 2010; Jackson et al. 2009). According to the transpiration-driven nutrient accumulation hypothesis, elevated vascular biomass in the hummocks compared to hollows leads to an elevated rate of transpiration on hummocks. The elevated demand for water then leads to the advective movement of water and associated ions from surrounding hollows toward the center of the hummock. The nutrients return to the underlying hummock pore water and groundwater as leaf litter is mineralized. Over time, a resource contrast develops between the hummock and hollow, as access to resources leads to a more productive 
hummock, while the lack of resources inhibits production in the adjacent hollow (Eppinga et al. 2010; Rietkerk et al. 2004).

The transpiration-driven nutrient accumulation is one mechanism hypothesized to create the ridge-slough-tree island landscape of the oligotrophic Everglades (Ross et al. 2006; Wetzel et al. 2005). Phosphorus and ion concentrations in the soil and groundwater on Everglades tree islands are one to three orders of magnitude higher than the adjacent marsh (Gann et al. 2005; Sullivan Chapter 4; Ross et al. 2006; Wetzel et al. 2005), and nutrient analysis and isotopic ratios of tree leaves confirm localized nutrient accumulation on these islands (Saha et al. 2009; Wang et al. 2010). Oxygen isotopes of tree water and source waters on tree islands suggests that trees relied to a greater extent on marsh surface water or groundwater during the dry season (Saha et al. 2009). Petrocalcic horizons found in some tree island soils, similar to those on tree islands in the Okavango delta (McCarthy et al. 1993), lend further support to the hypothesis that high rates of transpiration on tree islands contribute to nutrient and ion accumulation within the islands (Chmura and Graf 2011; Coultas et al. 2008; Graf et al. 2008; Schwadron 2010). Bird guano, dry deposition, and animal bones may also be critical inputs of nutrients on tree islands, but Wetzel et al. (2011) suggested that both the hydrologic and nutrient contrast between tree islands and the surrounding marsh may drive the landscape complexity and patterning of the Everglades. Regrettably, direct hydrologic data that defines tree island hydrodynamics in relation to transpiration-driven nutrient accumulation is lacking. 
Though nutrient and ion contrasts have been found in soil, groundwater and vegetation between tree islands and adjacent marsh across the Everglades, the strength of this nutrient contrast has been found to vary spatially (Sullivan et al. unpublished data; Wang et al. 2010; Wetzel et al. 2009). Concentrations of nutrients and ions in the soil and groundwater of tree islands in the northern Everglades, Loxahatchee National Wildlife Refuge (LWNR) and the northern portion of Water Conservation Area 3A (WCA3A), have been found to be substantially lower than those located further south in Shark Slough (Sullivan et al. unpublished data; Wetzel et al. 2009). Tree islands in the marl prairies, located on the eastern and western boundary of Shark Slough were found to have lower soil phosphorus concentrations, as well as elevated foliar nitrogen-to-phosphorus ratios compared to Shark Slough tree islands (Wang et al. 2010). These spatial variations in nutrient and ion concentrations are concurrent with variation in the underlying geology and overall forest structure of the tree islands. In the northern Everglades, the depth to limestone bedrock is up to $3 \mathrm{~m}$ deep from the top of the tree islands (Brandt et al. 2002), while typically the depth to bedrock is about $1 \mathrm{~m}$ for islands in Shark Slough (Stone et al. In Review), and $<30 \mathrm{~cm}$ on islands found in the marl prairies (Wang et al. 2010). In addition, the types of sediments found on these islands varies spatially: in the northern Everglades, tree islands are predominately underlain by peat (Brandt et al. 2002); in Shark Slough, tree island soils are highly mineralized (Ross and Jones 2004, Ross and Sah 2011); and, in marl prairie islands, soils are primarily organic (Wang et al. 2010). Hardwood hammock trees primarily exist in the central and southern portions of the Everglades, as cooler winter temperatures prevent their expansion to the north (Armentano et al. 2002). Furthermore, hardwood hammock trees are flood intolerant and 
therefore are limited to the portions of islands that remain dry year-round (Armentano et al. 2002). The spatial variability of tree islands is evident across the Everglades, yet a clear understanding of how underlying geologic materials and overlying forest structure influence tree island hydrodynamics is still needed.

Over the last century, there has been a marked decline in both the number and area of tree islands (60\% loss from 1940-1995 in WCA 3; Patterson and Finck, 1999; Sklar and van der Valk 2002; Wetzel et al. 2009), concurrent with the homogenization of the ridgeslough habitat (Odgen 2005). The loss in spatial heterogeneity is of serious concern for the maintenance of biodiversity and ecosystem function, especially in terms of tree islands, which foster some of the highest species diversity in the Everglades (Gawlik et al. 2002). Defining the mechanisms and feedbacks that create and reinforce the heterogeneity of the ecosystem becomes critical as efforts are made to restore and maintain the Everglades landscape under the Comprehensive Everglades Restoration Plan. As a large physical ecosystem model of the Everglades, the Loxahatchee Impoundment Landscape Assessment (LILA) is an experimental platform used to gain insight into the biological and physical feedback mechanisms critical to the health of the Everglades. Containing eight constructed tree islands characterized by variable underlying lithology, LILA provides an ideal setting to identify the effects of plant-groundwater-surface interactions on tree island hydrodynamics and groundwater geochemistry.

The objective of the paper is to test the hypothesis that forest structure and geologic material mediate groundwater-surface water interactions and the shallow groundwater 
geochemistry on tree islands, given similar climatic conditions. To test this hypothesis, water chemistry and temperature were monitored across eight recently planted tree islands with differing geologic materials (peat or peat and limestone) and stand ages ( 0.6 and 1.6 years in 2007) at LILA from 2007-2010. Twenty-eight groundwater wells and eight surface water sites were sampled biannually over the three year period. Groundwater and surface water samples were analyzed for major ions as well as dissolved and total nutrients. Stem water and soil water samples were also collected on six of the eight tree islands biannually from 2008-2010, while rainfall was collected bimonthly from 2009-2010. All water samples were analyzed for stable isotopes of oxygen and hydrogen. Aboveground tree biomass was estimated biannually using allometric biomass equations derived from tree height measurements from 2007-2010. Groundwater-surface water interactions were determined using temperature as well as chloride concentrations and oxygen isotopic values of the respective water bodies. The isotopic composition of groundwater, surface water, soil water and stem water were used to identify the sources of water utilized by the overlying trees and to determine the proportion of groundwater uptake. To determine the effect of plant-groundwater-surface water interactions on the concentration and distribution of nutrients and ions across the island, groundwater chemical constituents were compared to the aboveground tree biomass and groundwater uptake. Groundwater saturation indices were modeled with respect to aragonite and calcite to determine if calcium carbonate mineral formation was concurrent with tree growth and affected by geologic material. 


\subsection{Study Area}

The LILA site is located within LNWR in Boynton Beach, Florida (Figure 3. 1). Spanning over 34 ha in size, LILA consists of four, 8 ha macrocosms, each of which contains two tree islands, one constructed predominately of peat and the other constructed of a limestone rubble center overlain by a thin layer of peat (Figure 3. 2; Aich et al. 2011; van der Valk et al., 2008). The difference in lithology occurs in the center of the islands, while the surrounding edges primarily consist of peat. The tops of the tree islands are on average $5.00 \mathrm{~m}$ in elevation and are raised $0.90 \mathrm{~m}$ above the surrounding slough. The sides of the tree islands are sloped downward to meet the elevation of the slough. Four islands were planted with seedlings in March 2006 (Planting 1, P1, of two peat and of two limestone). The remaining islands were planted in March 2007 (Planting 2, P2). Each island was planted with 700 trees, across the topographic gradient, with the majority of trees residing at a ground elevation between 4.5 and $5.0 \mathrm{~m}$. Ten of the most common tree species found on tree islands in the Everglades were used in the planting (Stoffella et al. 2010).

Nine wells were installed on each island with an average depth of $1.34 \mathrm{~m}$ (Sullivan et al. 2011). Six wells were located on the edges of the islands and three were located along a transect down the center. Wells located on the edges of the islands reside at a lower ground elevation $(4.70 \mathrm{~m}$, lowland) compared to those in the center $(5.02 \mathrm{~m}$, upland, Figure 3. 2 Figure 3. 3). One additional deep well was installed in the center of each peat tree island with an average depth of $2.00 \mathrm{~m}$ (Figure 3. 2). All wells were screened at the bottom with a screen interval of 50-60 $\mathrm{cm}$ in length. Surface water levels at LILA were 
dictated according to an operational hydrograph that mirrored the seasonal variation seen in surface waters of the Everglades, with the highest surface water levels between October and November and the lowest surface water levels between April and June (Figure 3. 3).

Distinct wet and dry seasons drive the surface water levels in the Everglades, with the majority of rainfall occurring between June and November. On average, 130-160 cm of rainfall occurs annually near LNWP (Ali et al. 2000; Sullivan et al. 2011). The average air temperature hovers around $24{ }^{\circ} \mathrm{C}$ year-round but reaches an average maximum value close to $33{ }^{\circ} \mathrm{C}$ during the summer and average low near $11{ }^{\circ} \mathrm{C}$ during the winter (Abtew 1996; Duever et al. 1994).

\subsection{Methods}

\subsubsection{Monitoring and Sampling Design}

\subsubsection{Groundwater and Surface Water}

From October 2007 through April 2010, 32 groundwater wells and eight surface water sites were sampled biannually in October (wet season) and April/May (dry season, Figure 3. 2). At least three wells were sampled per island, one well located in the center of the islands and two wells located on the edges. Wells located on the edges of the islands were referred to as EDGE wells while those in the center were termed CENTER wells. Two additional wells were sampled on each of the four peat tree islands, one at an average depth $1.34 \mathrm{~m}$, with a $0.60 \mathrm{~m}$ slotted screen interval at the bottom, and the other at an 
average depth of $2.00 \mathrm{~m}$, with a $0.50 \mathrm{~m}$ slotted screen interval at the bottom, located in the center of the peat tree islands. All wells with the depth of $2.00 \mathrm{~m}$ were considered DEEP wells (Figure 3. 2). All groundwater and surface water sites were sampled with a peristaltic pump and each well was purged of three well volumes before sampling. Temperature, conductivity and $\mathrm{pH}$ were measured in the field with a relative accuracy of $\pm 0.1^{\circ} \mathrm{C}, \pm 0.1 \mu \mathrm{S} / \mathrm{cm}$, and \pm 0.002 , respectively. Two filtered ( $0.45 \mu \mathrm{m}$ membrane filter) and two unfiltered samples were collected at each well and surface water location. One each of the filtered and unfiltered samples were preserved with $10 \%$ hydrochloric acid, for cation and total phosphorus analysis, respectively. All samples were stored at $4{ }^{\circ} \mathrm{C}$ and transported to Florida International University.

Groundwater temperature was monitored in all wells from October 2007 through June 2010. Temperature was recorded every 15 minutes using In-Situ Level Troll 500 Pressure Transducers with an accuracy of $\pm 0.1^{\circ} \mathrm{C}$. From October 2007 through January 2009 surface water temperature was monitored every 30 minutes in two macrocosms using HOBO U22 Water Temp Pro v2 loggers, with an accuracy of $\pm 0.2^{\circ} \mathrm{C}$. The quarter- and half-hourly measurements were averaged daily to determine the daily average groundwater or surface water temperature at a given location.

\subsubsection{Precipitation}

From January 2009 through July 2010 rainfall was collected using a wet-dry collector made by Areochemetrics. The collector consisted of two collection buckets: a wet 
collector to collect rainfall and a dry collector to collect dry deposition. The wet collector was exposed during rain events and sealed at all other times to prevent evaporation (Price et al. 2008). Rainfall samples were collected every two weeks and stored in a plastic screw-top Nalgene bottle to prevent evaporation until the samples were analyzed for oxygen and hydrogen stable isotopes. The total volume of rainfall per sampling event was measured and used to determine the volume-weighted isotopic composition of each sample and the average-weighted deuterium excess. A total of 28 rainfall samples were analyzed. The isotopic values of rainfall in southeastern Florida were found to fall along the Global Meteoric Water Line (GMWL, $\delta \mathrm{D}=8.0^{*} \delta^{18} \mathrm{O}+10 \%$; Craig 1961) (Price et al. 2008); therefore the GWML was used for all graphical comparisons.

\subsubsection{Stem Water and Soil Water}

From October 2008 to April 2010, tree stem and soil water samples were collected biannually on six of the eight tree islands at LILA, three peat and three limestone based islands; consisting of three P1 and three P2 islands. On each island three species of trees were sampled: Chrysobalanus icaco (CI), Annona glabra (AG) and Morella cerifera $(M C)$. When available, six of each of these species were collected from two different areas on each island; the CENTER (upland) and the EDGE of the islands (lowland). To obtain stem water, a small section of bark-covered branch was removed from each tree. To reduce back flow from phloem or exposure to evaporation, leaf or node areas were avoided when the branch was sampled (Snyder and Williams 2000). The leaves on the sampled branch were located in direct sunlight to ensure transpiration was taking place 
during the sampling event. The epidermis and phloem were shaved off in the field and the stem was immediately placed in a glass cylinder that was capped to prevent evaporation.

Stem water was collected in conjunction with soil water. When possible, six soil samples were taken at the CENTER and EDGE of the tree islands at depths of 10 and $20 \mathrm{~cm}$. During the wet season, flooding prevented soil water sampling at the low elevation areas, and across three islands in October of 2008 (two P1 islands and one P2 island). Soils were also stored in glass cylinders and capped to prevent evaporation. All samples were stored in a cold dry cooler and transported back to FIU where they were frozen until they could be processed. A total of 700 stem water and 200 soil samples were collected over the four sampling events. All soil and stem samples were cryogenically distilled at the University of Miami, Laboratory of Stable Isotope Ecology in Tropical Ecosystems (LSIETE) (Vendramini and Sternberg 2006).

\subsubsection{Chemical Analysis}

\subsubsection{Ion and Nutrient Analysis}

Groundwater and surface water samples were analyzed for soluble reactive phosphorus (SRP), total phosphorus (TP) and total organic carbon (TOC) at the National Environmental Laboratory Accreditation Conference (NELAC) certified Southeastern Environmental Research Center (SERC) nutrient analysis laboratory using an Alpkem 300 Series 4 Channel Rapid Flow Analyzer, an Alpkem Rapid Flow Analyzer with 2Channel ER Detector and a Shimadzu TOC-V, respectively. Groundwater and surface 
water samples were also analyzed for total alkalinity, anions and cations at FIU's earth sciences HydroLab using a Brinkman Titrino 751/735 automated titration unit and a Dionex-120 Ion Chromatograph, respectively. To determine the total alkalinity, a Brinkman Titrino 751 titrated $40 \mathrm{~mL}$ water samples with $0.1 \mathrm{M}$ hydrochloric acid to a $\mathrm{pH}$ of 2. The total alkalinity was calculated on the basis of the $\mathrm{mL}$ of acid added at the inflection point of the titration curve closest to a $\mathrm{pH}$ of 2 . The change in volume of the sample that resulted from the addition of the titrant was not taken into account, as it was only a small portion of the total volume $(<10 \%)$. Total alkalinity was calculated as $\mathrm{mg} \mathrm{L}^{-1}$ of $\mathrm{HCO}_{3}{ }^{-}$as the $\mathrm{pH}$ of the water samples were near neutral. The charge balance of the major cations and anions for each water sample was less than 5 percent.

The mineral saturation indices (SI) for aragonite and calcite (both $\mathrm{CaCO}_{3}$ ) and the partial pressure of carbon dioxide $\left(\mathrm{pCO}_{2}\right)$ of each water sample were determined with the geochemical model PHREEQC (Parkhurst and Appelo 1999). The major ion concentrations $\left(\mathrm{HCO}_{3}^{-}, \mathrm{Cl}^{-}, \mathrm{SO}_{4}{ }^{2-}, \mathrm{Na}^{+}, \mathrm{K}^{+}, \mathrm{Mg}^{2+}\right.$ and $\left.\mathrm{Ca}^{2+}\right)$ and field parameters (temperature, $\mathrm{pH}$, and conductivity) of each water sample were the inputs for PHREEQC. Water samples with SI values of $0 \pm 0.05$ were considered at saturation (or at equilibrium) with respect to that mineral. Saturation indices values greater than 0.05 indicated that the water sample was supersaturated with respect to that mineral and precipitation was expected. A SI value less than -0.05 indicated an undersaturated condition with respect to that mineral and dissolution was expected. 


\subsubsection{Stable Isotopes}

All water samples collected were analyzed for hydrogen $(\delta \mathrm{D})$ and oxygen $\left(\delta^{18} \mathrm{O}\right)$ stable isotopes using a DTL-100 Liquid-Water Isotopes Analyzer (LWIA) with an accuracy of $0.2 \%$ and $0.6 \%$ for ${ }^{18} \mathrm{O} /{ }^{16} \mathrm{O}$ and $\mathrm{D} / \mathrm{H}$, respectively. All stem water and soil water samples were post-processed using Los Gatos LWAI-Spectral Contamination Identifier software, which identifies spectral contamination problems that could adversely affect the accuracy of the measurements. Spectral contamination could occur in water samples derived from soil and plants because of the possible production of methanol, ethanol and other compounds. The isotopic ratio of a subset of 56 stem and soil water samples were also analyzed by standard equilibration and Isotopic Ratio Mass Spectrometry (IRMS) connected to a Mulitflow System (MS) at LSIETE (Vendramini and Sternberg 2006). The values from the IRMS-MS were compared to the LWAI values using Mann-Whitney $\mathrm{U}$ Test, which revealed in no significant difference between the two methods ( $\mathrm{p}=0.45)$.

The percentage of groundwater $(\% \mathrm{GW})$ utilized by each tree was determined using a two-end member mixing model:

$$
\% \mathrm{GW}=\left[\left(\delta_{\text {plant }}-\delta_{\text {soil }}\right) /\left(\delta_{\mathrm{GW}}-\delta_{\text {soil }}\right)\right] 100
$$

\section{Eq 3. 1}

where $\delta_{\text {plant }}, \delta_{\text {soil }}$ and $\delta_{\mathrm{GW}}$ are $\delta^{18} \mathrm{O}$ values of the stem water, soil water and groundwater (Ewe et al. 1999; Saha et al. 2009). 
The average $\delta^{18} \mathrm{O}$ soil water and corresponding groundwater for a given area (CENTER or EDGE) were used to determine the percentage of groundwater utilized. When the EDGE portions of the tree islands were flooded, the $\delta_{\text {soil }}$ of EDGE was assumed to be equivalent to the isotopic value of the surface water $\left(\delta_{\mathrm{SW}}\right)$. To account for the variability in $\delta_{\text {soil }}, \% \mathrm{GW}$ was also calculated using the standard error value range of the isotopic values of the soil water. If calculations of $\% \mathrm{GW}$ were $>100$ or $<0$ using the average $\delta_{\text {soil, }}$ but fell between $0-100 \%$ given the standard error of $\delta_{\text {soil }}$, it was assumed that $\% \mathrm{GW}$ was $100 \%$ or $0 \%$, respectively. Values of $\% \mathrm{GW}$ outside this range were excluded from further analysis. Because of the greater variability of $\delta \mathrm{D}$ and possible discrimination of deuterium by plants during water uptake, $\delta \mathrm{D}$ was not used to determine $\% \mathrm{GW}$ (Ellsworth and Williams 2007; Lin and Sternberg 1993).

\subsubsection{Surface Water, Groundwater, Source Waters and Stem Water Analysis}

A Pearson Correlation was used to determine any significant linear relationships between the chemical constituents within the surface water and groundwater. Results with $\mathrm{R}$ values greater than 0.60 or less than -0.60 and $p<0.01$, were considered significant. A one-way Analysis of Variance (ANOVA) and post hoc Tukey $(\alpha=0.05)$ was used to detect significant differences between the surface water (SW), tree islands (TI) groundwater and DEEP groundwater. 
The groundwater chemistry was averaged and compared through time according to location, soil type, elevation and planting year. All the groundwater data collected were compared (except deep wells) using a two-way ANOVA and post-hoc Tukey test $(\alpha=0.05)$. To determine the effect of location and geologic material on groundwater chemistry, the water chemistry at the edges (EDGE), was compared to center of the peat (PC) and limestone (LC) islands. If no difference was observed in the water chemistry, the PC and LC results were averaged together and termed CENTER. To gain a better understanding of forest structure on underlying groundwater chemistry, the groundwater values were grouped according to the planting year of the tree islands: 2006 (P1) and 2007 (P2).

A similar progression of analysis occurred for the isotopic values of the stem water and source waters on the tree islands. The stem water and source waters (soil water, groundwater, surface water) were compared at EDGE (lowland) and CENTER (upland) of the islands. The trees at a ground elevation $\geq 4.90 \mathrm{~m}$ were considered CENTER trees, while all those with ground elevation $\leq 4.80 \mathrm{~m}$ were considered EDGE trees. The stem water and source waters of CENTER portion of the peat (PC) and limestone (LC) tree islands were then compared to determine the effect of underlying geology on plant water uptake. The P1 islands were also compared to the P2 islands to determine the effect of stand age and biomass. 


\subsubsection{Aboveground Tree Biomass}

A mixed-species regression allometric biomass model derived solely from total tree height, developed by Stoffella et al. (2009), was used to estimate aboveground biomass of individual trees at LILA through September 2010 (Stoffella et al. 2010). Trees were measured for height biannually in March and September from 2007 through 2010. The aboveground biomass for all trees was summed per island, according to elevation (CENTER and EDGE, same elevation range as stem water) and then normalized by the ground area represented by the elevation range (CENTER and EDGE) to obtain the amount of aboveground biomass per hectare $\left(\mathrm{t} \mathrm{ha}^{-1}\right)$. The total aboveground biomass was then averaged according to year of planting (P1 or P2), elevation (CENTER or EDGE) and underlying geologic material (Peat or Limestone) and compared to chemical constituents of the underlying groundwater chemistry.

\subsection{Results}

\subsubsection{Temperature}

Over the three year period, the average groundwater and surface water temperatures were similar, averaging 24.6 and $25.8{ }^{\circ} \mathrm{C}$, respectively. The surface water temperature however had much greater seasonal variability compared to the groundwater (Figure 3. 4). Surface and groundwater temperatures were elevated between June and October, and typically reached their lowest values in January. The seasonal variation in temperature was muted in the groundwater compared to the surface water. The average daily groundwater temperature in the $\mathrm{PC}$ was on average $2{ }^{\circ} \mathrm{C}$ cooler than the groundwater LC between May and August, and $1{ }^{\circ} \mathrm{C}$ warmer between December and February (Figure 3. 4). The 
groundwater temperature in the CENTER of the islands was $1-2{ }^{\circ} \mathrm{C}$ cooler than the EDGE during the summer but temperatures were similar in the winter. The daily average groundwater temperature in the DEEP wells fell between the groundwater temperature at the CENTER and EDGE of the islands (Table 3. 2).

\subsubsection{Nutrients}

Groundwater TP concentrations did not differ significantly with location (CENTER, EDGE), geologic material (PC, LC) or planting year (P1, P2) (Table 3. 1). The TP concentrations were substantially elevated in 2007 , with $120 \mu \mathrm{g} \mathrm{L}^{-1}$ as an average. The concentration of TP in the groundwater declined an average of $27 \mu \mathrm{g} \mathrm{L}^{-1} \mathrm{y}^{-1}$ (except in October of 2008) with the lowest values detected in April 2010 (Figure 3. 5). The DEEP groundwater had the lowest TP concentrations, with an average of $45 \mu \mathrm{g} \mathrm{L}^{-1}$ (Table 3. 2).

The groundwater concentrations of SRP differed significantly only between planting years, with lower concentrations of SRP detected on the P1 islands. The SRP concentrations in the groundwater were elevated in May and October of 2008, with an average of $35 \mu \mathrm{g} \mathrm{L} \mathrm{L}^{-1}$ and $52 \mu \mathrm{g} \mathrm{L} \mathrm{L}^{-1}$, respectively (Figure 3. 5). Groundwater concentrations of SRP were similar in all wells and lower than $20 \mu \mathrm{g} \mathrm{L}{ }^{-1}$ from May 2009 through April 2010. The DEEP groundwater wells had the lowest concentration averaging $\leq 5 \mu \mathrm{g} \mathrm{L}{ }^{-1}$. 
On the P1 islands the groundwater concentrations of TOC were significantly elevated in the CENTER of the island compared to the EDGE (Table 3. 1, Figure 3. 6). Over the three year period the groundwater TOC concentration in the center of the P1 islands had a larger increase compared to the $\mathrm{P} 2$ islands ( $15 \mathrm{mg} \mathrm{L}^{-1}$ and $2 \mathrm{mg} \mathrm{L}^{-1}$, respectively). Concentrations of TOC were lowest in the DEEP groundwater (Table 3. 2) and remained fairly constant over time.

The concentration of TP in the surface water was lower than in the tree island groundwater and averaged $11 \mu \mathrm{g} \mathrm{L}^{-1}$ (Table 3. 2). The surface water concentration of SRP was below the detection limit $\left(2 \mu \mathrm{g} \mathrm{L}^{-1}\right)$ for all sampling events. TOC was not measured in the surface water.

\subsubsection{Ions}

The overall average ionic strength of the surface water was significantly lower than the groundwater (CENTER, EDGE, DEEP) on the tree islands, averaging $412 \mu \mathrm{sm}^{-1}$ (Table 3. 2). The concentrations of all major ions were elevated in the surface water during the dry season (April or May) and decreased during the wet season (October). Surface water concentration of $\mathrm{Cl}^{-}, \mathrm{Na}^{+}, \mathrm{K}^{+}$and $\mathrm{Mg}^{2+}$ were all positively correlated with one another.

Concentrations of ions in the groundwater did not display as much seasonal variability as the surface water. Unlike the surface water, the groundwater concentrations of $\mathrm{HCO}_{3}{ }^{-}$and $\mathrm{Ca}^{2+}$, were positively correlated to $\mathrm{Cl}^{-}, \mathrm{Na}^{+}$and $\mathrm{Mg}^{2+}$. In addition, the groundwater 
concentration of $\mathrm{NH}_{4}{ }^{+}$was positively correlated to both $\mathrm{K}^{+}$and $\mathrm{TP}(\mathrm{R}=0.65, \mathrm{p}<0.001)$. All major ions were significantly lower on the EDGE compared to the CENTER of the islands (Table 3. 1). Groundwater concentrations of $\mathrm{HCO}_{3}{ }^{-}, \mathrm{Cl}^{-}, \mathrm{Mg}^{2+}$ and $\mathrm{Ca}^{2+}$ were significantly elevated in the P1 islands compared to the P2 islands. In the P1 islands, the groundwater concentrations of most major ions were elevated in the LC compared to the PC islands. Within the P2 islands, the groundwater concentrations of most of the major ions, except $\mathrm{Mg}^{2+}$ and $\mathrm{Ca}^{2+}$, were elevated in the PC islands compared to the LC (Table 3. 1). Similar to the concentrations of TP, the groundwater concentrations of $\mathrm{K}^{+}$and $\mathrm{NH}_{4}^{+}$ continuously declined over the study period. The concentration of most major ions decreased in the CENTER from October 2007 through May 2009, followed by a large increase in ion concentrations in October 2009 and April 2010 (Figure 3. 7; only $\mathrm{Cl}^{-}$ shown). Groundwater concentrations of major ions decreased on the EDGE throughout the study.

\subsubsection{SI and $\mathrm{pCO}_{2}$ Values}

The surface water was predominantly supersaturated with respect to aragonite and calcite, throughout the study (Table 3. 2). The only exception was in October 2008, when surface water samples were at saturation with respect to aragonite. The saturation state of the groundwater significantly differed on the tree islands with respect to location, geologic material and planting (Table 3. 1). The P2 islands were predominately undersaturated with respect to aragonite, while undersaturated or at saturation with respect to calcite. The P1 islands were typically at saturation or supersaturated with respect to both 
aragonite and calcite, except for in the PC, which was undersaturated with respect to aragonite. In general, the SI values of aragonite and calcite were significantly lower in the PC compared to LC (Table 3. 1). Over time, the SI values of aragonite and calcite became increasingly enriched in the LC but declined in October of 2010. SI values in the PC increased within the 1.5 years of the study and then decreased (Figure 3. 6c). Overall, the groundwater in the CENTER and EDGE was undersaturated with respect to aragonite and at saturation with respect to calcite. The only exception was between October 2008 and October 2009, when the CENTER groundwater was at saturation with respect to aragonite and supersaturated with respect to calcite. The DEEP groundwater was predominately at saturation or supersaturated with respect to both calcite and aragonite (Table 3. 2). Groundwater saturation indices of aragonite and calcite were positively correlated $(\mathrm{R}=0.79, \mathrm{p}<0.001)$ with the concentrations of $\mathrm{HCO}_{3}^{-}$and $\mathrm{Ca}^{2+}$, while no correlation was detected in the surface water.

The average $\mathrm{pCO}_{2}$ concentrations in the surface water and groundwater were all elevated compared to atmospheric values $\left(10^{-3.5}\right.$ bars, Table 3.2$)$. The surface water had significantly lower concentration of $\mathrm{pCO}_{2}$ compared to the DEEP tree island groundwater, while the concentration in the DEEP groundwater was significantly lower than tree island groundwater (both CENTER and EDGE) (Table 3. 2). The concentrations of $\mathrm{pCO}_{2}$ in the EDGE groundwater varied seasonally, with the highest concentrations detected in October. The concentrations in the LC and PC displayed no seasonal variation but the concentration of $\mathrm{pCO}_{2}$ was slightly lower in the $\mathrm{LC}$ groundwater compared to the $\mathrm{PC}$ 
(Figure 3. 6c, Table 3. 1). The average concentrations of $\mathrm{pCO}_{2}$ in the $\mathrm{P} 1$ and $\mathrm{P} 2$ islands were similar (Table 3. 1)

\subsubsection{Stable Isotopes}

\subsubsection{Precipitation}

The isotopic composition of the rainfall ranged from $\delta \mathrm{D}=-30.9 \%$ and $\delta^{18} \mathrm{O}=-5.30 \%$ o to $\delta \mathrm{D}=8.9 \%$ and $\delta^{18} \mathrm{O}=0.28 \%$ (Figure 3. 8). The average volume-weighted isotopic composition of rainfall was $\delta \mathrm{D}=-8.9 \pm 1.8 \%$ and $\delta^{18} \mathrm{O}=-2.46 \pm 0.25 \%$. The average weighted deuterium excess was $10.80 \%$. The intersection of the meteoric water line and the liner regression of the isotopic composition of the surface water, of estimated the average isotopic composition of the rainfall to be $\delta \mathrm{D}=-8.1 \%$ and $\delta^{18} \mathrm{O}=-2.57 \%$ o (Figure 3. 8), and was close to the volume weighted estimate. The isotopic composition of the rainfall was enriched in $2009\left(\delta^{18} \mathrm{O}=-1.75 \%\right)$ compared to the 2010 values $\left(\delta^{18} \mathrm{O}\right.$ $=-2.61 \%$ ) but did not vary substantially with wet and dry season.

\subsubsection{Surface Water and Groundwater}

The isotopic composition of the surface water at LILA varied seasonally, with the highest values typically detected at the end of the dry season (April or May) and the lowest values detected at the end of the wet season (October). The only exception occurred in October of 2009. The isotopic composition of the surface water over the three year period was elevated compared to the tree island groundwater (Table 3. 2). The isotopic composition of the surface water was found to have a positive correlation with surface 
water concentrations of $\mathrm{Cl}^{-}, \mathrm{Na}^{+}, \mathrm{K}^{+}$and $\mathrm{Mg}^{2+}$, while no correlation was detected in the tree island groundwater (Figure 3. 9, only average $\mathrm{Cl}^{-}$concentrations and $\delta^{18} \mathrm{O}$ values shown). The isotopic composition of the groundwater significantly differed on the islands with respect to geologic material, location and planting year (Table 3. 1). The isotopic signature of the PC groundwater was significantly depleted compared to LC, which was significantly depleted compared to the EDGE. The isotopic values of the P2 islands were considerably enriched compared to the P1 islands. The isotopic composition of the EDGE groundwater increased over time and was inversely related to the concentration $\mathrm{Cl}^{-}$(Figure 3. 10). The LC isotopic signature of the groundwater also increased over the three years, while the groundwater in the PC islands remained relatively stable (Figure 3. 11). The average isotopic values of the DEEP groundwater was typically elevated during the wet season and depleted during the dry season, but fell between the EDGE and CENTER groundwater compositions (Figure 3. 9 \& Figure 3. 11).

\subsubsection{Stem Water, Source Waters and Groundwater Uptake}

Stem water isotopic values ranged between those of the rainfall and surface water (Figure 3. 12). A seasonal variation in the isotopic signature of the stem water was observed spatially across the island; at the end of the wet season (October) the CENTER trees had lower isotopic values compared to the EDGE; at the end of the dry season (April/May) the isotopic composition of the stem water between the CENTER and EDGE of the trees was similar (Figure 3. 12). The variability of stem water values was greatest during the dry season, specifically May of 2009. The distinction between the CENTER and EDGE 
stem water values was greater in the older islands (P1) compared to the younger islands (P2) (Figure 3. 12).

The average isotopic composition of the soil water in the CENTER was always enriched compared to the underlying groundwater (Figure 3.12). The average composition of CENTER soil water and groundwater was always elevated in the P2 islands compared to the P1 islands. The P1 CENTER soil water and groundwater isotopic values were constant over time (Figure 3. 12). The composition of the P2 CENTER groundwater was also constant over time. The CENTER soil water fluctuated seasonally, with enriched values detected in the wet season. The difference in the isotopic signature of the EDGE and CENTER groundwater increased in time for both the $\mathrm{P} 1$ and $\mathrm{P} 2$ islands (Figure 3. 12). The average composition of the soil water (dry season) and surface water (wet season) at the EDGE showed the largest variation isotopic composition, with elevated values in May and October of 2009. The average LC groundwater and soil water isotopic composition was always elevated compared to the PC groundwater and soil water (Figure 3. 13). The LC soil water was also elevated compared to the underlying groundwater, while the composition of the PC groundwater and soil water differed only in May and October of 2009 (Figure 3. 13).

Stem water, groundwater and soil water indicated the $\% \mathrm{GW}$ uptake on the trees islands ranged from $17-50 \%$ over the sampling period, with the lowest values calculated in October 2009 (Figure 3. 14). The amount of groundwater utilized on the EDGE was elevated compared to the LC for all sample events, except October 2009 (Figure 3. 14a). 
The $\% \mathrm{GW}$ varied seasonally on the $\mathrm{PC}$, with elevated values in the wet season, while the LC remained fairly constant over time (Figure 3. 14a). The \%GW uptake on the EDGE was elevated compared to the PC during the dry season. Trees on P1 islands utilized substantially more groundwater in May 2008 and October 2009 compared to the trees on the P2 islands (Figure 3. 14b).

\subsubsection{Aboveground Tree Biomass}

Biomass on both P1 (planted 2006) and P2 (planted 2007) islands increased one to two orders of magnitude over the three years and averaged 3.4 and $1.7 \mathrm{t} \mathrm{ha}^{-1}$ by September 2010, respectively. The increase in biomass on the islands had a negative linear correlation to the groundwater concentrations of $\mathrm{K}^{+}$, while positive correlation to the isotopic composition of the groundwater (Figure 3. 15a, b). The aboveground biomass on the P1 islands was also positively correlated to groundwater concentrations of $\mathrm{Ca}^{2+}$ $\left(\mathrm{R}^{2}=0.62 \mathrm{p}=0.06\right)$, while the $\mathrm{P} 2$ islands were negatively correlated to groundwater concentrations of TP (Figure 3. 15c) and $\mathrm{NH}_{4}{ }^{+}\left(\mathrm{R}^{2}=0.83, \mathrm{p}=0.05\right)$. After the planting of P1 and P2 islands, biomass at EDGE and CENTER of the islands were relatively equal but after the 1.5 years the biomass in EDGE was substantially lower than the CENTER, and averaged $0.5 \mathrm{t} \mathrm{ha}^{-1}$ and $7.8 \mathrm{tha}^{-1}$ by September 2010, respectively. The aboveground biomass in the LC and PC was negatively correlated to the underlying groundwater

concentration of $\mathrm{K}^{+}$in the $\mathrm{LC}\left(\mathrm{R}^{2}=0.68, \mathrm{p}=0.04\right)$ and $\mathrm{PC}\left(\mathrm{R}^{2}=0.69, \mathrm{p}=0.04\right)$. Within the LC, aboveground biomass was also positively correlated with the underlying groundwater $\mathrm{Ca}^{+}$concentrations $\left(\mathrm{R}^{2}=0.70, \mathrm{p}=0.04\right)$ and the saturation state of aragonite 
and calcite $\left(R^{2}=0.66, p=0.05\right)$, and negatively correlated with TP concentrations $\left(R^{2}=0.92\right.$, $\mathrm{p}=0.002)$.

\subsection{Discussion}

The data from LILA indicate that forest structure and underlying geologic materials mediate groundwater-surface water interactions on tree islands given similar climatic conditions. They provide direct hydrologic evidence for three of the main feedback mechanisms associated with plant-groundwater-surface water interactions: first, transpiration of the overlying trees led to the advective movement of marsh groundwater into EDGE and LC of the tree islands; second, the increase in aboveground tree biomass was paralleled by the depletion of nutrients in the underlying groundwater; and third, the increase in aboveground tree biomass coincided with the enrichment of groundwater ion concentrations in the center of the tree island and the formation of calcium carbonate minerals. The following explains these interactions in detail and suggests how variations in tree island hydrodynamics may explain the spatial variability of soil and groundwater nutrient and ion concentrations found in tree islands across the Everglades.

\subsubsection{Effect of Groundwater Uptake by Trees on Groundwater Flow}

The stem water data indicated that trees on the EDGE and LC of the islands relied on groundwater more at the end of the dry season compared to the PC, while at the end of the wet season trees in the PC relied more on groundwater. The seasonal difference in groundwater uptake likely equates to a large loss of groundwater at the EDGE and LC of 
the islands, as transpiration rates were found to be two to three times higher on a tree island at the end of the dry season compared to the end of the wet season (Sullivan Chapter 4). Elevated groundwater evapotranspiration $\left(\mathrm{ET}_{\mathrm{GW}}\right)$ rates found at the EDGE of the islands and in the LC at LILA, support the stem water results (Sullivan et al. 2011). The larger proportion of groundwater uptake at the EDGE of the islands and in the LC was concurrent with the isotopic enrichment of the underlying groundwater. At the EDGE of the islands, the isotopic enrichment was also concurrent with a decrease in the concentrations of major ions in the groundwater (Figure 3. 10). These findings suggested that groundwater flowed from the surrounding marsh to the EDGE of the islands, as surface water and marsh groundwater (Sullivan et al., unpublished data) had an enriched isotopic composition and lower ionic strength compared to CENTER tree islands groundwater. Elevated groundwater to surface water levels detected at the EDGE of the islands by Sullivan et al. (2011), suggests that marsh groundwater likely flowed into the tree islands EDGE, not surface water (Figure 3. 16).

The concurrent enrichment of isotopic values and ion concentrations in the LC groundwater was attributed to two phenomena: first, the input of EDGE and DEEP groundwater (Figure 3. 16); and second, the accumulation of ions as a result of transpiration. The isotopic values of the DEEP groundwater indicated downward movement of water (Figure 3. 9), by which groundwater from the edge of the island flowed toward the deeper portion of the tree island's center, especially from May 2008 through October 2009. Downward flow of water indicated water levels in the center of the island were lower than those on the EDGE and corroborates the development of a 
sustained water table depression detected 2.3-2.5 years after planting the tree islands at LILA (Sullivan et al. 2011). The elevated groundwater uptake and enriched isotopic composition in the LC compared to the PC also supports the deeper water table depression detected on the LC islands at LILA (Sullivan et al. 2011). The elevated ion concentrations in the tree island groundwater compared to the marsh surface water suggests ion accumulation in the groundwater was taking place in the island. The buildup of ions, along with relatively depleted isotopic values of the groundwater in the center of the islands, indicated that transpiration and not evaporation was driving ion accumulations in the tree islands, as $\delta^{18} \mathrm{O}$ values of water are not affected by transpiration but lead to the elevated ion concentrations through root ion exclusion (Figure 3.9).

The significantly lower isotopic signature of the groundwater in the center compared to the EDGE of the islands indicated recharge from rainfall was also an important input. In the PC, the lower groundwater uptake during the dry season and fairly constant isotopic signature indicated that soil water, recharged from rainfall, supported a majority of transpiration in the PC (Figure 3. 16). The reduced reliance on groundwater by the overlying trees led to limited inputs of regional groundwater. Findings from the LILA supported the hypothesis that elevated groundwater uptake by overlying trees leads to inward flow of regional groundwater (Ross et al. 2006; Sullivan et al. 2011; Wetzel et al. 2005). 


\subsubsection{Effect of Underlying Geologic Material}

Similar to the isotopic data, groundwater and surface water temperature also indicated increased groundwater-surface water interactions in the center of the LC tree islands compared to the PC (Figure 3. 4 Figure 3. 11) and may also be attributed to an increase in groundwater uptake by the overlying trees. Lower soil moisture, that results from the lower specific retention of limestone compared to peat (Angers and Caron 1998), may explain the increased reliance on groundwater, as Engel et al. (2005) and Sullivan (Chapter 4) found that trees within forested patches in wetlands relied on groundwater more for transpiration as soil moisture decreased. The lower specific retention hypothesis on the limestone islands was reinforced by evidence of elevated soil water evaporation (enriched isotopic values) in the center of the limestone tree islands, which likely indicates lower soil moisture.

The findings on the LC and PC islands suggested differences in the soil water storage capacity during the dry season might govern the amount of regional groundwater input into tree islands. While the seasonal reliance on regional groundwater water may also support the resource contrast that has been detected between tree islands and the surrounding marsh. As only small differences in specific yield were estimated between the LC and PC islands at LILA (0.13 and 0.10, respectively; Sullivan et al. 2011), soil water storage capacity was likely governed by overall porosity and specific retention of the soils. The difference in underlying soil types of the northern Everglades peat tree islands and the Shark Slough limestone tree islands (Ross and Sah 2011) may function similarly to those at Loxahatchee Impoundment Landscape Assessment. A lower soil 
water storage capacity would cause trees on Shark Slough tree islands to more readily rely on groundwater during the dry season, which would result in elevated inputs of regional groundwater and associated ions compared to the northern peat tree islands. Over time the increased inputs of regional groundwater could in part explain the elevated nutrient and ion concentrations found on tree islands in Shark Slough.

Soil water storage during the dry season may also play a role in the lower nutrient concentrations of tree islands on the drier, eastern and western boundaries of Everglades National Park (marl prairie). Containing highly organic soils (Wang et al. 2010), the soil on these islands likely store water similarly to the PC islands at LILA, yet the depth to the underlying bedrock is typically much shallower than in tree islands of both the northern Everglades and Shark Slough. In effect, the thin soil horizon would reduce the soil water reservoir during the dry season. Unlike the islands in Shark Slough, the water table typically drops well below the surface of the marl prairies (Ross and Jones 2004, Wang et al. 2010), which would compound the dry season effect if the water table were too deep for trees to access. Elevated foliar $\delta^{13} \mathrm{C}$ values found on marl prairie tree islands in the dry season compared to the wet season, support that trees on the marl prairie islands experience seasonal water stress, while $\delta^{13} \mathrm{C}$ values from Shark Slough tree islands suggested ample access to water year-round (Wang et al. 2010). The depressed water table and small soil water reserves on the marl prairie tree islands during the dry season would result in a disconnect between the surrounding marsh and the tree island, curtailing the input of regional groundwater and associated ions into the islands. 


\subsubsection{Effects of Forest Structure}

The increase in tree biomass on the trees islands occurred with decreases in the groundwater concentrations of $\mathrm{TP}, \mathrm{K}^{+}$, and $\mathrm{NH}_{4}{ }^{+}$. Though other vegetation and/or microbes could be utilizing these pools of nutrients during this period, the decrease in nutrient concentrations can be explained by the increase in overlying biomass using a simple mass-balance equation. If phosphorus is used as an example, data from Sullivan et al. (2011) indicated that an average of 3-4 $\mathrm{mm} \mathrm{d}^{-1}$ of groundwater was taken up by trees on the islands at LILA and Subedi (2011) found that the average concentration of total phosphorus in leaves of three tree species at LILA ranged between $0.6-1.2 \mathrm{mg} \mathrm{g}^{-1}$. Combined with the increase in biomass at LILA, the groundwater concentration of phosphorus should have decreased by $60-176 \mathrm{ug} \mathrm{L}^{-1}$ over the three year period. Five assumptions were made in this rudimentary phosphorus budget: 1) wood and foliar phosphorus concentrations were the same; 2) the increase in belowground biomass was negligible; 3) the concentration of phosphorus in the recharge water (surface water, groundwater, soil water) was negligible; 4) uptake of groundwater by trees was similar year-round; and 5) all the total phosphorus was available. The observed decrease (average $87 \mathrm{ug} \mathrm{L}^{-1}$ ) in the groundwater phosphorus concentrations from 2007-2010 was on the low side of the estimated decrease (derived from the aboveground biomass) and may suggest the movement of associated nutrients with the recharge water. The uptake and sequestration of nutrients in the aboveground biomass, as indicated by a decrease in nutrient concentration and uptake of groundwater, lends further support to the hypothesis that transpiration-driven nutrient accumulation occurs on tree islands in the Everglades. 
The larger variance in groundwater TP and $\mathrm{NH}_{4}{ }^{+}$concentrations found on the $\mathrm{P} 1$ islands compared to the P2 islands may be attributed to the elevated biomass on the P1 islands and the development of a leaf litter layer. Microbial breakdown and mineralization of the leaf litter layer would then return nutrients to the underlying groundwater, altering its nutrient concentrations. The increase in TOC in the CENTER of the P1 islands over time also suggested the increase in microbial activity. Within the LC of the islands, the decline in groundwater TP concentrations may potentially be attributed to the precipitation of calcium carbonate, as the increase in biomass was negatively correlated with groundwater concentrations of TP and also positively correlated with $\mathrm{Ca}^{+}$concentrations and the saturation states of aragonite and calcite. The absorption of phosphorus and/or coprecipitation of calcium phosphate is a common phenomena observed with the formation of calcium carbonate in $\mathrm{Ca}^{+}$rich water of periphyton mats in the Everglades (Dodds, 2003).

The data further suggests that the density of aboveground biomass influenced soil water evaporation across the islands, as lower isotopic values of soil water were found on the P1 islands and CENTER of the islands. The reduction in soil water evaporation may be attributed to increased shading, lower air temperatures and reduced air flow associated with elevated aboveground biomass (Holmgren et al. 1997; Le Maitre et al. 1999). The increased soil moisture associated with increased biomass may support the negligible annual change in groundwater evapotranspiration detected on the tree islands at LILA (Sullivan et al. 2011), as soil water resources likely increased. 
The larger amount of aboveground biomass found in the CENTER and P1 islands was also concurrent with the most elevated groundwater ion concentrations, and indicated that the distribution and concentration of ions across the islands were related to the density of the aboveground biomass. Though these data only demonstrate that aboveground biomass affects the distribution of ions and nutrients across tree islands, seral stage, species composition and disturbance regime may all play critical roles in dictating aboveground biomass and may explain the variability of nutrient and ion concentrations seen across the Everglades.

\subsubsection{Mineral Formation}

The data from LILA suggest the formation of calcium carbonate minerals in DEEP and LC portions of the islands and on the P1 islands, as the groundwater was predominately at saturation with respect to aragonite and supersaturated with respect to calcite (Table 3. 1, Figure 3. 6). The results further suggest the dissolution of calcium carbonate minerals at the EDGE and $\mathrm{PC}$ of islands and on the P2 islands where the groundwater was undersaturated with respect to aragonite and undersaturated or at saturation with respect to calcite. The saturation state of carbonate minerals is dictated by several factors: fluxes of $\mathrm{CO}_{2}$, solubility of other carbonate minerals (the Common Ion Effect; Langmuir 1997), changes in temperature, ion exchange processes, and changes in ionic strength (Wigley and Plummer 1976). The saturation of calcium carbonate in the groundwater at LILA correlated with the concentration of most major ions, while no correlation was detected between major ion concentrations and calcium carbonate saturation in the surface water. 
Temperature and $\mathrm{pCO}_{2}$ did not correlate with the saturation of groundwater or surface water and ion exchange processes were ruled out as the concentration of $\mathrm{Na}^{+}$or $\mathrm{Mg}^{2+}$ were not depleted in relation to chloride. These findings agree with those of a tree island in Shark Slough (Sullivan Chapter 4), where transpiration-driven ion accumulation was suggested as the driving mechanism that led to the year-round precipitation of calcite and aragonite from the groundwater. Elevated inputs of regional groundwater (EDGE or DEEP) into the LC provides a larger source of ions compared to the PC, which was primarily recharged by low ionic rainfall. Thus, the difference in water inputs to the shallow tree island groundwater would be expected to promote the formation of calcium carbonate at a faster rate in the LC compared to the PC. The saturated and supersaturated conditions with respect to aragonite and calcite on the LC suggests that inputs of regional water due to groundwater uptake by overlying trees promotes the formation of calcium carbonate and may explain why petrocalcic horizons have only been found in the hammock portions of tree islands (Chmura and Graf 2011; Colutas et al. 2008; Graf et al. 2008; Schwadron 2010), though calcite and aragonite formation also persisted in the bayheads and bayhead swamp portions of tree islands (Sullivan et al. Chapter 4).

\subsection{Conclusion}

The present study provides direct hydrologic and geochemical evidence that groundwater uptake by trees on the burgeoning LILA tree islands led to inputs of regional groundwater into the islands. Elevated groundwater uptake by trees in the center of the limestone islands during the dry season led to increased inputs of regional groundwater compared to 
the peat islands. The difference in groundwater uptake in the limestone and peat islands was attributed to differences in the water storage capacity of the underlying material, as isotopic data indicated that trees on the peat islands relied more on soil water that was recharged by rainfall. The observed increase in aboveground biomass was concurrent with the depletion of nutrients in the groundwater on all islands. The large variation of groundwater nutrient concentrations detected in the P1 tree islands was attributed to nutrient recycling from the litter layer as well as aboveground biomass sequestration. Stable isotopes and ion chemistry data indicate that transpiration, not evaporation was the dominant driver of elevated ion concentrations in the tree islands. The groundwater ion concentrations were spatially variable, with the highest concentrations detected in the center of the islands where the aboveground biomass was most elevated. The increase in aboveground biomass and elevated inputs of regional groundwater in the center of the limestone tree islands was positively correlated with the saturation state of the groundwater with respect to aragonite and calcite, and led to conditions that promoted the precipitation of calcium carbonate minerals. In conclusion, the spatial variability of ion concentrations in both soil and groundwater of tree islands across the Everglades may be explained in part by variation in geologic materials and variation in overlying forest structure, as was observed at LILA. The present paper identifies that hydrological feedback mechanisms differ on limestone and peat tree islands tree islands. Findings further suggested that a more mechanistic study of the underlying geology and forest structure that categorizes tree islands based on hydrodynamics may be necessary to properly manage water levels so as to maintain and promote tree island habitat in the Everglades. 


\subsection{References}

Abtew W (1996) Evapotranspiration measurements and modeling for three wetland systems in south Florida. Water Resources Bulletin 32 (3): 465-473

Aich S, Dreschel TW, Cline EA, Sklar FH (2011) The development of a geographic information system (GIS) to document research in an Everglades Physical Model. Journal of Environmental Science and Engineering 5:289-302

Ali A, Abtew W, Van Horn S, Khanal N (2000) Temporal and spatial characterization of rainfall over central and south Florida. Journal of the American Water Resources Association 36(4):833-848

Angers DA, Caron J (1998) Plant-induced changes in soil structure: processes and feedbacks. Biogeochemsitry 42:55-72

Armentano TV, Jones DT, Ross S, Gable BW (2002) Vegetation pattern and process in tree islands of the southern Everglades and adjacent areas. In: Sklar FH, van der Valk AG (eds) Tree Islands of the Everglades. Dordecht, The Netherlands: Kluwer Academic Publishers

Brandt LA, Siliveria JE, Kitchens WM (2002) Tree islands of Arthur R. Marshall Loxahatchee National Wildlife Refuge. In: Sklar FH, van der Valk AG (eds) Tree Islands of the Everglades. Dordecht, The Netherlands: Kluwer Academic Publishers

Cheng Y, Stieglitz M, Turk G, Engel V (2011) Effects of anisotropy on pattern formation in wetland ecosystems. Geological Research Letter 38, L04402

Chruma GL, Graf MT (2011) The human trigger for development of tree islands in the Florida Everglades. American Geophysical Union (AGU)-Chapman Conference on Climates, Past Landscapes, and Civilizations. Sante Fe NM. AGU Release No. 11-12. March 21

Coultas CL, Schawrdon M, Galbraith JM (2008) Petrocalcic horizon formation and prehistoric people's effect on Everglades tree island soils, Florida. Soil Survey Horizon 49:16-21

Dodds WK (2003) The role of periphyton in phosphorus retention in shallow freshwater aquatic systems. Journal of Phycology 39(5):840-849

D’Odorico P, Engel V, Carr JA, Oberbauer SF, Ross MS, Sah JP (2011) Tree-grass coexistence in the Everglades freshwater system. Ecosystems Online

Duever MJ, Meeder JF, Meeder LC, McCollom JM (1994) Chapter 9: The climate of South Florida and it role in shaping the Everglades. In: Davis S, Odgen J (eds) Everglades, The ecosystem and its restoration. Saint Lucie Press. Boca Raton, FL 
Ellsworth P, Williams D (2007) Hydrogen isotope fractionation during water uptake by woody xerophytes. Plant and Soil. 291:93-107

Engel V, Jobbágy EG, Stieglitz M, Williams M, Jackson RB (2005) Hydrological consequences of Eucalyptus afforestation in Argentine Pampas. Water Resources Research 41, W10409

Eppinga MB, Rietkerk M, Belyea LR, Nilsson MB, De Ruiter PC, Wassen MJ (2010) Resource contrast in patterned peatlands increases along a climatic gradient. Ecology 91:2344-2355

Eppinga MB, Rietkerk M, Borren W, Lapshina ED, Bleuten W, Wassen MJ (2008) Regular surface patterning of peatlands: confronting theory with field data. Ecosystems 11:520-536

Eppinga MB, Rietkerk M, Wassen MJ, De Ruiter PC (2009) Linking habitat modification to catastrophic shifts and vegetation patterns in bogs. Plant Ecology 200: 53-68

Ewe SML, Sternberg LO, Busch DE (1999) Water-use patterns of woody species in pineland and hammock communities of South Florida. Forest Ecology and Management 118: 139-148

Gann TT, Childers DL, Randeaau DN (2005) Ecosystem structure, nutrient dynamics, and hydrologic relationships in tree islands of the southern Everglades, Florida, USA. Forest Ecology and Management 214: 11-27

Gawlik DE, Gronemyer P, Powell RA (2002) Habitat-use patterns of avian seed dispersers in the central Everglades. In: Sklar FH, van der Valk AG (eds) Tree Islands of the Everglades. Dordecht, The Netherlands: Kluwer Academic Publishers

Gibbs JP (2000) Wetland loss and biodiversity conservation. Conservation Biology 14(1):314-317

Graf MT, Schwardon M, Stone PA, Ross M, Chmura GL (2008) An enigmatic carbonate layer in Everglades tree island peats. Eos 89:117-119

Holmgren M, Scheffer M, Huston AM (1997) The interplay of facilitation and competition of plant communities. Ecology 78(7):1966-1975

Jackson RB, Jobbágy EG, Nosetto MD (2009) Ecohydrology bearing-invited commentary ecohydrology in a human-dominated landscape. Ecohydrology 2:383-389

Langmuir D (1997) Aqueous environmental geochemistry. Upper Saddle River, New Jersey: Princeton-Hall Inc. 
Larsen LG, Harvey JW, Crimaldi JP (2007) A delicate balance: ecohydrological feedbacks governing morphology in a lotic peatland. Ecological Monographs 77:591-614

Le Maitre DC, Scott DF, Colvin C (1999) A review of information on interactions between vegetation and groundwater. Water S A 25(2): 137-152

Lin G, Sternberg L (1993) Hydrogen isotopic fractionation by plant roots during water uptake in coastal plants. In: Ehleringer JH, Farquhar GD (eds) Stable isotopes and plant carbon-water relations. Academic Press, New York, pp 497-510

McCarthy TS, Ellery WN, Danergfield JM (1998) The role of biota in the intiation and growth of islands on the floodplain of the Okavanga Alluvial Fan, Bostwana. Earth Surface Processes and Landforms 23:281-316

McCarthy TS, Ellery WN, Ellery K (1993) Vegetation-induced, subsurface precipitation of carbonate as an aggradational process in permanent swamps of Okavango (delta) fan, Botswana. Chemical Geology 107:111-13

Ogden JC (2005) Everglades ridge and slough conceptual ecological model. Wetlands $25: 810-820$

Patterson K, Finck R (1999) Tree Islands of the WCA 3A Aerial photointerpretation and trend analysis project summary report. Geonex Corporation, St. Petersburg, FL. Report to the South Florida Water Management District, West Palm Beach, FL

Parkhurst DL, Appello CAJ (1999) User's guid to PHREEQC (version 2) - A computer program for speciation, batch-reaction, one-dimensional transport, and inverse geochemical calculations. U.S. Geological Survey Water-Resources Investigations. Report 99-4259: 738 p.

Price RM, Swart PK, Willoughby H (2008) Seasonal and spatial variations in the stable isotopic composition $\left(\delta^{18} O\right.$ and $\left.\delta D\right)$ of precipitation in south Florida. Journal of Hydrology 358:193-205

Rietkerk M, Dekker SC, Wassen MJ, Verkroost AWM, Bierkens MFP (2004). A putative mechanism for bog patterning. The American Naturalist 163: 699-708

Ross MS, Jones DT (2004) Tree islands in the Shark Slough landscape: Interactions of vegetation, hydrology and soils. Final Report. Submitted to the Everglades National Park, Homestead, Florida, pp 1-196

Ross MS, Mitchell-Brucker S, Sah JP, Stothoff S, Ruiz PL, Reed DL, Jayachandran K, Coultas CL (2006) Interaction of hydrology and nutrient limitation in ridge and slough landscape of southern Florida. Hydrobiologia 569:37-59 
Ross MS, Sah JP (2011) Forest resource islands in a sub-tropical marsh: soil:site relationships in Everglades hardwood hammocks. Ecosystems 14: 632-64

Saha AK, Sternberg LO, Miralles-Wilhelm F (2009) Linking water sources with foliar nutrient status in upland plant communities in Everglades National Park, USA. Ecohydrology 2:42-54

Schwadron M (2006) Everglades tree islands prehistory: Archeological evidence for regional Holocene variability and early human settlement. Antiquity $80(310)$

Schwardon M (2010) Prehistoric landscapes of complexity: archaic and woodland period shell works, shell rings and tree islands of the Everglades, south Florida. In: Thomas D C, Sanger MC (eds) Trend, Tradition, and Turmoil: What Happened to the Southeastern Archaic. Anthropological Papers of the American Museum of Natural History 93, pp113-146

Sklar FH, van der Valk A (2002) Tree islands of the Everglades: an overview. In: Sklar FH, and van der Valk AG (eds) Tree Islands of the Everglades. Dordecht, The Netherlands: Kluwer Academic Publishers

Snyder KA, Williams DG (2000). Water sources used by riparian trees varies among stream types on the San Pedro River, Arizona. Agricultural and Forest Meteorogoly. 105, 227-240.

Stoffella SL, Ross MS, Sah JP, Price MP, Sullivan PL, Cline AE, Scinto LJ (2010) Survival and growth responses of eight Everglades tree species along an experimental hydrologic gradient on two tree island types. Applied Vegetation Science 13(4):439-449

Stoffella SL, Ross MS, Sah J, Ruiz P, Lopez L, Colbert N, Dodge C, Heinrich J, Trujillo D (2009) Estimating biomass production and nutrient concentrations of tree species growing along hydrologic gradient on LILA tree islands biomass estimation. Report to the South Florida Water Management District, pp12

Stone PA, Ross MS, Chmura GL, Gleason PJ, Graf MT, Schwadron M (In review) Sedimentation and landscape evolution in Shark Slough, Southern Everglades-a rough-cut history. Journal of Paleolimnology.

Sullivan PL, Price RM, Ross MS, Scinto LJ, Stoffella SL, Cline E, Dreschel TW, Sklar FH (2011) Hydrologic processes on tree islands in the Everglades (Florida, USA): tracking the effects of tree establishment and growth. Hydrogeology Journal 19(2):367-37

Swanson DK, Grigal DF (1988). A simulation model of mire patterning. Oikos 53:309314 
Subedi SC (2011) Determination of nutrient limitation on trees growing in Loxahatchee Impoundment Landscape Assessment (LILA) tree islands, Florida. Thesis. Florida International University.

van der Valk A, Wetzel P, Cline E, Sklar FH (2008) Restoring tree islands in the Everglades: experimental studies of tree seedling. Restoration Ecology 16(2):281289

Verndramini PF, Sternberg L (2006) A faster plant stem-water extraction method. Rapid Communications in Mass Spectrometry 21(2):164-168

Wang X, Sternberg LO, Ross MS, Engel VC (2010) Linking water use and nutrient accumulation in tree islands upland hammock plant communities in the Everglades National Park, USA. Biogeochemistry 104(1-3):133-146

Weerman EJ, van de Koppel J, Eppinga MB, Montserrat F, Liu Q, Herman PMJ (2010) Spatial self-organization of intertidal mudflats through biophysical stress divergence. The American Naturalist 176(1):E15-32

Wetzel PR, van der Valk AG, Newman S, Gawlik DE, Gann TT, Coronado-Moliana CA, Childers DL, Sklar FH (2005) Maintaining tree islands in the Florida Everglades: nutrient redistribution is the key. Front. Ecol. Environ 3:370-376

Wetzel PR, van der Valk AG, Newman S, Coronado CA, Troxler TG, Childers DL, Orem WH, Sklar FH (2009) Heterogeneity of phosphorus distribution in a patterned landscape, Florida Everglades. Plant Ecology 200:83-90

Wetzel PR, Sklar FH, Coronado CA, Troxler TG, Krupa SL, Sullivan PL, Ewe S, Price RM, Newman S, Orem WH (2011). Biogeochemical processes on tree islands in the Greater Everglades: Initiating a new paradigm. Critical Reviews in Environmental Science and Technology 41:670-701

Wigley TML, Plummer LN (1976) Mixing of carbonate waters. Geochimca et Cosmochimcia Act 40: 989-995 


\subsection{Tables}

Table 3. 1 Mean and standard error of field parameters, major ion and nutrient concentrations, stable isotope values and SI values of groundwater in the Limestone Center (LC), Peat Center (PC) and EDGEs of the tree islands for the Planting-1 (P1) and Planting-2 (P2) tree islands. A two way ANOVA and post-hoc Tukey test $(\alpha=0.05)$ was used to determine significant difference between location and planting and within groups.

\begin{tabular}{|c|c|c|c|c|c|c|c|c|c|c|}
\hline \multirow[b]{2}{*}{ Constituents } & \multirow[b]{2}{*}{ Units } & \multicolumn{3}{|c|}{ P1 } & \multicolumn{3}{|c|}{$\mathrm{P} 2$} & \multicolumn{3}{|c|}{$\mathrm{F}$ values $(1,2,2)$} \\
\hline & & $\mathrm{LC}$ & $\mathrm{PC}$ & EDGE & $\mathrm{LC}$ & $\mathrm{PC}$ & EDGE & $\begin{array}{c}\text { Location } \\
(1,180)\end{array}$ & $\begin{array}{c}\text { Planting } \\
(2,180)\end{array}$ & $\begin{array}{c}\text { Interactions } \\
(2,180) \\
\end{array}$ \\
\hline \multirow[t]{2}{*}{$\mathrm{pH}$} & & 6.66 & 6.54 & 6.54 & 6.55 & 6.41 & 6.47 & 1.397 & $9.957 * *$ & 0.747 \\
\hline & & 0.05 & 0.04 & 0.03 & 0.04 & 0.07 & 0.19 & & & \\
\hline \multirow[t]{2}{*}{ Temp } & ${ }^{\circ} \mathrm{C}$ & 25.3 & 25.3 & 25.70 & 25.7 & 25.6 & 25.9 & 2.221 & 3.164 & 0.251 \\
\hline & & 0.3 & 0.3 & 0.3 & 0.4 & 0.5 & 0.3 & & & \\
\hline \multirow[t]{2}{*}{ Cond } & $\mu \mathrm{s} \mathrm{cm}-1$ & 1267 & 1163 & 1035 & 940 & 945 & 749 & $3.897 * * *$ & $24.494^{*}$ & 1.783 \\
\hline & & 46 & 36 & 40 & 25 & 130 & 61 & & & \\
\hline \multirow[t]{2}{*}{ Alkalinity } & mg L-1 & 693.65 & 657.42 & 610.87 & 504.56 & 534.91 & 505.34 & 1.187 & $25.571^{*}$ & 0.920 \\
\hline & & 24.79 & 20.18 & 26.15 & 16.93 & 41.04 & 26.21 & & & \\
\hline \multirow[t]{2}{*}{$\mathrm{Cl}^{-}$} & mg L-1 & $61.44^{\mathrm{a}}$ & $57.60^{\mathrm{a}, \mathrm{b}}$ & $41.84^{\mathrm{c}}$ & $46.88^{\mathrm{c}, \mathrm{d}}$ & $50.07^{\mathrm{b}, \mathrm{d}, \mathrm{e}}$ & $39.07^{\mathrm{c}, \mathrm{d}}$ & $20.212 *$ & $13.202 *$ & $2.641 * * *$ \\
\hline & & 2.94 & 2.88 & 2.04 & 2.95 & 3.41 & 2.04 & & & \\
\hline \multirow[t]{2}{*}{$\mathrm{SO}_{4}{ }^{2-}$} & $\mathrm{mg} \mathrm{L}-1$ & $10.71^{\mathrm{a}}$ & $0.87^{b}$ & $0.07^{\mathrm{b}}$ & $2.33^{c}$ & $1.79^{b, c}$ & $0.11^{b, c}$ & $13.063 *$ & $5.44 * * *$ & $7.321^{*}$ \\
\hline & & 2.65 & 0.51 & 0.04 & 0.94 & 1.52 & 0.03 & & & \\
\hline \multirow[t]{2}{*}{$\mathrm{Na}^{+}$} & mg L-1 & $41.21^{\mathrm{a}}$ & $34.76^{\mathrm{b}}$ & $27.67^{\mathrm{c}}$ & $32.78^{d}$ & $35.51^{b, d}$ & $29.61^{c, d}$ & $15.528 *$ & 1.720 & $5.200 * *$ \\
\hline & & 3.83 & 1.63 & 0.80 & 1.89 & 2.18 & 1.29 & & & \\
\hline \multirow[t]{2}{*}{$\mathrm{K}^{+}$} & mg L-1 & 4.67 & 6.40 & 3.99 & 6.25 & 6.52 & 3.99 & $4.688 * *$ & 0.721 & 0.484 \\
\hline & & 2.65 & 0.69 & 0.72 & 0.81 & 1.52 & 0.64 & & & \\
\hline \multirow[t]{2}{*}{$\mathrm{Mg}^{2+}$} & mg L-1 & $15.72^{\mathrm{a}}$ & $13.63^{\mathrm{a}, \mathrm{b}}$ & $11.80^{\mathrm{b}}$ & $10.95^{b, c}$ & $10.24^{\mathrm{c}}$ & $10.85^{b, c}$ & $5.998 * *$ & $34.860^{*}$ & $5.942 * *$ \\
\hline & & 0.52 & 0.66 & 0.52 & 0.67 & 0.77 & 0.42 & & & \\
\hline \multirow[t]{2}{*}{$\mathrm{Ca}^{2+}$} & $\mathrm{mg} \mathrm{L}-1$ & $206.79^{a}$ & $198.65^{\mathrm{a}, \mathrm{b}}$ & $172.25^{\mathrm{b}, \mathrm{c}}$ & $149.04^{\mathrm{d}}$ & $117.99^{d}$ & $137.27^{\mathrm{d}}$ & $4.035 * *$ & $62.136^{*}$ & $3.644 * *$ \\
\hline & & 0.72 & 5.99 & 6.71 & 5.05 & 11.83 & 7.12 & & & \\
\hline \multirow[t]{2}{*}{$\mathrm{NH}_{4}^{+}$} & $\mathrm{mg} \mathrm{L}-1$ & $7.12^{\mathrm{a}}$ & $5.36^{\mathrm{a}, \mathrm{b}}$ & $4.91^{\mathrm{a}, \mathrm{b}}$ & $4.92^{b}$ & $6.72^{\mathrm{a}, \mathrm{b}, \mathrm{c}}$ & $3.60^{b}$ & 2.670 & 3.730 & $3.274 * * *$ \\
\hline & & 1.03 & 0.47 & 0.81 & 0.76 & 0.91 & 0.47 & & & \\
\hline \multirow[t]{2}{*}{$\mathrm{TP}$} & $\mu \mathrm{g} \mathrm{L}-1$ & $91.40^{\mathrm{a}}$ & $61.06^{\mathrm{a}}$ & $73.29^{\mathrm{a}}$ & $87.55^{\mathrm{a}}$ & $185.44^{\mathrm{b}}$ & $79.66^{\mathrm{a}}$ & 2.083 & $4.748 * * *$ & $3.912 * * *$ \\
\hline & & 21.61 & 10.27 & 16.26 & 30.92 & 50.65 & 14.98 & & & \\
\hline \multirow[t]{2}{*}{ SRP } & $\mu \mathrm{g} \mathrm{L}-1$ & 26.00 & $21.55^{\mathrm{e}}$ & 16.90 & 43.65 & $44.06^{b, f}$ & $15.62^{\mathrm{e}}$ & 2.827 & 2.764 & 1.082 \\
\hline & & 12.41 & 6.38 & 5.72 & 20.92 & 7.24 & 2.89 & & & \\
\hline \multirow[t]{2}{*}{ TOC } & $\mathrm{mg} \mathrm{L}-1$ & $44.93^{\mathrm{a}}$ & $49.41^{\mathrm{a}}$ & $31.64^{b}$ & $32.42^{\mathrm{b}}$ & $51.34^{\mathrm{a}, \mathrm{c}}$ & $36.58^{\mathrm{b}}$ & $14.246^{*}$ & 0.694 & $4.480 * * *$ \\
\hline & & 3.46 & 5.55 & 1.80 & 1.44 & 4.24 & 2.06 & & & \\
\hline \multirow[t]{2}{*}{$\delta \mathrm{D}$} & $\%$ & $-2.7^{a}$ & $-3.3^{\mathrm{a}, \mathrm{b}}$ & $2.8^{\mathrm{c}}$ & $2.8^{\mathrm{d}}$ & $0.7^{\mathrm{d}, \mathrm{e}}$ & $4.0^{\mathrm{d}}$ & $28.091 *$ & $36.653^{*}$ & $5.935 * *$ \\
\hline & & 1.0 & 0.8 & 0.6 & 0.7 & 0.6 & 0.4 & & & \\
\hline \multirow[t]{2}{*}{$\delta^{18} \mathrm{O}$} & $\%$ & $-0.90^{\mathrm{a}}$ & $-1.01^{\mathrm{a}, \mathrm{b}}$ & $0.25^{\mathrm{c}}$ & $0.43^{c, d}$ & $-0.38^{\mathrm{e}}$ & $0.62^{d}$ & $34.758 *$ & $41.826^{*}$ & $6.379 * *$ \\
\hline & & 0.16 & 0.15 & 0.14 & 0.14 & 0.09 & 0.10 & & & \\
\hline \multirow[t]{2}{*}{$\mathrm{SI}_{\text {ARGONITE }}$} & & 0.16 & -0.06 & -0.04 & -0.19 & -0.46 & -0.34 & $6.620 * *$ & $42.795^{*}$ & 0.372 \\
\hline & & 0.06 & 0.04 & 0.05 & 0.05 & 0.08 & 0.06 & & & \\
\hline \multirow[t]{2}{*}{$\mathrm{SI}_{\text {CALCITE }}$} & & 0.29 & 0.05 & 0.10 & -0.04 & -0.32 & -0.20 & $6.608 * *$ & $37.827^{*}$ & 0.147 \\
\hline & & 0.07 & 0.07 & 0.05 & 0.07 & 0.08 & 0.05 & & & \\
\hline \multirow[t]{2}{*}{$\log \left(\mathrm{pCO}_{2}\right)$} & BAR & -0.88 & -0.76 & -0.88 & -0.95 & -0.83 & -0.86 & 1.476 & 0.727 & 0.552 \\
\hline & & 0.04 & 0.04 & 0.04 & 0.04 & 0.08 & 0.03 & & & \\
\hline
\end{tabular}


Table 3. 2 The mean and standard error of chemical constituents in tree island groundwater (TI-GW), deep groundwater (DEEP GW) and Surface Water (SW). A one way ANOVA and post-hoc Tukey test $(\alpha=0.05)$ was used to determine significant difference between and within locations.

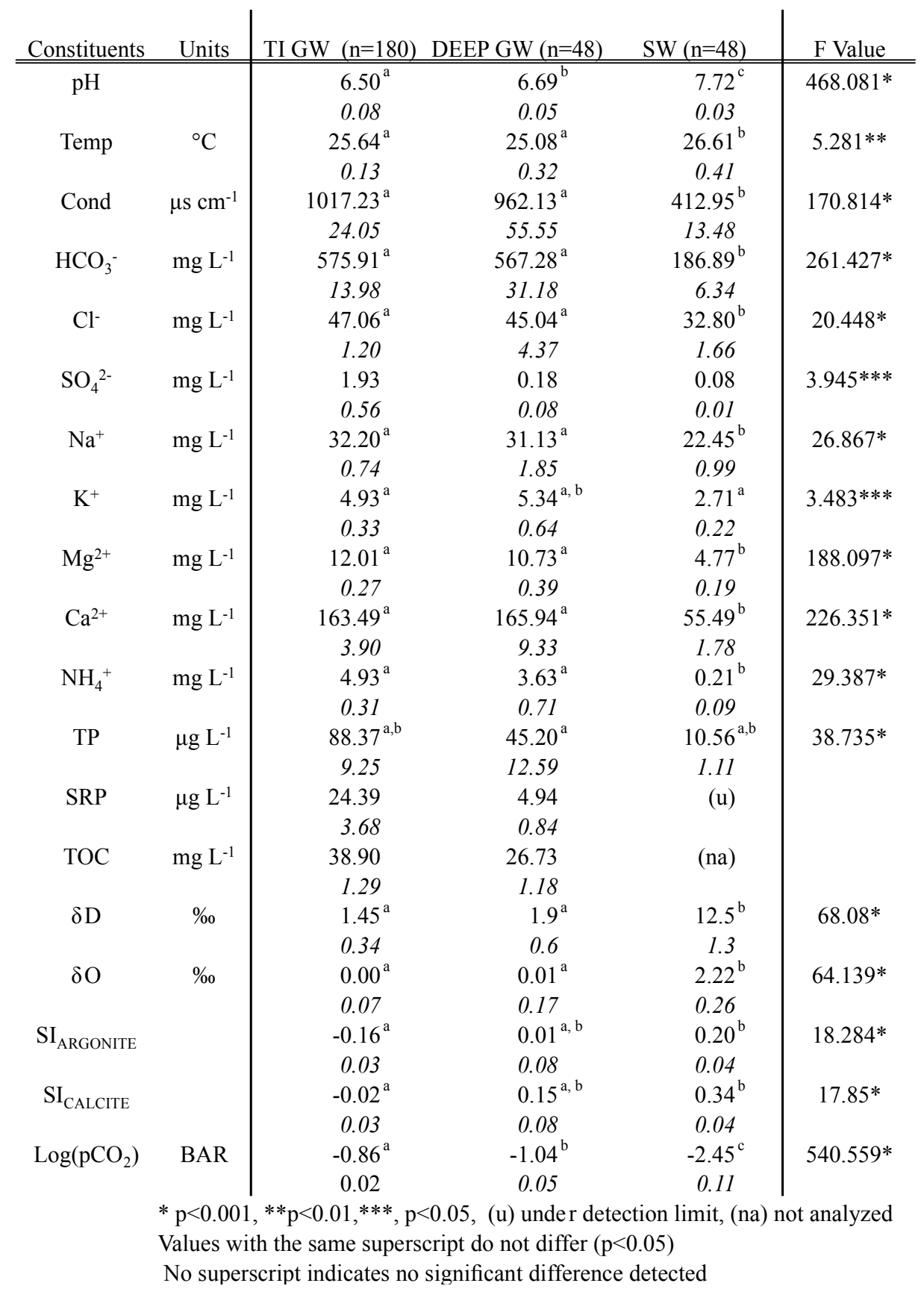




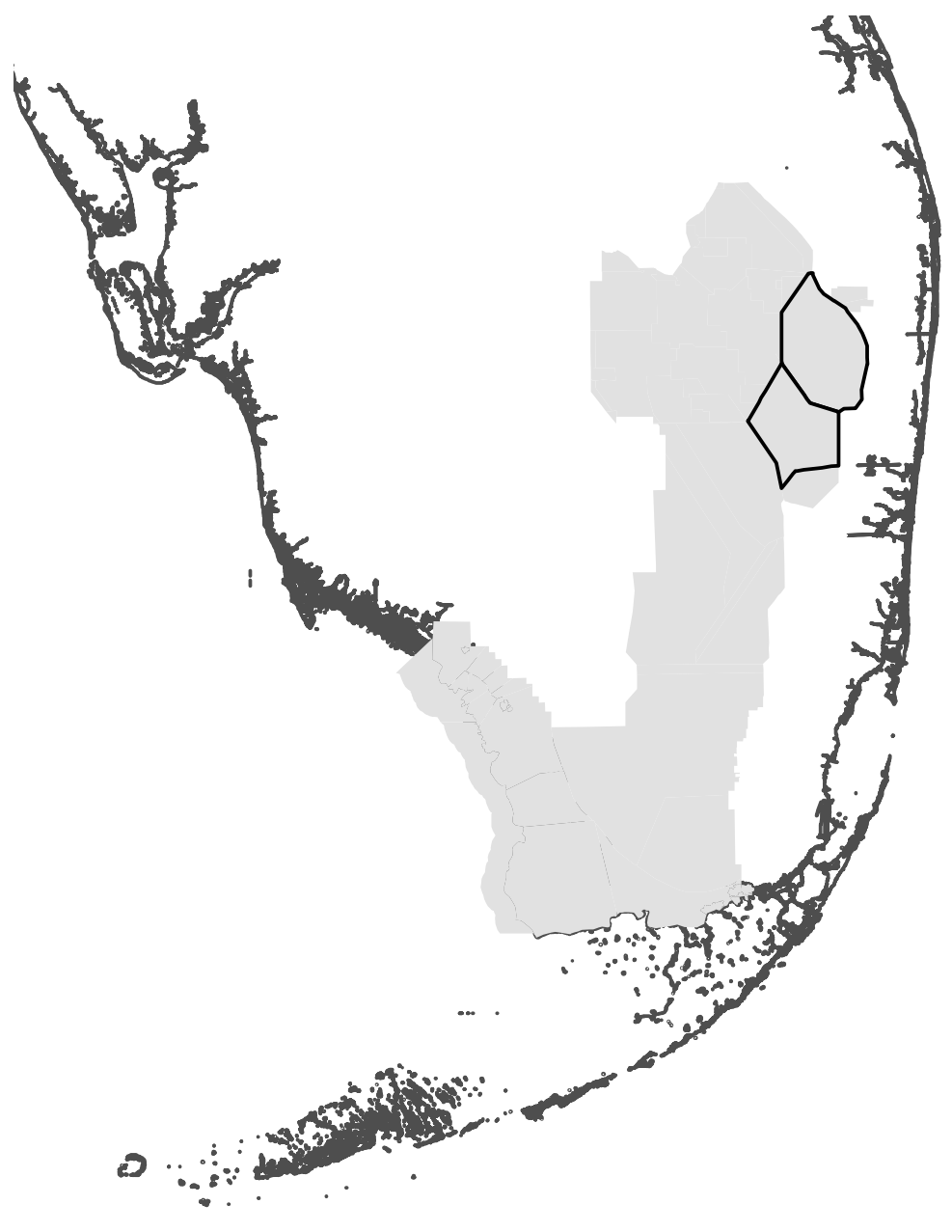

